
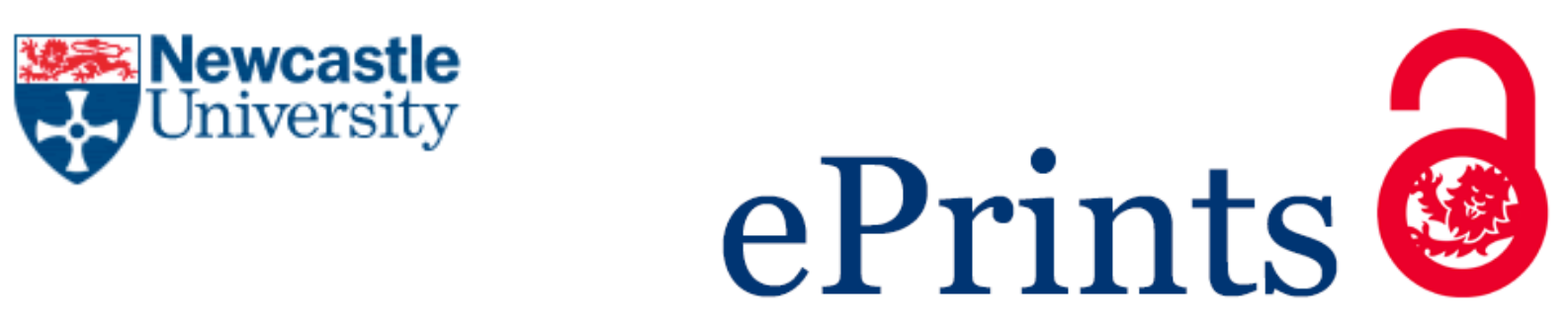

Sansiviero M, Morales-Maqueda MA, Fusco G, Aulicino G, Flocco D, Budillon G.

Modelling sea ice formation in the Terra Nova Bay polynya.

Journal of Marine Systems 2016

DOI: http://dx.doi.org/10.1016/j.jmarsys.2016.06.013

\title{
Copyright:
}

(C) 2016. This manuscript version is made available under the CC-BY-NC-ND 4.0 license

DOI link to article:

http://dx.doi.org/10.1016/j.jmarsys.2016.06.013

Date deposited:

$29 / 07 / 2016$

Embargo release date:

29 June 2017

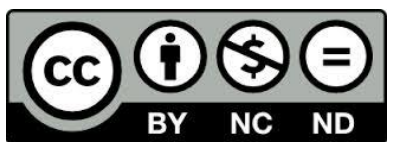

This work is licensed under a

Creative Commons Attribution-NonCommercial-NoDerivatives 4.0 International licence 
Highlights:

1) Simple coupled sea ice - ocean model has been developed to simulate the seasonal cycle of sea ice formation.

2) Salt flux associated with the wind-forced ice production causes haline convection affecting the characteristics of the entire water column.

3) The comparison between model-derived polynya extents and MODIS IST images was performed.

4) High resolution wind forcing is necessary to capture in more detail coastal sea ice processes, such as coastal polynyas, ice drift and ice compression against coastline features. 


\section{Modelling sea ice formation in the Terra Nova Bay polynya}

2

3

4 Sansiviero M. ${ }^{1}$, Morales Maqueda M. Á., ${ }^{2,3}$, Fusco G. ${ }^{1}$, Aulicino G. ${ }^{1}$, Flocco D. ${ }^{4}$ and Budillon G. ${ }^{1}$

5

$6 \quad{ }^{1}$ Università degli Studi di Napoli "Parthenope" (Italy)

$7 \quad{ }^{2}$ School of Marine Science and Technology, Newcastle University (United Kingdom)

$8 \quad{ }^{3}$ National Oceanography Centre (United Kingdom)

$9 \quad{ }^{4}$ Centre for Polar Observation and Modelling, University of Reading (United Kingdom)

13 Corresponding author: manuela.sansiviero@uniparthenope.it 


\section{Abstract}

Antarctic sea ice is constantly exported from the shore by strong near surface winds that open leads and large polynyas in the pack ice. The latter, known as wind-driven polynyas, are responsible for significant water mass modification due to the high salt flux into the ocean associated with enhanced ice growth. In this article, we focus on the wind-driven Terra Nova Bay (TNB) polynya, in the western Ross Sea. Brine rejected during sea ice formation processes that occur in the TNB polynya densifies the water column leading to the formation of the most characteristic water mass of the Ross Sea, the High Salinity Shelf Water (HSSW). This water mass, in turn, takes part in the formation of Antarctic Bottom Water (AABW), the densest water mass of the world ocean, which plays a major role in the global meridional overturning circulation, thus affecting the global climate system. A simple coupled sea ice - ocean model has been developed to simulate the seasonal cycle of sea ice formation and export within a polynya. The sea ice model accounts for both thermal and mechanical ice processes. The oceanic circulation is described by a one-and-a-half layer, reduced gravity model. The domain resolution is $1 \mathrm{~km} \times 1 \mathrm{~km}$, which is sufficient to represent the salient features of the coastline geometry, notably the Drygalski Ice Tongue. The model is forced by a combination of Era Interim reanalysis and in-situ data from automatic weather stations, and also by a climatological oceanic dataset developed from in situ hydrographic observations. The sensitivity of the polynya to the atmospheric forcing is well reproduced by the model when atmospheric in situ measurements are combined with reanalysis data. Merging the two datasets allows us to capture in detail the strength and the spatial distribution of the katabatic winds that often drive the opening of the polynya. The model resolves fairly accurately the sea ice drift and sea ice production rates in the TNB polynya, leading to realistic polynya extent estimates. The model-derived polynya extent has been validated by comparing the modelled sea ice concentration against MODIS high resolution satellite images, confirming that the model is able to reproduce reasonably well the TNB polynya evolution in terms of both shape and extent. 


\section{Introduction}

Observations and models have clearly shown that changes in atmospheric forcing and ocean circulation affect the Antarctic sea ice extent (Jacobs and Comiso, 1997; Liu et al., 2004; Lefebvre et al., 2005; Zhang 2007; Turner et al., 2009; Liu and Curry, 2010). The pronounced pattern of increasing ice cover in the Ross Sea region, found to be the highest contributor to sea ice expansion amongst the five Southern Ocean sectors in the 1979 - 2010 period with a positive trend of $13700 \pm$ $1500 \mathrm{~km}^{2} \mathrm{yr}^{-1}$, has been ascribed to changes in atmospheric circulation (Parkinson and Cavalieri, 2012). Enhanced northward winds have changed sea ice drift and export offshore affecting the dynamics of the local oceanography. These changes impact on the occurrence of wind driven polynyas along the Antarctic coastal margin, modifying the production of dense water masses through sea ice growth (Holland and Kwok, 2012). Variation in size or extent of polynyas are believed to be suitable indicators of climatic change (Morales Maqueda et al., 2004).

The wind-driven Terra Nova Bay (TNB) polynya, located in the western sector of the Ross Sea, plays a major role in shaping the sea ice and ocean dynamics of this region (Kurtz and Bromwich, 1985; Bromwich, 1989). The polynya opening results principally from the synergy of meteorological, oceanographic, and physical geography features of this region (Fig.1). Especially during winter, the TNB polynya is frequently forced by cold and strong katabatic downslope flows that push sea ice away from the coast. Their action prevents sea ice from consolidating as a thick pack and, at the same time, facilitates its continuous formation by leaving the relatively warm open water exposed to the cold atmosphere. Also, the presence and the orientation of the Drygalski Ice Tongue is essential for the polynya maintenance, since this barrier blocks the incoming sea ice from the south and controls, through its length, the polynya extent (Frezzotti and Mabin, 1994). Due to the constant formation and offshore drift of new ice, the TNB polynya contributes significantly to the sea ice mass budget of the whole area, producing approximately $10 \%$ of the sea ice formed annually in the Ross Sea (Kurtz and Bromwich, 1985; Van Woert, 1999b). Associated with the wind-forced ice production is a salt flux that causes haline convection that affects the characteristics 
of the entire water column in the TNB polynya and the thermohaline structure of the whole Ross

68 Sea (Kurtz and Bromwich, 1985; Trumbore et al., 1991). The TNB polynya is considered to be by far the largest producer of High Salinity Shelf Water (HSSW) (Kurtz and Bromwich, 1983, 1985; Jacobs et al., 1985; Van Woert, 1999a, b; Budillon and Spezie, 2000; Budillon et al., 2003; Fusco et al., 2009), a water mass that plays a crucial role in the formation of Antarctic Bottom Water (AABW) (Kurtz and Bromwich, 1985; Jacobs and Comiso, 1989; Van Woert, 1999a), thus contributing to deep ocean ventilation and the global thermohaline circulation (Jacobs et al., 1985; Orsi et al., 1999; Jacobs 2004).

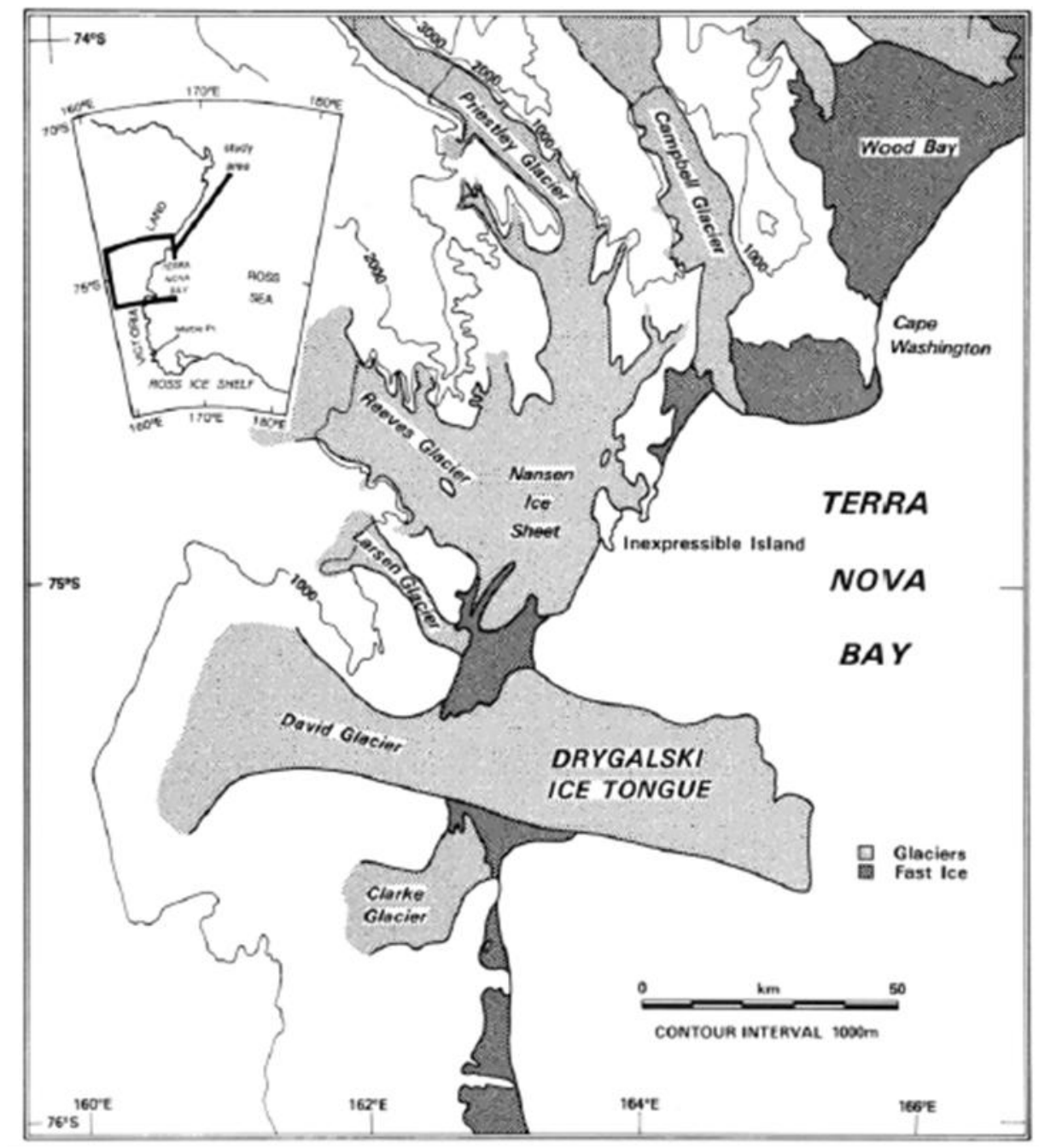

Fig. 1: Overview map of TNB (Western Ross Sea) showing the major geographical features of this region and its surroundings (Kurtz and Bromwich, 1983). 
The main goal of this study is to investigate the sea ice behaviour in the Terra Nova Bay polynya in response to external forcing and to estimate the associated sea ice and HSSW production. To this purpose, a coupled sea ice - ocean model was developed and applied to the TNP polynya area. The model simulates the seasonal cycle of sea ice formation in the TNB polynya, accounting for both sea ice dynamic and thermodynamic processes. Dynamics does not produce ice directly, but causes the ice to drift in and out of the area and leads to ice deformation in form of rafting or ridging due to convergence. Thermodynamics processes are responsible for local ice growth or melt and heat transfer at the ice-air and ice-ocean interfaces (Rothrock, 1979). Both ice dynamics and thermodynamics alter the local mean thickness (ice volume per unit area) and result in the exchange of mass, momentum and energy with the atmosphere and the ocean (Flato, 2003).

A further goal of this work is to estimate the variation of the TNB polynya extent, i.e. the size of the area of low ice concentration, in response to the forcing. Computing the polynya extent is difficult given the limitations of models and remote sensing tools as regards both their accuracy and their ability to resolve polynya variability in space and time. Polynya extent estimates are not trivial to derive since local ice thickness and ice production rates are often unknown. Papers focusing on the variability of sea ice and open water in the TNB polynya exist in literature, mainly concerning the wintertime season. Authors have investigated the TNB polynya extent either through one dimensional models forced by in situ and reanalysis data (Van Woert, 1999a, 1999b; Fusco et al., 2002; Petrelli et al., 2008) or through satellite observations (Kern, 2007; Ciappa et al., 2012).

The polynya extent in this paper is derived from modelled sea ice concentration (Markus et al., 1998; Kwok et al., 2007; Tamura et al., 2008) and validated by comparison with polynya extents estimates from MODIS satellite images (Key et al., 1994; Key et al., 1997).

The paper is organized as follows. Section 2 provides a description of the coupled sea ice - ocean model and the main formulations adopted to resolve sea ice dynamics and thermodynamics. Section 3 presents experiments on model sensitivity to variations in specific physical processes and parameterizations in order to better tune the model to the peculiarities of the TNB polynya region. 
In particular, the sea ice and polynya response to wind forcing variations is studied. Section 4 shows the results of a one year simulation of sea ice formation and polynya extent in the TNB polynya region. Section 5 focuses on the comparison between the numerical TNB polynya extent estimates and those derived from high resolution MODIS images. Finally, a discussion of results and a few concluding remarks are presented in Section 6.

\section{Description of the model}

\subsection{Model equations}

The coupled sea ice - ocean model presented here provides an intermediate complexity formulation of the TNB polynya dynamics. In contrast by polynya flux models describing the evolution of a polynya in terms of the polynya edge contour, our model predicts sea ice concentrations over a regular spatial grid (Willmott et al., 2007). The model has a relatively high resolution $(1 \mathrm{~km} \times 1$ $\mathrm{km}$ ) in order to capture the complexity of the coastline geometry and the meteorological patterns of the region. Both dynamic and thermodynamic sea ice and ocean processes are incorporated in the model. An accurate representation of the main sea ice processes, often overlooked in numerical simulations of the polar regions (Russell et al., 2006; Maksym et al., 2012), and a realistic representation of sea ice dynamics, are crucial for the accurate description of the interactions of thin ice and polynyas with the atmospheric and oceanic circulation (Stössel et al, 1990). The ocean is represented by a one-and-a-half layer, reduced gravity, Boussinesq ocean model. The stratification is simplified using a description in which the active layer (effectively, the upper ocean mixed layer) moves above a lower stagnant (motionless) layer of infinite depth. The formulation of the ocean model is inspired in Morales Maqueda et al. (1999) and Biggs and Willmott (2001), with the only major departure that an eddy bolus transport term is added to the advection of scalars. The equations are as follows. 
$h_{1}\left(\frac{\partial U_{1}}{\partial t}+\frac{\partial\left(U_{1} U_{1}\right)}{\partial x}+\frac{\partial\left(V_{1} U_{1}\right)}{\partial y}\right)-f h_{1} V_{1}=-\frac{\partial}{\partial x}\left(\frac{1}{2} g \frac{\rho_{r}-\rho_{1}}{\rho_{r}} h_{1}^{2}\right)+\frac{1}{\rho_{r}}\left(\tau_{s}^{x}-\tau_{b}^{x}\right)+\frac{1}{\rho_{r}}\left(\frac{\partial}{\partial x}\left(A_{H} h_{1} \frac{\partial U_{1}}{\partial x}\right)+\right.$

$\left.127 \frac{\partial}{\partial y}\left(A_{H} h_{1} \frac{\partial U_{1}}{\partial y}\right)\right)$

128

$h_{1}\left(\frac{\partial V_{1}}{\partial t}+\frac{\partial\left(U_{1} V_{1}\right)}{\partial x}+\frac{\partial\left(V_{1} V_{1}\right)}{\partial y}\right)+f h_{1} U_{1}=-\frac{\partial}{\partial y}\left(\frac{1}{2} g \frac{\rho_{r}-\rho_{1}}{\rho_{r}} h_{1}^{2}\right)+\frac{1}{\rho_{r}}\left(\tau_{s}^{y}-\tau_{b}^{y}\right)+\frac{1}{\rho_{r}}\left(\frac{\partial}{\partial x}\left(A_{H} h_{1} \frac{\partial V_{1}}{\partial x}\right)+\right.$

$\left.\frac{\partial}{\partial y}\left(A_{H} h_{1} \frac{\partial V_{1}}{\partial y}\right)\right)$

130

$\frac{\partial h_{1}}{\partial t}=-\left\{\frac{\partial\left[h_{1}\left(U_{1}+U_{e}\right)\right]}{\partial x}+\frac{\partial\left[h_{1}\left(V_{1}+V_{e}\right)\right]}{\partial y}\right\}-E+P+M_{S}+M_{i}-G_{i}+w_{b}$,

131

$\frac{\partial\left(h_{1} T_{1}\right)}{\partial t}=-\left\{\frac{\partial\left[h_{1} T_{1}\left(U_{1}+V_{e}\right)\right]}{\partial x}+\frac{\partial\left[h_{1} T_{1}\left(V_{1}+V_{e}\right)\right]}{\partial y}\right\}+\frac{Q_{1}+Q_{i}}{\rho_{r} c_{p}}+w_{b} T_{b}+h_{1} \frac{T_{c}-T_{1}}{\mathrm{~T}_{r}}$,

$\frac{\partial\left(h_{1} S_{1}\right)}{\partial t}=-\left\{\frac{\partial\left[h_{1} S_{1}\left(U_{1}+U_{e}\right)\right]}{\partial x}+\frac{\partial\left[h_{1} S_{1}\left(V_{1}+V_{e}\right)\right]}{\partial y}\right\}+\left(M_{i}-G_{i}\right) S_{i}+w_{b} S_{b}+h_{1} \frac{S_{c}-S_{1}}{\mathrm{~T}_{r}}$.

In the equations above, $h_{1}$ is the depth of the ocean active layer, $U_{1}$ and $V_{1}$ are the $x$ and $y$ components of the ocean current in the active layer, $\mathbf{U}_{1}, f$ is the Coriolis parameter, $g$ is the acceleration of gravity, $\rho_{r}$ is a constant and uniform reference density representative on average of the densities encountered in the region below the active layer, $\rho_{1}$ is the density of the active layer, $\tau_{s}^{x}$ and $\tau_{s}^{y}$ are the components of the horizontal wind stress at the top of the active layer and, similarly, $\tau_{b}^{x}$ and $\tau_{b}^{y}$ are the components of the vertical shear stress at the bottom of the active layer, $U_{e}=-\kappa_{e} h_{1}^{-1} \partial h_{1} / \partial x$ and $V_{e}=-\kappa_{e} h_{1}^{-1} \partial h_{1} / \partial y$ are the components of the eddy bolus velocity (Gent and McWilliams, 1990), with $\kappa_{e}$ a constant and uniform thickness diffusivity, $E$ is evaporation, $P$ is precipitation, $M_{s}$ and $M_{i}$ are the volume fluxes associated with snow and ice melt, respectively, $G_{i}$ is ice growth (exception made of snow ice formation, which is described below), $w_{b}$ represents the vertical volume flux at the base of the active layer caused by entrainment, $T_{1}$ is the temperature of the active layer, and $Q_{1}$ is the net surface heat flux into the layer, incorporating contributions from the ice free and ice covered areas and also including the latent heat loss required to melt the snow that falls over leads. Specifically, 
$Q_{1}=(1-A)\left(Q_{s w}+Q_{l w}+Q_{s}+Q_{e}-P L_{f} \rho_{s}\right)-A Q_{c}$

$Q_{i}=\rho_{r} c_{p}\left\{H(A)+[1-H(A)] H\left(T_{f}-T_{1}\right)\right\} h_{1} \frac{T_{f}-T_{1}}{\mathrm{~T}_{i}}$. is parameterized according to Lemke (1987) as

where $A$ is the fractional oceanic area covered by ice, or ice concentration, $Q_{s w}, Q_{l w}, Q_{s}$ and $Q_{e}$ are the shortwave, longwave, sensible and latent heat fluxes in the open ocean, the four quantities positive if they flow into the ocean and calculated according to Budillon et al. (2000), $L_{f}$ is the latent heat of fusion of ice, $\rho_{s}$ is snow density, and $Q_{c}$ is the conductive heat flux through ice, which we take as positive if directed upwards and assume to be identical to the heat flux from the ocean into the ice at the base of the ice cover. Small enthalpy changes associated with the mass fluxes $E$, $P, M_{s}, M_{i}$ and $G_{i}$ are all ignored here since we neglect the thermal inertia of both snow and ice. Further in (4), $Q_{i}$ is a latent heat flux associated with the formation or melting of ice in the active oceanic layer (see below) and $T_{b}$ is the temperature associated with the volume flux $w_{b}$ across the base of the active layer. The last term on the right hand side of (4) represents a relaxation to observations, $T_{c}$, with a time scale $\mathrm{T}_{r}$. In (5), $S_{1}$ is the salinity of the active layer and $S_{i}$ and $S_{b}$ are the salinity of sea ice, which we take as constant and equal to 4, and the salinity of water entrained at the base of the active layer, respectively. Relaxation to salinity observations, $S_{c}$, is also included. The temperature $T_{1}$ is approximately maintained at the freezing point, $T_{f}$, which is calculated according to Fofonoff and Millard (1983), for as long as ice is present or if ice forms for the first time in the season in the open ocean. The term $Q_{i}$ in (4) ensures this, and it has the form

In (7), $H$ is the Heaviside function, $A$ is the ice concentration, and $\mathrm{T}_{i}$ is a restoring time scale which we have chosen to be equal to the model time step. The entrainment velocity, $w_{b}$, depends on the air-sea stress and buoyancy fluxes that control the strength of turbulence in the mixed layer and

$w_{b}=\frac{2 u^{* 3} e^{-h_{1} / h_{w}+h_{1} B\left[1+H(B)\left(e^{\left.-h_{1} / h_{c}-1\right)}\right]\right.}}{g^{\frac{\rho_{r}-\rho_{1}}{\rho_{r}} h_{1}}}$ 
171 where $\rho_{r} u^{* 2}=\sqrt{\tau_{s}^{x^{2}}+\tau_{s}^{y^{2}}}, h_{w}=7 \mathrm{~m}, B$ is the surface buoyancy flux, and $h_{c}=50 \mathrm{~m}$. The 172 temperature and salinity of entrained water, $T_{b}$ and $S_{b}$, are determined using mooring based 173 observations (see Section 2.3) linearly interpolated onto the bottom of the active layer.

174 The surface stress term is formulated as in Mellor and Kantha (1989) and is a linear combination of 175 the shear stress at the surface of the ice covered ocean and the wind stress acting on the open ocean, 176 weighted by the fractional area of sea ice and leads, respectively, namely, $\tau_{s}^{x}=(1-A) \tau_{s w}^{x}+A \tau_{s i}^{x}$, 177 where $\tau_{s w}^{x}$ is the $x$ component of the surface stress over the ocean and $\tau_{s i}^{x}$ is the sea ice counterpart. 178 An analogous equation holds for $\tau_{s}^{y}$. In full, the ice-ocean stress components are

$\left(\tau_{s i}^{x}, \tau_{s i}^{y}\right)=\rho_{i} C_{i} \sqrt{\left(U_{1}-U_{i}\right)^{2}+\left(V_{1}-V_{i}\right)^{2}}\left(U_{i}-U_{1}, V_{i}-V_{1}\right)$

where $C_{i}=5 \times 10^{-3}$ is the ice-ocean drag coefficient, and $U_{i}$ and $V_{i}$ are the components of the ice velocity. The stress at the base of the active layer is calculated according to the parameterization of Pacanowski and Philander (1981):

$$
\left(\tau_{b}^{x}, \tau_{b}^{y}\right)=\left(v_{b}+\frac{v_{0}}{(1+\alpha R i)^{n}}\right) \frac{1}{h_{1}}\left(U_{1}, V_{1}\right)
$$

where $v_{b}=1 \times 10^{-3} \mathrm{~m}^{2} \mathrm{~s}^{-1}, v_{0}=1 \times 10^{-1} \mathrm{~m}^{2} \mathrm{~s}^{-1}, \alpha=0.5, n=2$

and $R i$ is a Richardson number:

$R i=\frac{g \frac{\rho_{r}-\rho_{1}}{\rho_{r}} h_{1}}{u_{1}^{2}+v_{1}^{2}}$

The horizontal friction terms in (1) and (2) are included to make it possible to impose no-slip boundary conditions at coastlines. The viscosity, $A_{H}$, has a value of $2 \times 10^{2} \mathrm{~m}^{2} \mathrm{~s}^{-1}$.

Sea ice behaves as a floating, zero layer system (i.e., without thermal inertia), as proposed by Semtner (1976). Sea ice interacts thermodynamically and dynamically with the atmosphere and the underlying mixed layer of the ocean. The coupling of sea ice with the surface ocean layer allows us to simulate the seasonal cycle of sea ice formation and export within the polynya. The model requires atmospheric and ocean forcing as inputs that are applied as surface and bottom boundary conditions. The atmospheric forcing is given by air temperature, surface pressure, humidity, cloud 
cover, precipitation and wind fields, from which surface heat, moisture and momentum fluxes can be derived. The model needs also the solar radiation in order to compute the balance of radiative and the turbulent heat fluxes. The ocean forcing consists of the ocean surface temperatures and interfaces.

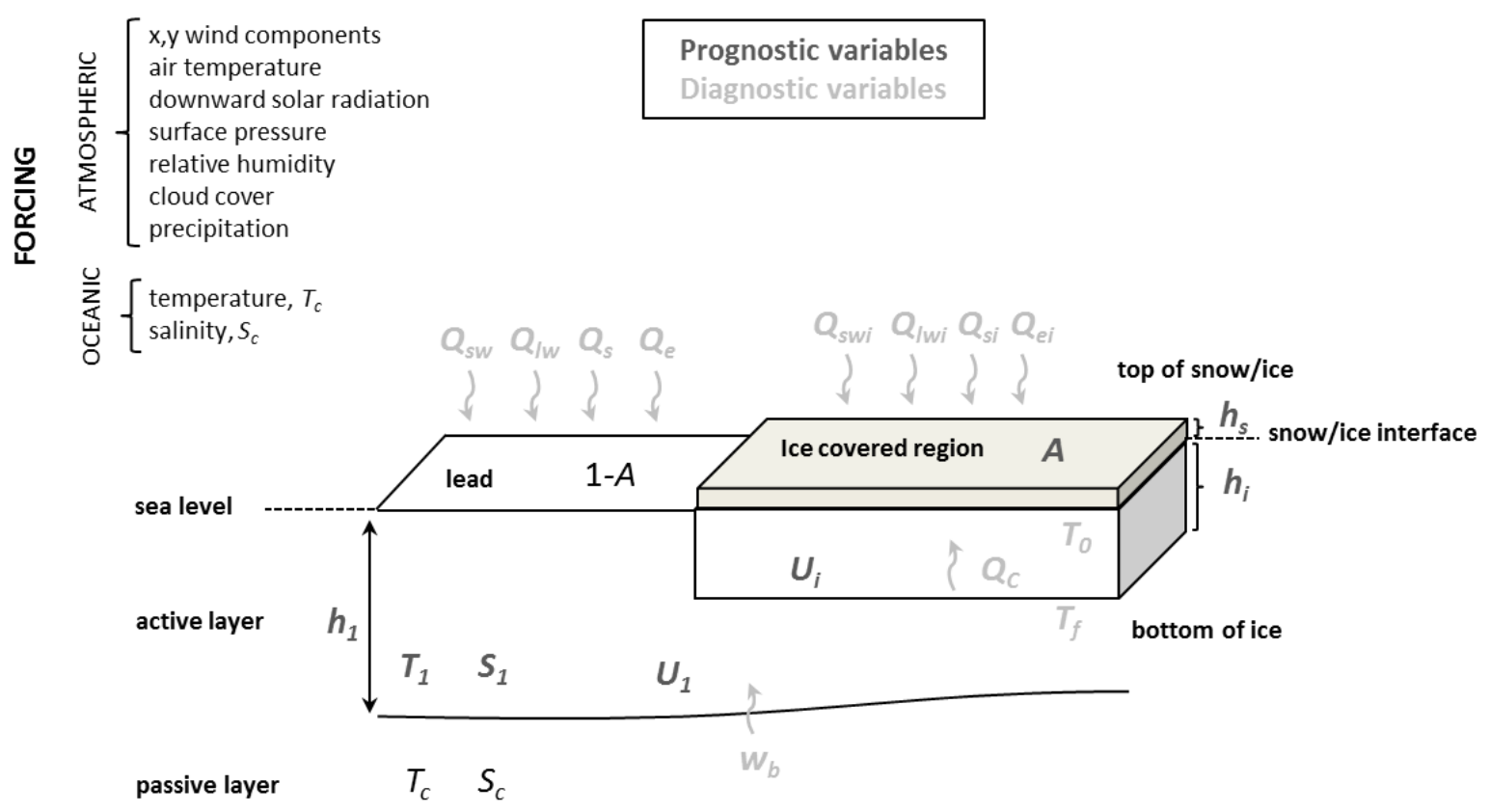

Fig. 2: Schematic view of the main variables of the coupled sea ice - ocean model. The radiative and turbulent heat fluxes are separately calculated over the ice free (leads) and ice covered areas.

The sea ice state is characterized by the ice concentration, $A$, defined as the fraction of a grid cell covered by ice varying between zero and one, and by the ice thickness, $h_{i}$. The non-covered fraction of each grid cell, $1-A$, is referred to as the lead fraction. Sea ice is allowed to be covered by a snow layer, $h_{s}$, that is important for the determination of the growth rates of sea ice (Stössel et al., 1990). Also, snow-ice formation from Fichefet and Morales Maqueda (1999), which takes part in 
the thickening of sea ice when the snow layer is depressed below the sea surface by its own weight, is parameterized. The conservation equations for the sea ice and snow state variables are as follows.

$\frac{\partial A}{\partial t}==-\left\{\frac{\partial\left(A u_{i}\right)}{\partial x}+\frac{\partial\left(A v_{i}\right)}{\partial y}\right\}+S_{A}$

$\frac{\partial\left(A h_{i}\right)}{\partial t}=-\left\{\frac{\partial\left(A h_{i} u_{i}\right)}{\partial x}+\frac{\partial\left(A h_{i} v_{i}\right)}{\partial y}\right\}+\dot{V}_{i}+\dot{V}_{i 0}+\dot{V}_{s i}$,

$\frac{\partial\left(A h_{s}\right)}{\partial t}=-\left\{\frac{\partial\left(A h_{s} u_{i}\right)}{\partial x}+\frac{\partial\left(A h_{s} v_{i}\right)}{\partial y}\right\}+\dot{V}_{s 0}-\frac{\rho_{i}}{\rho_{s}} \dot{V}_{s i}$,

where $u_{i}$ and $v_{i}$ are the components of the sea ice velocity. The term $S_{A}$ is a placeholder for all nonadvective processes that lead to changes in ice concentration. It is formulated in the following way.

$S_{A}=(1-A) \frac{Q_{i} /\left(L_{f} \rho_{i}\right)}{d}$

where, $L_{f}$ is the latent heat of formation of ice, and, if $Q_{i}>0$ (i.e., there is frazil ice formation in the water column), $d$ is a collection thickness of frazil ice which is either a constant or a function of wind speed as in Winsor and Bjork (2000), and we denote it by $H$, while, if $Q_{i}<0, d=h_{i}$. The terms $\dot{V}_{i}=Q_{i} /\left(L_{f} \rho_{i}\right), \dot{V}_{i 0}$ and $\dot{V}_{s i}$ in (13) account for ice growth/decay as a result of the heat budget in the active oceanic layer, for sea ice melting at the ice-atmosphere interface when the ice heat balance is such that the surface is at the melting point, and for snow ice formation, respectively. We note that the term $G_{i}$ in (3) is simply equal to $\rho_{i} / \rho_{r} \dot{V}_{i}$. Snow ice formation occurs when the weight of snow depresses the snow-ice interface below sea level. In such cases, we transform the submerged snow into ice, leading to a contribution to the ice growth rate that obeys the formula

$\dot{V}_{s i}=\frac{A}{\mathrm{~T}_{s i}} H\left(\frac{\rho_{s} h_{s}-\left(\rho_{r}-\rho_{i}\right) h_{i}}{\rho_{r}}\right) \frac{\rho_{s}}{\rho_{i}} \frac{\rho_{s} h_{s}-\left(\rho_{r}-\rho_{i}\right) h_{i}}{\rho_{r}}$,

where $\mathrm{T}_{s i}$ is a time scale that we take to be equal to the time step in the model. The term $\dot{V}_{s 0}$ in (14) accounts for both the accumulation of precipitating snow on top of sea ice and the subsequent surface snow melt during the thaw. As stated above, we make use of an approach for the sea ice and snow thermodynamics that is commonly termed zero layer approximation. This means that the vertical temperature profiles in the snow and the ice are linear and fully determined by the 
temperature is always taken to be $T_{f}$, and we further assume that the oceanic heat flux into the ice matches the conductive heat flux through the ice, $Q_{c}$, so that there is never a flux divergence at the bottom of the ice cover. At the ice-snow interface, the conductive heat flux is also assumed to be continuous. The conductive heat flux is given by the following expression (e.g., Fichefet and Morales Maqueda, 1997):

$Q_{c}=\frac{\kappa_{i}}{h_{i}+\frac{\kappa_{i}}{\kappa_{S}} h_{s}}\left(T_{f}-T_{0}\right)$

where $\kappa_{i}$ and $\kappa_{s}$ are the heat conductivities of ice and snow, respectively, and $T_{0}$ is the surface temperature. Finally, at the surface of the ice or snow cover a balance is postulated between surface and conductive heat fluxes, namely,

$Q_{0}=Q_{s w i}+Q_{l w i}+Q_{s i}+Q_{e i}+Q_{c}=0$

where $Q_{s w i}, Q_{l w i}, Q_{s i}$ and $Q_{e i}$ are the shortwave, longwave, sensible and latent heat fluxes at the surface of the snow or ice layer. The balance $Q_{0}=0$ in (18) can be guaranteed as long as $T_{0}$ remains below the freezing point. However, if (18) requires that the surface temperature be above freezing then melting will ensure. During melting, $T_{0}$ will remain at the freezing point for freshwater (if snow is present) or for ice (if there is no snow) and the excess heat $Q_{0}>0$ will be used to melt snow, $M_{s}=Q_{0} /\left(L_{f} \rho_{s}\right)$, or ice $M_{i}=Q_{0} /\left(L_{f} \rho_{i}\right)$.

Sea ice drift, $\mathbf{U}_{\mathrm{i}}$, with components $U_{i}$ and $V_{i}$, is computed by postulating a balance of momentum between the Coriolis force, wind and ocean stresses and the ice internal force resulting from the interaction between floes during ice deformation. The momentum equations are:

$m \frac{\partial U_{i}}{\partial t}-f m V_{i}=A\left(\tau_{w}^{x}-\tau_{o}^{x}\right)+F^{x}$,

$m \frac{\partial V_{i}}{\partial t}+f m U_{i}=A\left(\tau_{w}^{y}-\tau_{o}^{y}\right)+F^{y}$

where $m$ is the mass of snow plus ice per unit area, $\tau_{w}^{x}$ and $\tau_{w}^{y}$ are the components of the wind stress acting on the ice, $\tau_{o}^{x}$ and $\tau_{o}^{y}$ are the components of the ice-ocean stress at the base of the ice, and $F^{x}$ and $F^{y}$ are the components of the ice internal stress force. Note that advection of sea ice 
258

momentum is ignored and that the atmosphere and ocean stresses term includes the ice concentration as a multiplicative factor to be consistent with the theory of free drift in regions of low ice concentration according to Connolley et al. (2004). The internal ice forces are resolved using the elastic-viscous-plastic rheology by Hunke and Dukowicz (1997). The internal ice pressure is formulated as a function of sea ice thickness, $h_{i}$, and concentration, $A$, as in Hibler (1979) (see further discussion in section 3.1).

\subsection{Model domain and set up}

The model domain consists of a wide region of the western Ross Sea including an extended area along the coast of Victoria Land south of the Drygalski Ice Tongue and the northern region of the Wood Bay (Fig. 3). It is $154 \mathrm{~km} \times 488 \mathrm{~km}$, extending approximately from $74^{\circ} \mathrm{S}$ to $78^{\circ} \mathrm{S}$ in latitude and from $162^{\circ} \mathrm{E}$ to $168^{\circ} \mathrm{E}$ in longitude. A spatially uniform horizontal resolution of $1 \mathrm{~km}$ is used to study the small scale behaviour of sea ice in TNB. This resolution is considered to be sufficient in representing the salient features of the coastline geometry, such as the Drygalski Ice Tongue. Hence, the horizontal grid is a rectangle of width $X$ and length $Y$ subdivided in square grid cells resulting in a grid of $154 \times 488=75152$ grid points. An Arakawa B-grid is used for the spatial discretization. A land mask is specified in the center of the cells with 0 representing land and 1 oceanic cells. A corresponding mask is defined for all corner quantities such as the wind speed, sea ice velocity and stress components. 


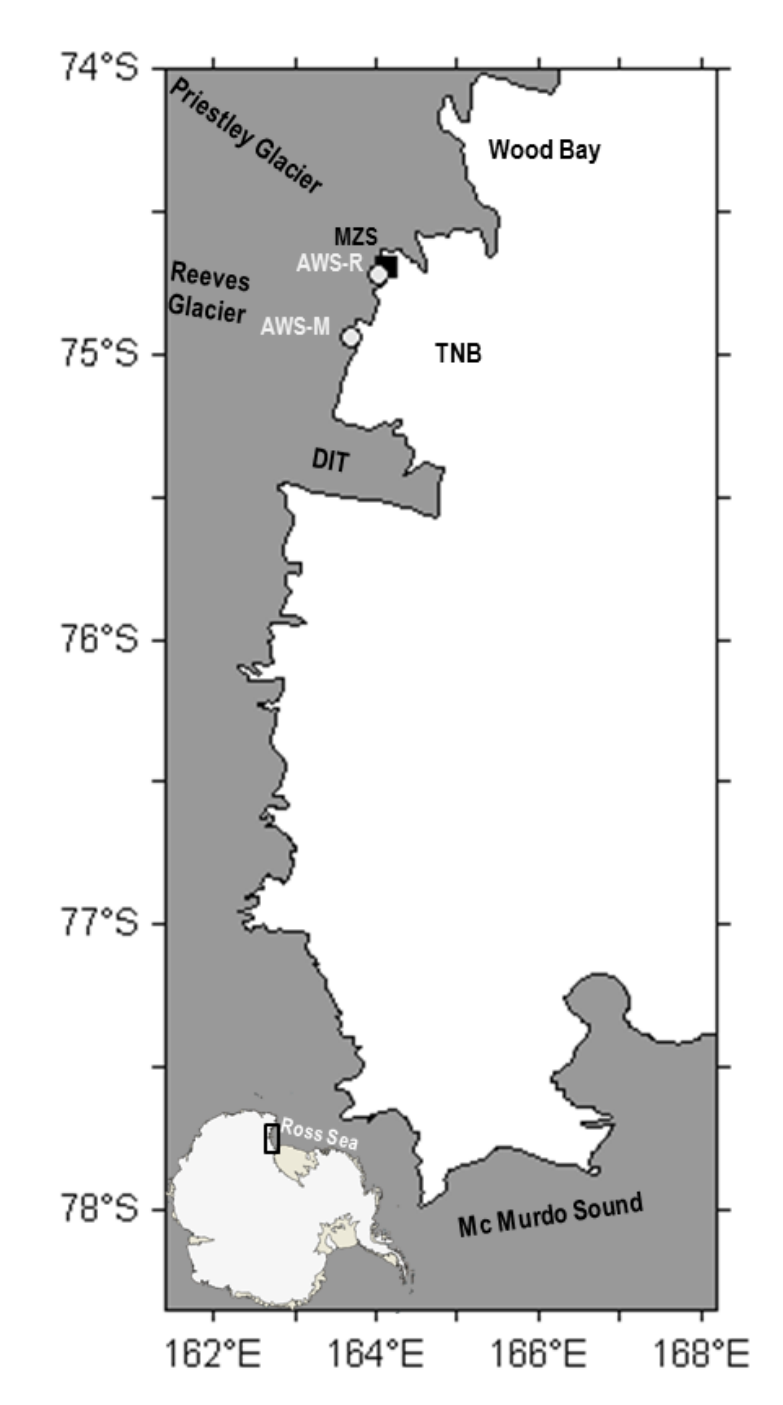

Fig. 3: The model domain showing the Drygalski Ice Tongue (DIT) and the two preferential paths of the katabatic flows, the Priestley and the Reeves Glaciers. The italian base, Mario Zucchelli Station (MZS), and the location of the automatic weather stations, Rita (AWS-R: $74.72^{\circ} \mathrm{S}, 164.03^{\circ} \mathrm{E}$ ) and Manuela (AWS-M: $74.95^{\circ} \mathrm{S}, 163.69^{\circ} \mathrm{E}$ ) are also indicated.

278 The advection of scalars is discretized with a first order upstream scheme. The solutions of the 279 momentum equations (1), (2), (19) and (20) and the advective and thermodynamic processes in eqs. 280 (3), (4), (5), (12), (13) and (14) are computed using two different time steps: a small one for the 281 momentum $(\Delta \mathrm{t})$ and a larger one for the advection $\left(\Delta \mathrm{T}_{\mathrm{a}}\right)$. All the input parameters such as constants 282 and coefficients are shown in Table 1. Some values of the input parameters, referred to as " $\mathrm{x}$ " in 283 Table 1, are let to vary in the sensitivity experiments. A one month spin-up length (repeated twice) 284 is used for each experiment. Sea ice concentration and thickness and ocean fields are initialized at 285 the beginning of each integration with a prescribed value or with a restart from a previous 
integration. The initial values are zero for both ice concentration and thickness. The initial temperature and salinity of the ocean are from monthly climatological observations (described in section 2.3) and the initial active layer depth is determined from the former using the density threshold criterion of $0.125 \mathrm{~kg} \mathrm{~m}^{-3}$ relative to near surface densities (Monterey and Levitus, 1997).

Open lateral boundary conditions ensuring a minimum of signal reflections at the boundary have 291 been used so that advective flows leaving the domain are allowed to freely exit the domain using an 292 upstream formulation, while flows into the domain use a simple sponge boundary condition that 293 relaxes the variables to their climatological external values (Martinsen and Engedahl, 1987). The 294 main physical parameters of atmosphere, sea ice and ocean used in the model are showed in Table 2. Figure 4 is the flow diagram of the coupled sea ice-ocean model, showing the basic steps in computing the diagnostic variables of the model.

\begin{tabular}{lcc}
\hline Parameter & Symbol & Value \\
\hline X domain & $X$ & $154000 \mathrm{~m}$ \\
Y domain & $Y$ & $488000 \mathrm{~m}$ \\
T domain & $T$ & x days \\
Time step for momentum & $\Delta t$ & $1.2 \mathrm{~s}$ \\
Time step for advection & $\Delta t_{a}$ & $600 \mathrm{~s}$ \\
Elastic timescale (EVP ice rheology) & $\Delta t e$ & $180 \mathrm{~s}$ \\
Air drag coefficient & $C_{d a}$ & $\mathrm{X}$ \\
Ocean drag coefficient & $C_{d o}$ & $\mathrm{x}$ \\
Ice strength parameter & $P^{*}$ & $\mathrm{~N} / \mathrm{m}^{2}$ \\
Ice concentration parameter & $C$ & 20 \\
Creep limit & $c$ & $5 \times 10^{-11} 1 / \mathrm{s}$ \\
Eccentricity of the elliptical yield curve & $e$ & 2 \\
Demarcation ice collection thickness in leads & $H$ & $\mathrm{x} \mathrm{m}$ \\
\hline
\end{tabular}




\begin{tabular}{|c|c|c|}
\hline Parameter & Symbol & Value \\
\hline Ocean horizontal viscosity & $A_{H}$ & $2 \times 10^{2} \mathrm{~m}^{2} \mathrm{~s}^{-1}$ \\
\hline Ocean eddy thickness diffusivity & $\kappa_{e}$ & $2 \times 10^{2} \mathrm{~m}^{2} \mathrm{~s}^{-1}$ \\
\hline Thermal conductivity of sea ice & $\kappa_{i}$ & $2.2 \mathrm{~W} / \mathrm{m} / \mathrm{K}$ \\
\hline Thermal conductivity of snow & $\kappa_{s}$ & $0.3 \mathrm{~W} / \mathrm{m} / \mathrm{K}$ \\
\hline Emissivity of atmosphere & $\varepsilon_{a}$ & 0.95 \\
\hline Emissivity of ocean & $\varepsilon_{o}$ & 0.985 \\
\hline Albedo of ocean & $\alpha_{o}$ & 0.07 \\
\hline Albedo of ice & $\alpha_{i}$ & $0.07-0.7$ \\
\hline Albedo of snow & $\alpha_{s n}$ & 0.85 \\
\hline Latent heat of fusion of ice & $L_{f i}$ & $3.34 \times 10^{5} \mathrm{~J} / \mathrm{kg}$ \\
\hline Latent heat of vaporization of water & $L_{e}$ & $2.5 \times 10^{6} \mathrm{~J} / \mathrm{kg}$ \\
\hline Latent heat of fusion of snow & $L_{f s n}$ & $3.34 \times 10^{5} \mathrm{~J} / \mathrm{kg}$ \\
\hline Latent heat of sublimation of snow & $L_{s n}$ & $2.834 \times 10^{6} \mathrm{~J} / \mathrm{kg}$ \\
\hline Specific heat capacity of ocean & $c_{p a}$ & $3985 \mathrm{~J} / \mathrm{kg} / \mathrm{K}$ \\
\hline Specific heat capacity of air & $c_{p a}$ & $1004 \mathrm{~J} / \mathrm{kg} / \mathrm{K}$ \\
\hline Density of air & $\rho_{a}$ & $1.3 \mathrm{Kg} / \mathrm{m}^{3}$ \\
\hline Density of ice & $\rho_{i}$ & $900 \mathrm{Kg} / \mathrm{m}^{3}$ \\
\hline Density of snow & $\rho_{s}$ & $330 \mathrm{Kg} / \mathrm{m}^{3}$ \\
\hline Density of ocean & $\rho_{o}$ & $1024 \mathrm{Kg} / \mathrm{m}^{3}$ \\
\hline Melting point of freshwater ice & $t_{\text {fus }}$ & $0^{\circ} \mathrm{C}$ \\
\hline Salinity of sea ice & $s_{i}$ & 4 \\
\hline Exchange coeff. for sensible heat (leads/ice) & $c_{H}$ & $1.75 \times 10^{-3}$ \\
\hline Exchange coeff. for latent heat over leads & $c_{E}$ & $1.75 \times 10^{-3}$ \\
\hline Exchange coeff. for latent heat over ice & $c_{E}$ & $1 \times 10^{-3}$ \\
\hline Stefan-Boltzmann constant & $K$ & $5.67 \times 10^{-8} \mathrm{~W} \mathrm{~m}^{-2} \mathrm{~K}^{-4}$ \\
\hline Minimum vertical viscosity & $v_{\min }$ & $1 \times 10^{-3} \mathrm{~m}^{2} \mathrm{~s}^{-1}$ \\
\hline Scale depth of mechanical dissipation & $h_{w}$ & $7 \mathrm{~m}$ \\
\hline Scale depth of convective dissipation & $h_{c}$ & $50 \mathrm{~m}$ \\
\hline
\end{tabular}

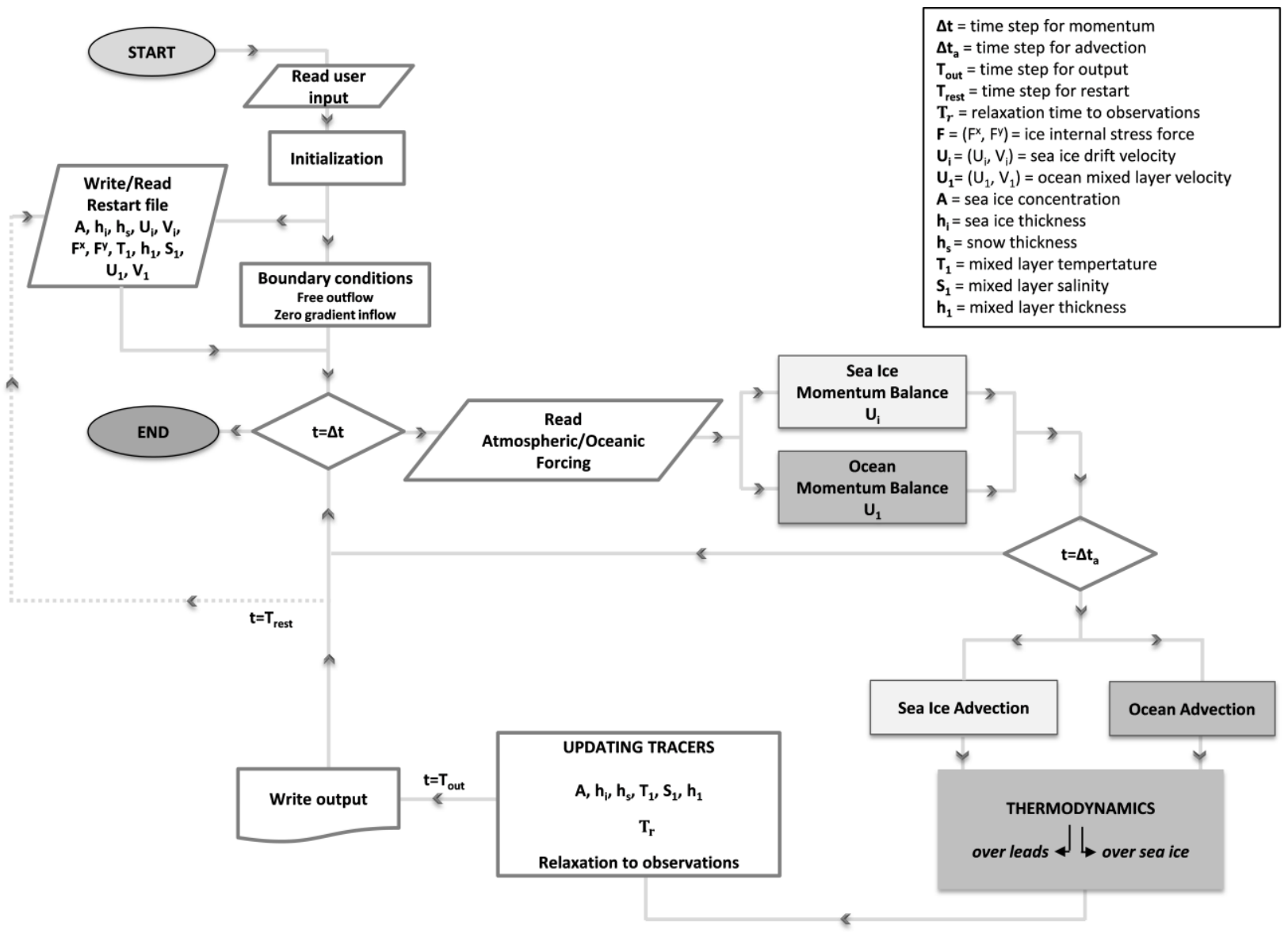




\subsection{Forcing Fields}

The ocean forcing consists of climatological oceanographic profiles of ocean temperature and salinity developed through the analysis of available in situ temperature and salinity datasets. These datasets consist of hydrographic mooring and CTD profile data collected from February 1995 to January 2008 within the CLIMA (Climatic Long-term Interaction for the Mass-balance in Antarctica) project of the Italian National Research Antarctic Program (PNRA). The two climatological datasets include idealized monthly temperature and salinity values, spatially uniform in the model domain and varying vertically down to 800 meters in depth. In detail, 8 depth levels $(0$ $\mathrm{m},-30 \mathrm{~m},-50 \mathrm{~m},-100 \mathrm{~m},-150 \mathrm{~m},-300 \mathrm{~m},-500 \mathrm{~m},-800 \mathrm{~m})$ are chosen for the computation of climatological temperature and salinity profiles (see Section 2.3) that are subsequently used to calculate, by linear interpolation, the temperature, $T_{b}$, and salinity, $S_{b}$, at the base of the active layer as well as the restoring temperature, $T_{c}$, and salinity, $S_{c}$, in the active layer. As main atmospheric forcing, the Era-Interim reanalysis from the European Centre for Medium-Range Weather Forecasts (ECMWF), has been prescribed. The data extracted from the global domain provide surface sixhourly parameters at a $0.5 \times 0.5$ degree horizontal resolution covering the model domain with $16 \times$ 11 grid points, in latitude $\times$ longitude. Specifically, the input data consist of the 10 meter eastward and northward wind components $(\mathrm{m} / \mathrm{s})$, the 2 meter temperature $(\mathrm{K})$, the downward surface solar radiation $\left(\mathrm{Wm}^{-2} \mathrm{~s}\right)$, the surface $(1000 \mathrm{mb}$ level) pressure $(\mathrm{Pa})$, the relative humidity $(\%)$, the total cloud cover (0-1) and the total precipitation accumulation (m of water). The oceanographic and atmospheric data have been spatially and temporally interpolated over the whole model domain. Meteorological observations form Automatic Weather Stations (AWSs) have also been employed to force the model. 


\subsubsection{Atmospheric field setting}

The resolution of the local winds is a crucial factor in estimating sea ice and HSSW production, especially in a small coastal polynya like the TNB. In particular during winter, sea ice production in TNB is largely determined by katabatic winds which are the main control of the TNB polynya size (Petrelli et al., 2008; Gallé, 1997). Petrelli et al. (2008) showed that an insufficient resolution of the katabatic winds leads to an underestimation of sea ice winter production of up to $50 \%$, which results in an underestimation of the formation rate of HSSW and consequently of AABW. On the other hand, low resolution winds reanalyses can also result in higher ice and AABW production because of an overestimated offshore component due to the coarse resolution orography (Stössel et al., 2011).

In spite of their relatively high resolution, the ECMWF reanalysis have been found to underestimate the wind speeds in several studies (Cullather et al., 1997; Fusco et al., 2002; Petrelli et al., 2008), providing therefore an improper representation of the wind fields along and offshore TNB. Also Mathiot et al. (2010) investigated the effect of the katabatic winds on sea ice and shelf water properties by correcting the ECMWF reanalyses winds with results from the MAR regional atmospheric model. To remedy this problem, we have applied a wind correction to coastal and offshore model grid points value combining the Era Interim data with in-situ atmospheric data from Automatic Weather Stations (AWSs), which show a significantly increased skill over ECMWF atmospheric variables (Petrelli et al., 2008).

A merging function has been designed so that the correction factor for each grid point value varies with the distance from the weather station. Era Interim and AWS data are merged resulting in the effective wind vector defined as

$V_{e f f}=V_{A W S} e^{-\frac{r}{R}}+V_{E r a}\left(1-e^{-\frac{r}{R}}\right)$,

where $V_{A W S}$ and $V_{E r a}$ are the wind vectors from AWS and ERA-Interim, respectively, $\mathrm{r}$ is the distance from the AWS and R is an e-folding length scale. 
In particular, atmospheric data from two AWSs have been used. In a first phase of the sensitivity tests, only the Rita AWS $\left(-74.72^{\circ} \mathrm{S}, 164.03^{\circ} \mathrm{E}\right)$, installed within the Meteo-Climatological Observatory of the PNRA in close proximity to the Italian base "Mario Zucchelli", downstream of the Priestley Glacier (Fig. 3), has been considered.

Subsequently, the Manuela AWS $\left(-74.95^{\circ} \mathrm{S}, 163.69^{\circ} \mathrm{E}\right)$, installed as part of the AWS project of the University of Wisconsin-Madison Antarctic Meteorology Program on Inexpressible Island, has been also included. The AWS Manuela lies downstream of the Reeves Glacier (Fig. 3), which represents one of the main routes for the katabatic flows from the interior of Antarctica.

The Rita and Manuela datasets consist, respectively, of one hourly and ten minute intervals data including air temperature $\left({ }^{\circ} \mathrm{C}\right)$, wind speed $(\mathrm{m} / \mathrm{s})$ and direction $\left({ }^{\circ} \mathrm{N}\right)$, surface pressure $(\mathrm{hPa})$, and relative humidity $(\%)$. The merging function (21) has been applied also to the air temperature and relative humidity data.

Three experiments (Table 3) were carried out in order to examine the influence of the parameter $R$ (see eq. 21) on the wind fields and, consequently, on sea ice and ocean currents in the TNB area. The model was run with the rheology parameter $P^{*}=27500 \times 10^{4} \mathrm{~N} / \mathrm{m}^{2}$, as in Hibler and Walsh (1982), which is the most widely used value for the ice strength parameter. A demarcation ice collection thickness, $H=0.1 \mathrm{~m}$ and a relaxation time of $\mathrm{T}_{r}=7$ days to climatological oceanic data were used. The time interval of the atmospheric input was set to 6 hours, while that of the output fields is such that the model gives a daily output for each computed variable.

The control experiment, referred to as CASE 1, uses $R=25 \mathrm{~km}$, the second experiment, CASE 2 , uses a larger $R=50 \mathrm{~km}$, while CASE 3 differs from the control experiment in the absence of the merging between reanalyses and AWS data. The results of the simulations (Fig. 5a to c) show that an increasing of the parameter $R$ (CASE 2) leads, as expected, to larger wind and ice drift and ocean velocities. The wind velocities have maximum values of $19.66 \mathrm{~m} / \mathrm{s}$ in CASE 1 and $20.65 \mathrm{~m} / \mathrm{s}$ in CASE 2, while in CASE 3, where the merging function is switched off, they reach a maximum 
405 value of only $7.27 \mathrm{~m} / \mathrm{s}$. Also sea ice and ocean current velocities, which reach values of $0.34 \mathrm{~m} / \mathrm{s}$ 406 and $0.06 \mathrm{~m} / \mathrm{s}$ respectively in CASE 2, are significantly reduced in CASE 3.

\begin{tabular}{cc}
\hline Experiment & $\boldsymbol{R}(\mathbf{k m})$ \\
\hline CASE 1 & 25 \\
CASE 2 & 50 \\
CASE 3 & no merging \\
\hline
\end{tabular}

410 Table3: Case studies on the influence of the parameter $R$ on wind fields. 

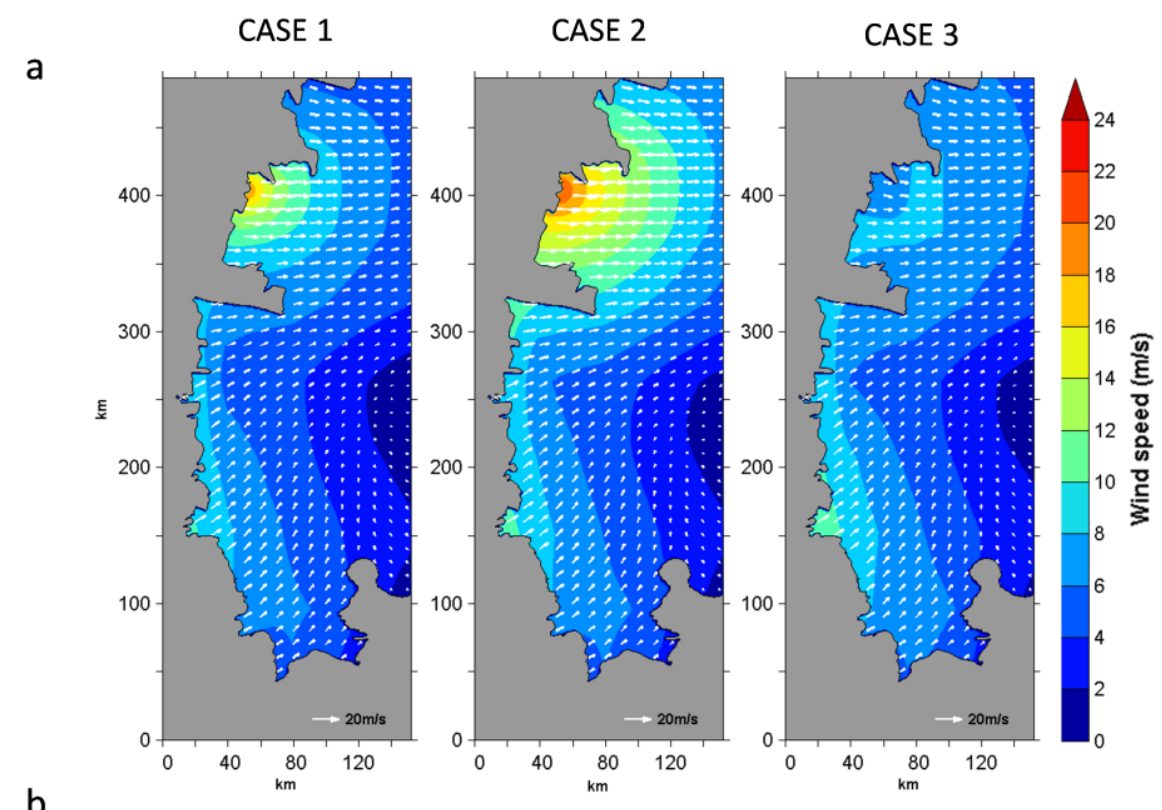

b
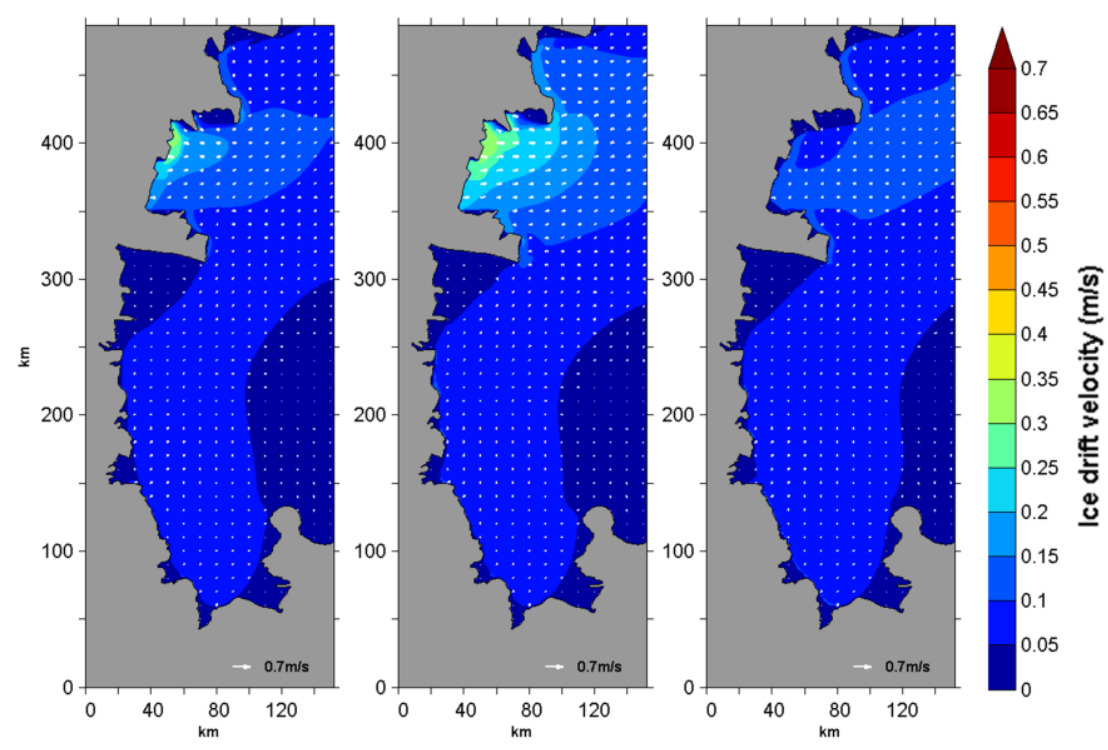

C
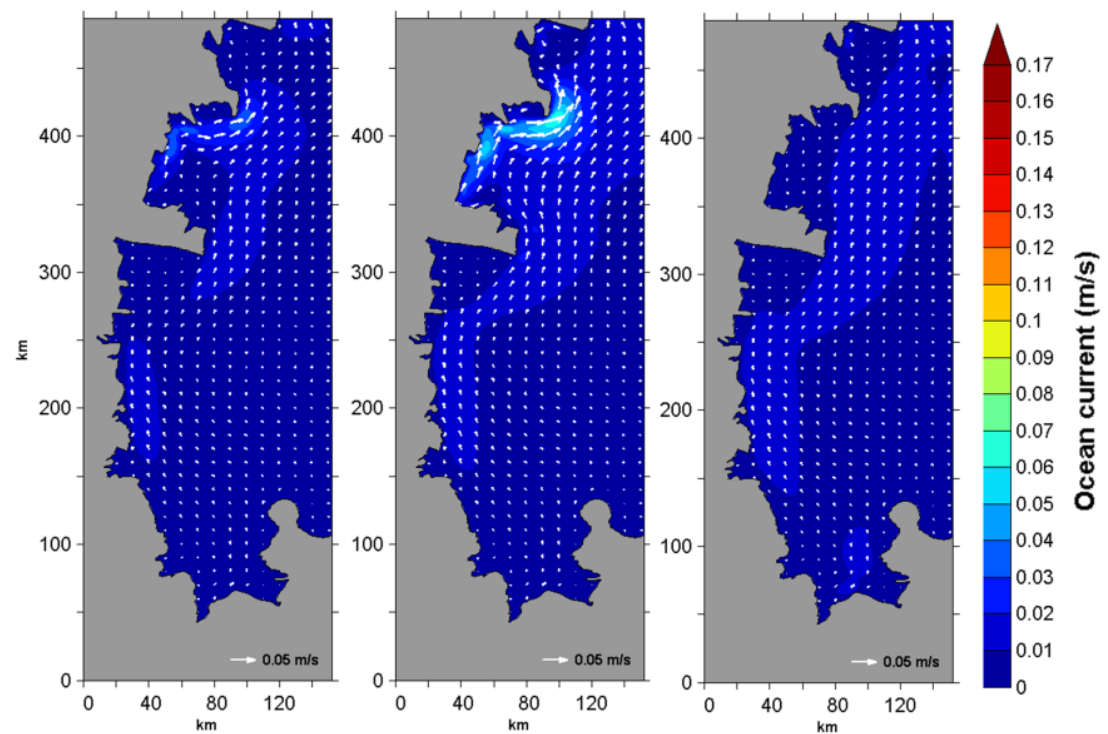

Fig. 5: Maps of wind speed (a), modelled ice drift velocity (b) and modelled ocean current (c) overlaid by the corresponding wind speed vectors, ice drift velocity vectors and ocean current vectors on $8^{\text {th }}$ July 2000 for CASE 1 to CASE 3. 
413 An improper choice of the parameters which describe sea ice evolution results often in unrealistic 414 simulations leading to inaccurate results. Several sensitivity experiments were performed to define the best set of parameters controlling TNB sea ice dynamics and thermodynamics in response to wind forcing. Two key parameters have been found to control the wind driven polynyas: the rheological ice strength parameter $P^{*}$ and the demarcation ice collection thickness $H$, also named the lead-closing parameter. The rate at which the leads close under freezing conditions is inversely proportional to the value of $H$. Both parameters have a strong effect on polynya size and sea ice extent and volume estimates (Hibler, 1979; Stössel et al., 1990; Stössel, 1992).

Finally a sensitivity analysis was carried out turning attention to the air-ice and ice-ocean drag coefficients which control the stresses on the sea ice cover. The choice of these parameters depends on the study area and especially on the wind forcing time and spatial resolution, therefore the model was opportunely tuned and optimized in this regard.

\subsection{Sensitivity to ice strength parameter}

The ice strength parameter $P^{*}$ is a key element in sea ice rheology that relates sea ice strength $(\mathrm{P})$ to its concentration, $A$, and mean thickness, $A h_{i}$. It was first introduced by Hibler (1979) in the constitutive equation for sea ice strength as

$\mathrm{P}=P^{*} A h_{i} \exp [-C(1-A)]$

where $P^{*}$ and $C$ are empirical values. The ice strength exhibits a strong dependence on sea ice concentration and especially on the amount of thin ice. For a large amount of thin ice, the ice strength decreases significantly and most of thin ice is deformed (Hibler, 1979; Willmott et al., 2007; Feltham, 2008). Sea ice also offers less resistance to compression when $A h_{i}$ and $P^{*}$ are low, and tends to pile up more easily because of enhanced mechanical ridging and rafting. Therefore, $P^{*}$ is a critical parameter controlling sea ice drift behaviour in wind driven polynyas and represents the 
main tuning parameter to achieve a realistic sea ice drift pattern (Owens and Lemke, 1990; Stössel et al., 1990; Steele et al., 1997).

439 The strength of the ice internal forces depends on the state of deformation of the sea ice cover, 440 which will, in turn be partly controlled by the wind stress field. Based on this observation, a 441 sensitivity experiment was performed to investigate the impact on the ice dynamics of varying $P^{*}$. 442 This experiment, referred to as CASE 4, is equal to CASE 1 shown in section 2.3.1 except for $P^{*}=$ $4435000 \mathrm{~N} / \mathrm{m}^{2}$ (Hibler, 1979). The wind field is the same as CASE 1 (see Fig. 5a) and the sea ice drift 444 and ocean fields on $8^{\text {th }}$ July 2000 for CASE 4 are shown in Fig. 6 . These results are very similar to 445 those of CASE 1 for both sea ice and ocean outputs.

446 The reduced ice strength does not affect significantly the ridging of sea ice or the sea ice drift in 447 convergent regions, altering relatively little the ice concentration and thickness distribution (not 448 shown). This indicates the polynya area is not highly sensitive to $P^{*}$ in the determination of its 449 opening/closure for this set of forcing.

\section{CASE 4}
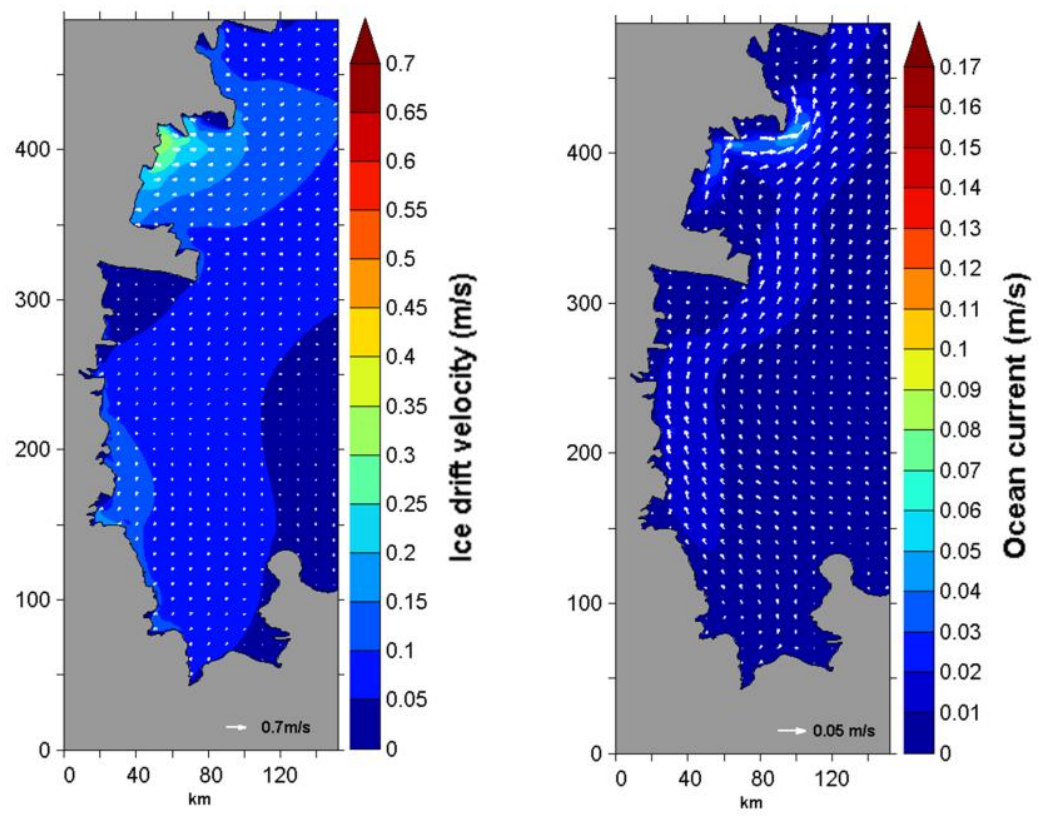

Fig. 6: Modelled ice drift velocity (left) and modelled ocean current (right) overlaid by the corresponding 450 ice drift velocity vectors and ocean current vectors on $8^{\text {th }}$ July 2000 for CASE 4. 
451 This is probably due to the fact that this parameter has a major influence only in areas of thick ice but not so much in regions covered by thin and broken ice cover (Kreysher et al., 2000).

\subsection{Sensitivity to demarcation ice collection thickness}

While the dynamic behaviour of the consolidated ice is greatly determined by the ice rheology, the interior of the polynya is affected by the new ice thickness parameterization. The new ice thickness is controlled by the demarcation ice collection thickness parameter $H$ in eq. (15) that is expressed as a transition value between thin ice (open water) and thick ice (Hibler, 1979). It is as crucial an element in sea ice models as the ice thickness collection depth in polynya flux models (Tear et al., 2003; Willmott et al., 2007) since it represents the thickness at which newly-formed ice in the polynya is transferred into thicker sea ice. Thereby, it affects sea ice thermodynamics, lowering heat loss through thin ice inside the polynya and determining primarily the mean thickness and sea ice concentration of newly formed ice (Hibler, 1979; Olason and Harms, 2010).

$H$ has been often defined as a constant in the literature, with typical values in the range $0.1-0.5 \mathrm{~m}$ (Hibler, 1979; Pease, 1987; Ou, 1988; Darby et al. 1994, 1995). However, wind speed is an important controlling factor of the collection thickness of new ice (Mellor and Kantha, 1989; Winsor and Björk, 2000; Olason and Harms, 2010).

A number of experiments, outlined in Table 4, were performed with different values of $H$. The control experiment (CASE 5) was run with $H=0.2 \mathrm{~m}$, that is considered more appropriate than the $H=0.5 \mathrm{~m}$ proposed by Hibler (1979), in simulating the behaviour of thin ice inside the polynya (Olason and Harms, 2010). In the second (CASE 6) and third experiment (CASE 7), sea ice concentration and thickness are simulated using a constant $H=0.3 \mathrm{~m}$ and $H=0.4 \mathrm{~m}$ respectively, while in the fourth experiment (CASE 8) a varying $H$ has been used. Specifically, the collection depth parameterization of Winsor \& Björk (2000) is employed, namely,

$$
H=\frac{a+V \cdot b}{c}
$$


476 where $V$ is the surface wind speed $(\mathrm{m} / \mathrm{s})$ and the constants are $a=1 \mathrm{~m}, b=0.1 \mathrm{~s}$ and $c=15$. This 477 means that $H$ varies in the range $0.1-0.3 \mathrm{~m}$ in the presence of wind speeds between $5-35 \mathrm{~m} / \mathrm{s}$.

478 In all these experiments, $R$ is fixed to $50 \mathrm{~km}$, except in CASE 9, in which the merging function is 479 not applied. The value of $27500 \mathrm{~N} / \mathrm{m}^{2}$ for $P^{*}$ and of 30 days for the relaxation time to oceanic 480 forcing were used. Figure 7 shows the results of sea ice concentration (a) and thickness (b) 481 simulation on $8^{\text {th }}$ July 2000 for CASE 5-to-CASE 9. Note that a lower ice demarcation thickness 482 gives higher ice concentration values and lower ice thickness values due to lower heat losses 483 through leads.

\begin{tabular}{cc} 
& \\
\hline Experiment & $\boldsymbol{H}(\mathbf{m})$ \\
\hline CASE 5 & 0.2 \\
CASE 6 & 0.3 \\
CASE 7 & 0.4 \\
CASE 8 & $\mathrm{f}(\mathrm{V})$ \\
CASE 9 & 0.2 no merging \\
\hline
\end{tabular}

Table 4: Sensitivity tests of sea ice evolution with respect to $H$. 

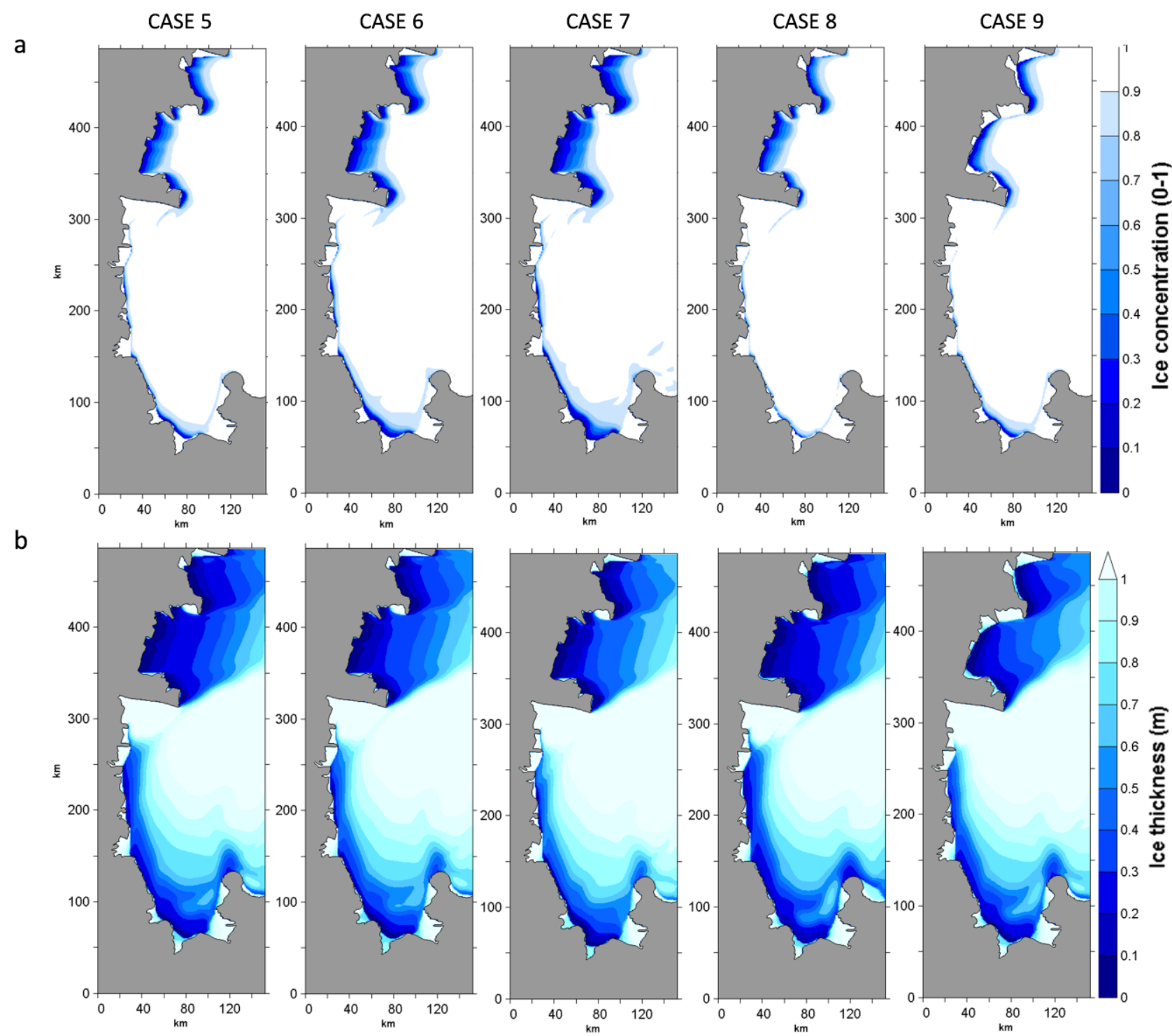

Fig. 7: Modelled sea ice concentration (a) and thickness (b) on $8^{\text {th }}$ July 2000 for CASE 5 to CASE 9.

491 The sea ice distribution in CASE 8 is similar to that of CASE 5, suggesting that the dependence of the ice collection thickness on the wind velocities provides plausible values for $H$. This is well supported by the estimates of daily sea ice production ( $\mathrm{km}^{3} /$ day) in TNB region on July 2000 (Fig. 8). Cumulative sea ice production $\left(\mathrm{km}^{3}\right)$ for the whole of July 2000 is also showed in Table 5. Note that the TNB region is identified by the area of the domain that extends within the ranges $1-120 \mathrm{~km}$ in $\mathrm{X}$ (longitude) and $310-425 \mathrm{~km}$ in $\mathrm{Y}$ (latitude) as shown in Fig. 8. Sea ice production rate computed using a non-spatially uniform $H$ (CASE 8) depicted by the solid line with square markers shows a trend very similar to that of CASE 5, except for a few days when wind speeds in the 
polynya were particularly large. As it can easily be observed, CASE 9, where wind forcing is given by the winds reanalysis alone, underestimates considerably sea ice production rate compared to CASE 5 and, indeed, all the others. These results suggest reasonable agreement between the wind forcing and the simulated sea ice dynamics in the TNB.

In the next section we will consider the sensitivity of the TNB polynya to the wind forcing and wind stress (Stössel, 1992; Stössel et al., 2011) pointing out the importance of high temporal resolution of wind data.

\begin{tabular}{cc}
\hline Experiment & Sea ice production $\left(\mathbf{k m}^{\mathbf{3}}\right)$ in July $\mathbf{2 0 0 0}$ \\
\hline CASE 5 & 10.08 \\
CASE 6 & 11.09 \\
CASE 7 & 12.12 \\
CASE 8 & 9.79 \\
CASE 9 & 6.83 \\
\hline
\end{tabular}

Table 5: Sea ice production in July 2000 for the experiments CASE 5 to CASE 9.

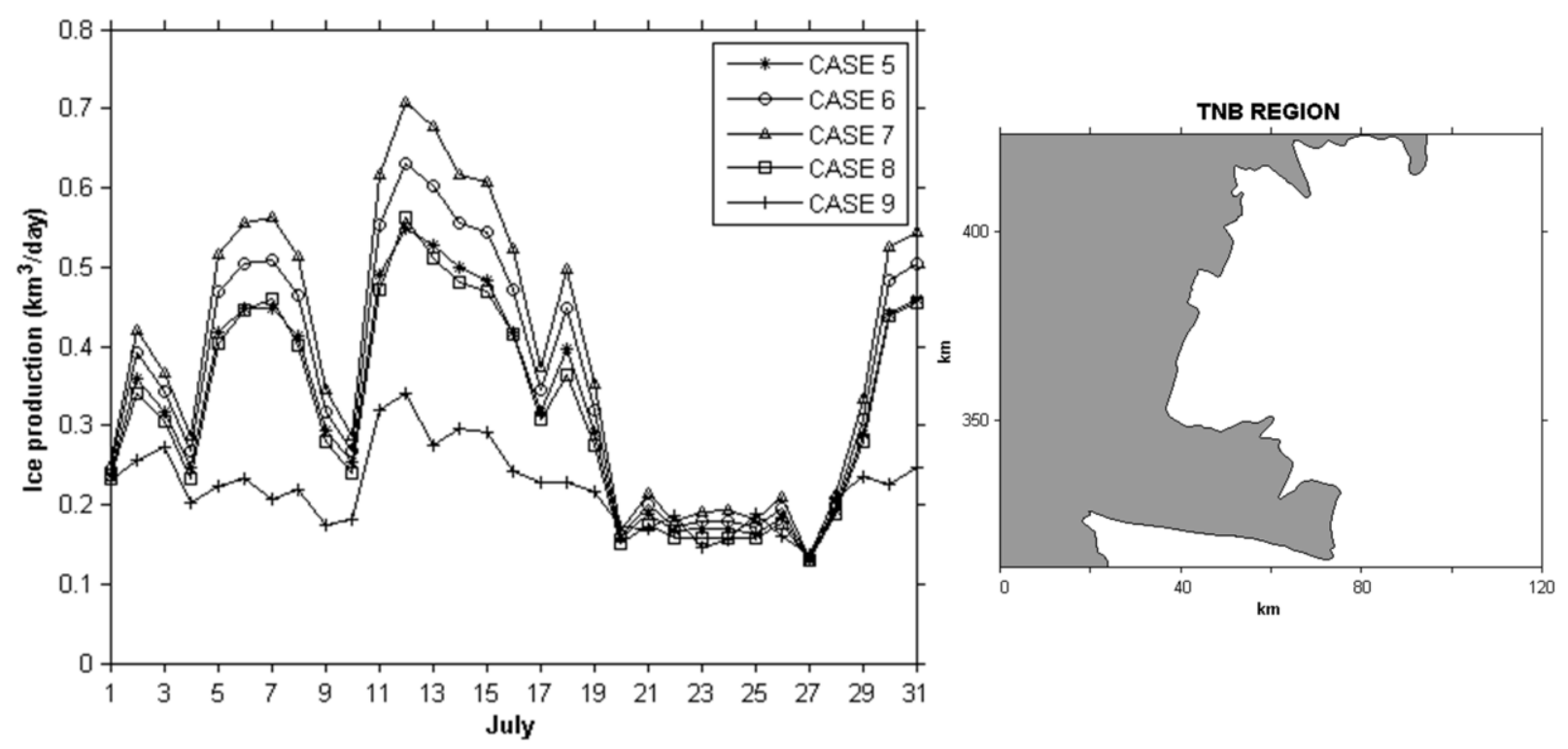




\subsection{Sensitivity to air-ice and ice-ocean drag coefficients}

514 Along with $P^{*}$, the atmospheric and oceanic drag coefficients have been identified as crucial parameters for sea ice drift. Several sensitivity experiments were performed to obtain the optimal set of drag coefficients that would allow us to run the model under more realistic conditions.

We also focused on the regime of the katabatic winds and its impact on sea ice evolution in the TNB and on the polynya size. The latter, in fact, is very responsive to variations in the freezing rates in the bay as a result of a weakening of the katabatic flows or a change in their direction (Bromwich and Kurtz, 1984; Priestley, 1914). The duration of the katabatic wind events has a greater contribution than the intensity and frequency of the katabatic flows in determining the polynya extent (Ciappa et al., 2012; Rusciano et al., 2013). Rusciano et al. (2013) found most frequent katabatic events take place during the winter season and last on average from one to three hours. That means that long time intervals (daily/six hourly) atmospheric input probably misrepresent the real and local atmospheric fields in a given temporal period. On the other hand, a single source of AWS data fails to properly reproduce the geometry of the coastal wind regime resulting from the drainage of the interior katabatic airflows through the different confluence pathways (Petrelli et al., 2008). In view of these considerations, in the next experiments, the time 529 resolution was increased so that the model is able to capture any katabatic events. Furthermore, a 530 second dataset from AWS Manuela (see section 2.3.1) was taken into account to enlarge the area of

531 influence of the katabatic flows. Unfortunately, no other weather station is available in the 532 southernmost region of the bay and near to the Drygalski Ice Tongue. In addition, the merging 533 function was modified and the range of influence of the AWS data on the reanalysis data was let to 534 assume an elliptic shape rather than a circumference as follows:

$535 V_{e f f}=V_{A W S} e^{-\sqrt{\frac{x^{2}}{R_{1}^{2}}+\frac{y^{2}}{R_{2}^{2}}}}+V_{E r a}\left(1-e^{-\sqrt{\frac{x^{2}}{R_{1}^{2}}+\frac{y^{2}}{R_{2}^{2}}}}\right)$, 
where $x$ and $y$ are the components of the position vector of a particular point in the domain with respect to the AWS, and $R_{1}=50 \mathrm{~km}$ and $R_{2}=20 \mathrm{~km}$ are e-folding length scales in the $\mathrm{x}$ and $\mathrm{y}$ directions. Table 6 summarises the experiments performed to explore the impact of varying the $C_{d a}$ and $C_{d o}$ drag coefficients, increasing and/or decreasing the one with respect to the other, on sea ice drift and polynya dynamics. Substantially, an increasing of $C_{d a}$ and/or at the same time a decreasing of $C_{d o}$ allows sea ice to move faster and vice versa. We have made use of a double sub-index to identify easily the wind and ocean drag coefficients used in a particular experiment, e.g. the experiment denoted by $\mathrm{E}_{\mathrm{ab}}$ uses $C_{d a}=\mathrm{a} \times 10^{-3}$ and $C_{d o}=\mathrm{b} \times 10^{-3}$.

The first experiment $\left(E_{15}\right)$ is the control simulation of one winter month of the year 2005 for which the model has been configured with constant and more commonly used values for the drag coefficients, $C_{d a}=1 \times 10^{-3}$ and $C_{d o}=5 \times 10^{-3}$. In the next experiments, the values of the two drag coefficients were allowed to vary individually or simultaneously with respect to those of the control run. Specifically, in the second experiment $\left(\mathrm{E}_{35}\right) C_{d a}$ varies and $C_{d o}$ is the same as in the control run, in the third experiment $\left(\mathrm{E}_{11}\right)$, only $C_{d o}$ varies, while, in the fourth $\left(\mathrm{E}_{31}\right)$ and in the fifth $\left(\mathrm{E}_{34}\right)$ experiments, both parameters vary together. The sixth experiment $\left(\mathrm{E}_{\mathrm{r}}\right)$, which is in more detail described afterwards, was carried out using non constant values for the drag coefficients. All the experiments are forced with atmospheric forcing from the AWS Manuela at ten minutes resolution, combined with hourly data from the AWS Rita. The resulting values are averaged with the six hourly ERA-Interim data so as to adjust the background atmospheric fields, especially the winds. In addition, the output time of the variables simulated by the model were set equal to 3 hours since, as explained above, this value would appear to be a good compromise to capture the effects of katabatic winds.

As the sensitivity experiments described in previous sections, a significant dependence of the sea ice simulation on the wind forcing can be inferred from the results of the modelled output fields. The sea ice distribution appears to be very sensitive to the pattern of the wind stress which varies considerably depending on the surface winds. Fig. 9a shows the wind speeds and the wind stress 
vector fields for the $\mathrm{E}_{15}, \mathrm{E}_{35}, \mathrm{E}_{11}, \mathrm{E}_{31}$ and $\mathrm{E}_{34}$. The wind field is the same for all the experiments 563 since they have been forced with the same wind configuration, which has maximum wind speed 564 values of up to $23 \mathrm{~m} / \mathrm{s}$ and a mean value of $9 \mathrm{~m} / \mathrm{s}$. The wind stress, depending on the drag 565 parameters, exhibits average values of $0.16,0.41,0.13,0.27$ and $0.40 \mathrm{~N} / \mathrm{m}^{2}$ in $\mathrm{E}_{15}, \mathrm{E}_{35}, \mathrm{E}_{11}, \mathrm{E}_{31}, \mathrm{E}_{34}$, 566 respectively. The largest values have been found, as expected, in $\mathrm{E}_{35}, \mathrm{E}_{31}$ and $\mathrm{E}_{34}$ with maxima of $5671.48,1.34$ and $1.47 \mathrm{~N} / \mathrm{m}^{2}$ versus much smaller maxima in the CTRL run $\left(\mathrm{E}_{15}\right)$ and in $\mathrm{E}_{11}$ of 568 approximately $0.54 \mathrm{~N} / \mathrm{m}^{2}$.

\begin{tabular}{|c|c|c|c|}
\hline 569 & Experiment & $\overline{C_{d a}}$ & $\overline{C_{d}}$ \\
\hline \multirow{3}{*}{570} & $\mathrm{E}_{15} \quad$ CTRL & $1 \times 10^{-3}$ & $5 \times 10^{-3}$ \\
\hline & $E_{35}$ & $3 \times 10^{-3}$ & $5 \times 10^{-3}$ \\
\hline & $\mathrm{E}_{11}$ & $1 \times 10^{-3}$ & $1 \times 10^{-3}$ \\
\hline 571 & $E_{31}$ & $3 \times 10^{-3}$ & $1 \times 10^{-3}$ \\
\hline \multirow[b]{2}{*}{572} & $\mathrm{E}_{34}$ & $3 \times 10^{-3}$ & $4 \times 10^{-3}$ \\
\hline & $\mathrm{E}_{\mathrm{r}}$ & $\begin{array}{ll}1 \times 10^{-3} & V \leq 10 \mathrm{~m} / \mathrm{s} \\
3 \times 10^{-3} & V \geq 20 \mathrm{~m} / \mathrm{s}\end{array}$ & $1.3 \times C_{\mathrm{da}}$ \\
\hline
\end{tabular}

Table 6: Sensitivity tests with respect to the air-ice and ice-ocean drag coefficients. The double sub-index identifies the wind and ocean drag coefficients used in each experiment. 

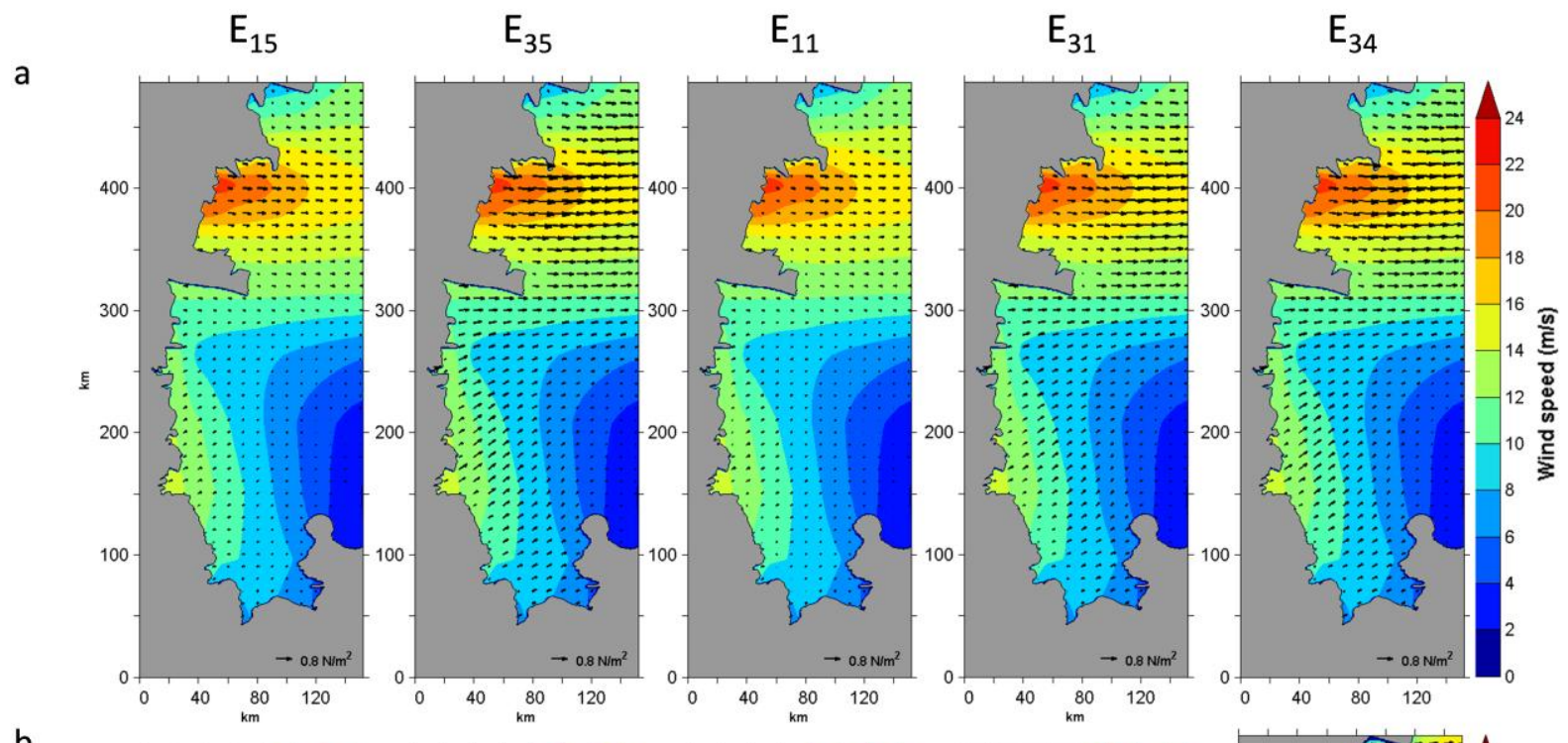

b

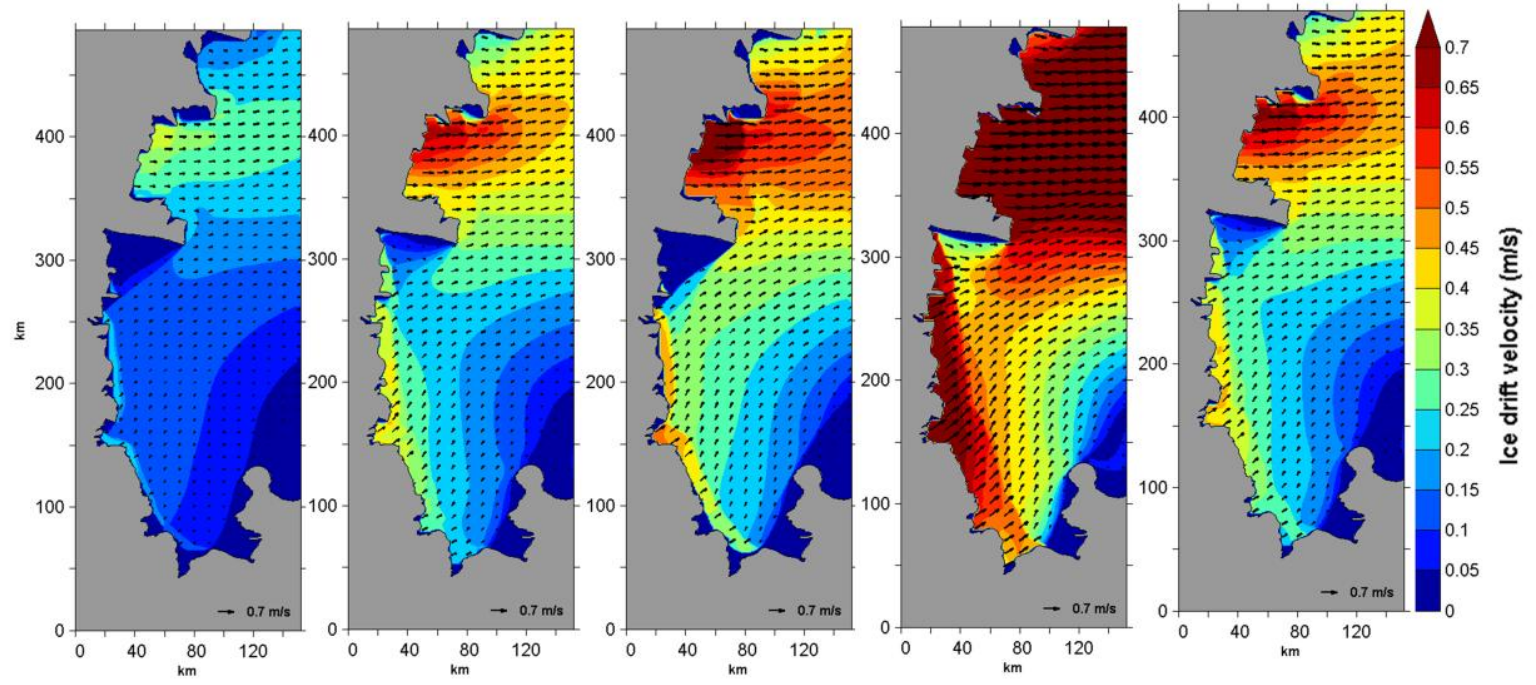

C
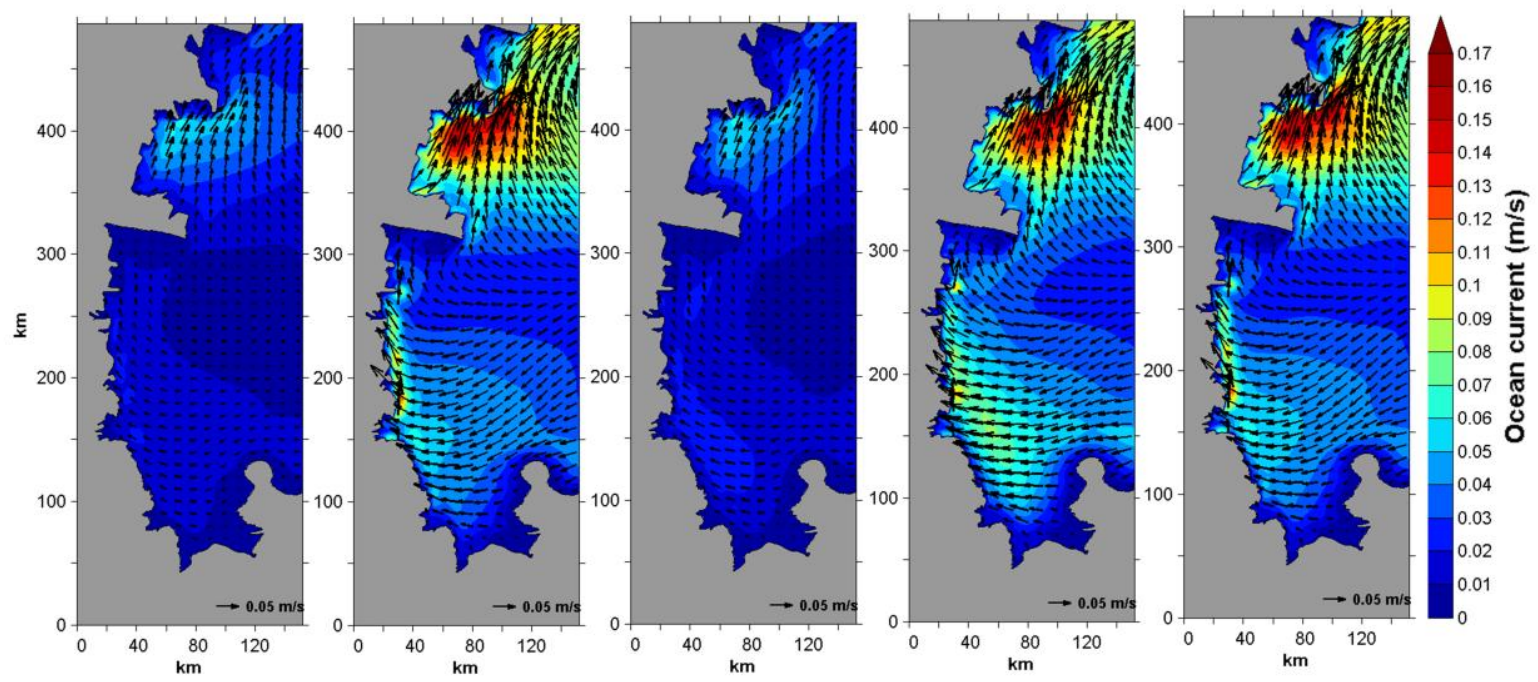

Fig. 9: Wind speeds (a), sea ice drift velocities (b) and ocean currents (c) with the superimposed wind stress, ice drift and ocean current vectors, respectively on $30^{\text {th }}$ July 2005 for $E_{15}, E_{35}, E_{11}, E_{31}$ and $E_{34}$. 
581 The bigger wind stress in $\mathrm{E}_{35}, \mathrm{E}_{31}$ and $\mathrm{E}_{34}$ leads to maximum ice drift speeds (Fig. 8b) of 0.65, 1.37 582 and $0.70 \mathrm{~m} / \mathrm{s}$ respectively, and also to larger ocean currents ( e. $8 \mathrm{c}$ ). A maximum ice drift of 0.81 $583 \mathrm{~m} / \mathrm{s}$, comparable to that from $\mathrm{E}_{34}$, result from $\mathrm{E}_{11}$, where the two coefficients $C_{d a}$ and $C_{d o}$ differ the 584 least from each other. Smaller values, as expected, result from $\mathrm{E}_{15}$ with a maximum of $0.37 \mathrm{~m} / \mathrm{s}$ and 585 a mean of $0.12 \mathrm{~m} / \mathrm{s}$. Sea ice concentration and thickness charts displayed in Fig. 10a and b reveal 586 that the sea ice distribution in $\mathrm{E}_{35}, \mathrm{E}_{11}$ and $\mathrm{E}_{34}$ show a good comparison, from a qualitative point of 587 view, with MODIS scenes represented in Ciappa et al. (2012). In these experiments the gap between $588 C_{d a}$ and $C_{d o}$ is small. In contrast, when $C_{d o}$ is much smaller than $C_{d a}$, the ice drift becomes 589 unrealistic and too strong also in regions out of the range of the coastal winds or, in the opposite 590 case, really insignificant along shore. These results supports the importance of the $C_{d a} / C_{d o}$ ratio 591 considered to be the most basic dynamics parameter determining the mean drift speed (McPhee, 592 1980; Lepparänta, 1981; Stössel, 1992; Geiger et al., 1998; Harder and Fisher, 1999). 

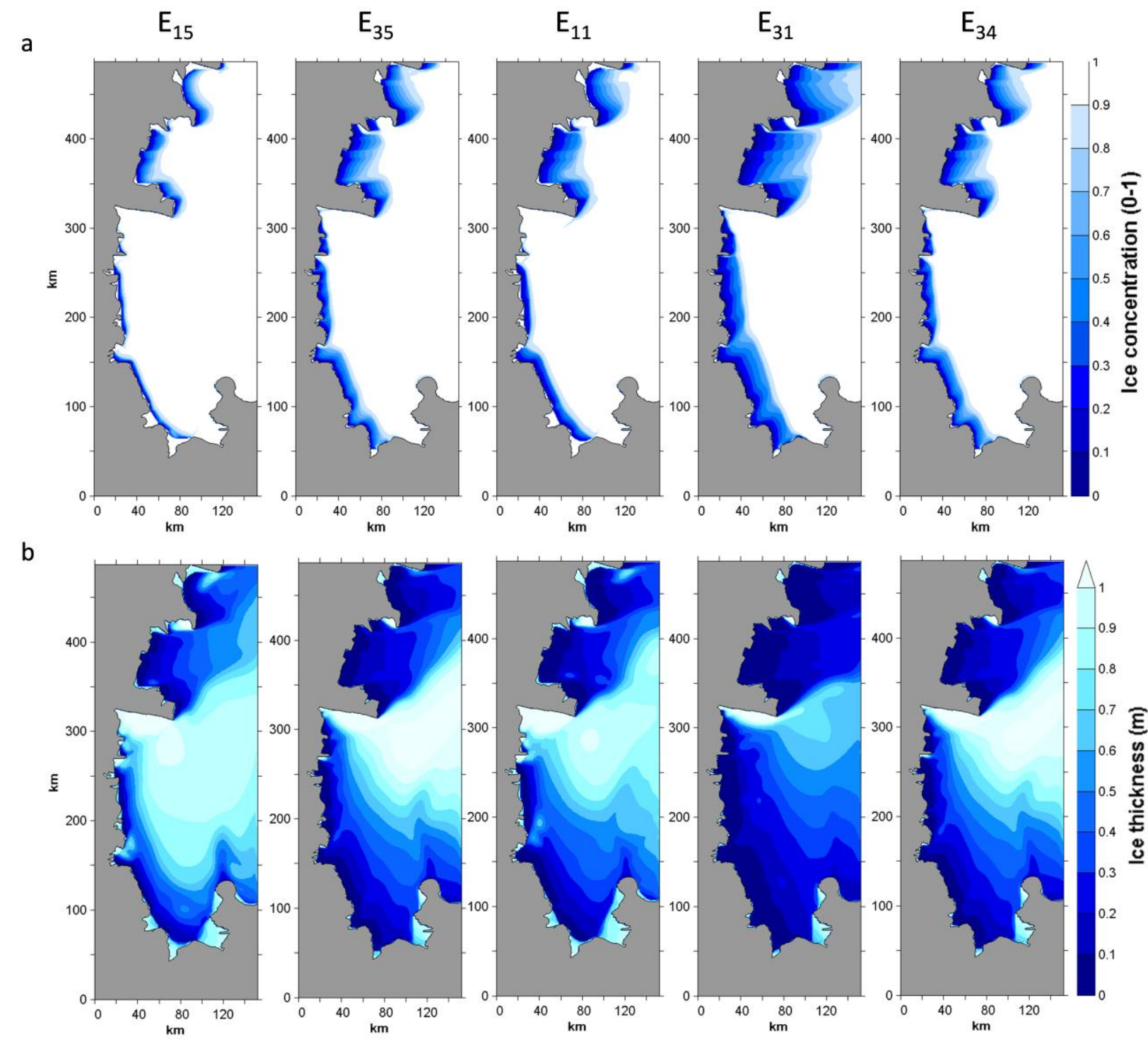

Fig. 10: Modelled sea ice concentration (a) and thickness (b) on $30^{\text {th }} \mathrm{July} 2005$ for $\mathrm{E}_{15}, \mathrm{E}_{35}, \mathrm{E}_{11}, \mathrm{E}_{31}$ and $\mathrm{E}_{34}$.

596 Furthermore, unlike the strength parameter $P^{*}$ which has a strong impact mainly on thick and more compact areas of the pack ice, the $C_{d a} / C_{d o}$ ratio influences the ice drift in all regions during all seasons (Kreysher et al., 2000). The dependence of the air-ice drag coefficient on the wind speed has been also investigated by several authors (Large and Pond, 1981; Overland, 1985; Lynch et al., 1997). Accordingly, in the last experiment $\left(\mathrm{E}_{\mathrm{r}}\right) C_{d a}$ was allowed to vary linearly from $1 \times 10^{-3}$ for 601 wind speeds below $10 \mathrm{~m} / \mathrm{s}$, to $3 \times 10^{-3}$ for wind speeds above $20 \mathrm{~m} / \mathrm{s}$. Then, $C_{d o}$ is allowed to depend linearly on the $C_{d a}$ through a constant factor of 1.3 (McPhee, 1980; Lepparänta, 1981; 
604 Figure 11 shows wind and ice velocities with the superimposed wind stress and ice velocity vector

605 fields, ice concentration and thickness maps for $E_{r}$ on the $30^{\text {th }}$ July 2005 at 24:00. Mean and 606 maximum values of the wind stress are very similar to those resulting from $E_{34}$. The results of $E_{r}$ 607 provide the best simulations of the sea ice dynamics of TNB.

608

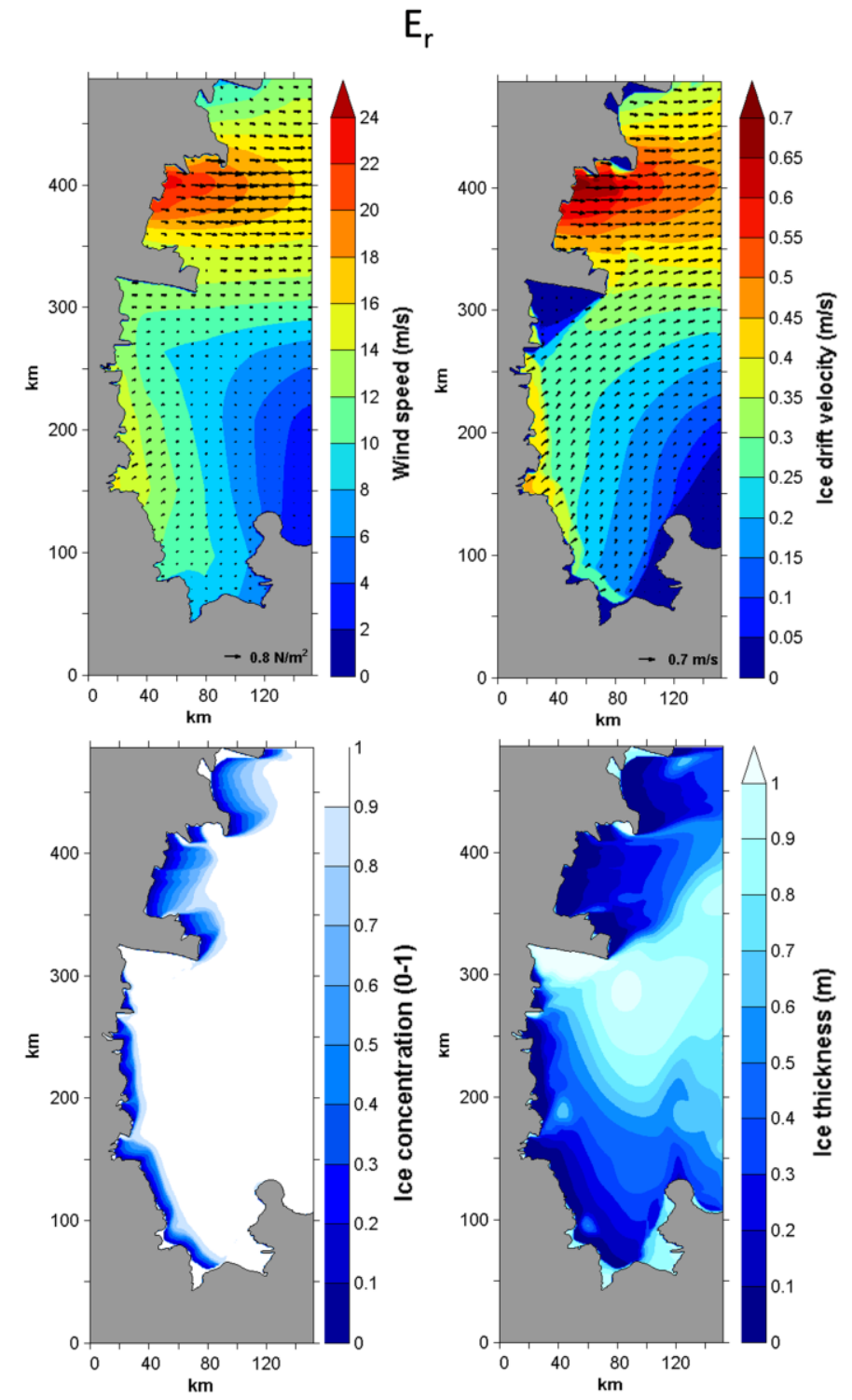

Fig. 11: Wind speeds and modelled sea ice drift velocities with the superimposed wind and ice drift vectors field (top) and sea ice concentration and thickness distribution (bottom) on $30^{\text {th }}$ July 2005 for $\mathrm{E}_{\mathrm{r}}$. 
612 One year simulation of the TNB sea ice evolution has been carried out to investigate the polynya 613 behaviour in response to the local katabatic flows. The main results of the 2005 simulation are 614 discussed. The modelled polynya behaviour follows the characteristic dynamics of sea ice and 615 ocean circulation in TNB. During the summer season, approximately from November to March, the 616 bay is mostly ice free. It starts to be covered by sea ice in late March, when the low atmospheric and 617 oceanic temperatures let the sea surface freeze. The evolution of the polynya is strongly controlled 618 by the action of katabatic winds which allow TNB to be almost never completely ice covered in 619 winter. Katabatic winds are very intense between April and October (Rusciano et al. 2013), and 620 within this period several cycles of opening/closure of the polynya occurred.

621 Model-derived polynya extents in TNB region, defined in the section 3.2, have been computed for 622 2005. The polynya area is usually defined as the sum of the surfaces of open water and thin sea ice 623 and therefore is restricted to the oceanic region within which the ice concentration is smaller than a 624 given threshold (Willmott et al. 2007). This threshold is rather arbitrary, varying commonly from 6250.5 to 0.7 (Parmiggiani 2006; Kern et al., 2007). An ice concentration threshold of 0.7 has been 626 used here to estimate the TNB polynya extent (Fig. 12). 


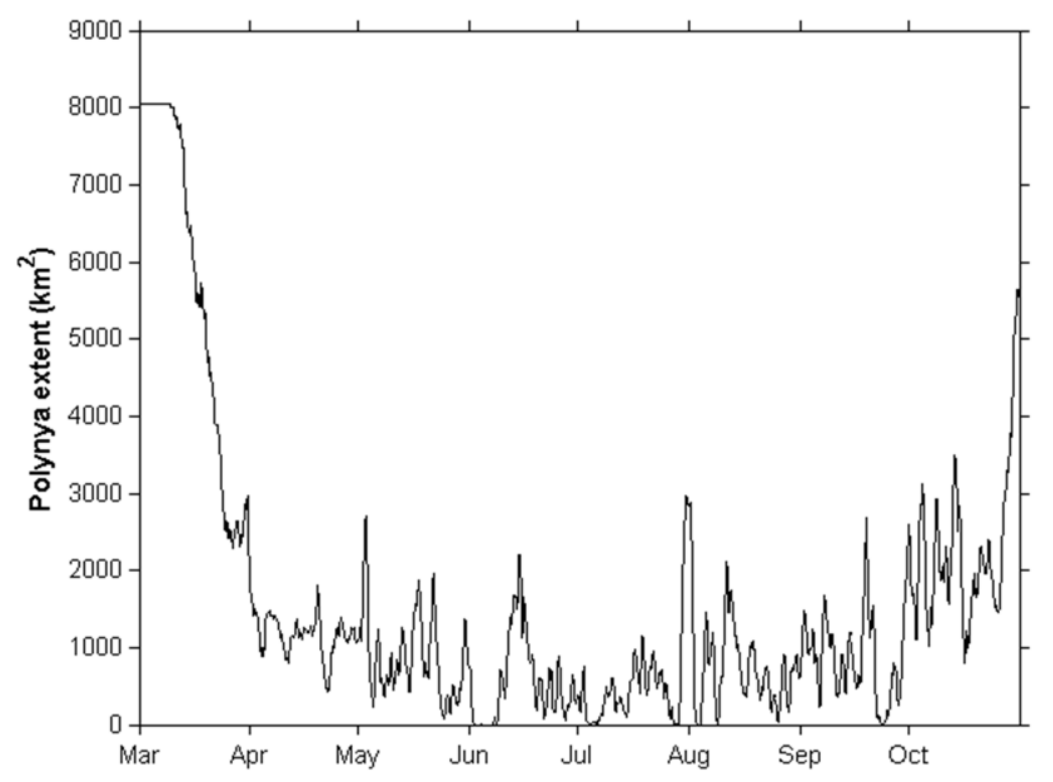

Fig. 12: Model-derived polynya extent in the TNB region from March to October 2005.

628 An increase of the polynya size is associated with the occurrence of katabatic events (not shown). 629 The peak extent in midwinter occurred in July with a maximum value of $2962 \mathrm{~km}^{2}$, followed by 630 other two large extents of the polynya in August and September of $2868 \mathrm{~km}^{2}$ and $2674 \mathrm{~km}^{2}$ 631 respectively (Table 7).

632 Polynya mean extents vary approximately from just over $500 \mathrm{~km}^{2}$ up to almost $900 \mathrm{~km}^{2}$, except in 633 March/April, when sea ice formation processes start, and in October, which represents the end of 634 the wintertime and the beginning of sea ice melting processes. The computed polynya extents are in 635 good agreement with the wintertime values estimated by Petrelli et al. (2008) and with those 636 recently published by Ciappa et al. (2012) who computed a mean annual open water of around 900 $637 \mathrm{~km}^{2}$ in the period 2005-2010 and $600 \mathrm{~km}^{2}$ in 2006 using MODIS thermal infrared data. In any case, 638 the computation of the polynya extent is not trivial since it depends on the accuracy and the 639 limitations of the models and the remote sensing tools, as well as on their capability to resolve in 640 time and in space the processes involved in the polynya variability. In addition, the local coastal 641 winds have a strong but not exclusive impact on the polynya size which is caused by the interaction 642 between katabatic forcing and synoptic weather conditions on longer timescales. The major effect 
643

of the katabatic winds on short timescales is the local recirculation of sea ice in TNB and its redistribution within the polynya area (Petrelli et al., 2008). The recirculation forced by these local winds enhances the ice production maintaining high ice production rates in open water and thin ice regions.

\begin{tabular}{|c|c|c|}
\hline Winter months & Maximum Polynya extent $\left(\mathrm{km}^{2}\right)$ & Mean Polynya extent $\left(\mathrm{km}^{2}\right)$ \\
\hline March & 7946 & 5574 \\
\hline April & 1806 & 1174 \\
\hline May & 2688 & 871.2 \\
\hline June & 2205 & 557.2 \\
\hline July & 2962 & 532.5 \\
\hline August & 2868 & 766.9 \\
\hline September & 2674 & 875.6 \\
\hline October & 5637 & 2304 \\
\hline
\end{tabular}

Table 7: Monthly maximum and mean polynya extent of the TNB polynya from March to October 2005.

Sea ice production in the TNB region (Table 8) has been also computed by model sea ice fields outputs. The ice production rate, depends primarily on the presence of open water and on the surface wind speeds, therefore following the same trend as the TNB polynya extent. The spatial maximum sea ice production daily rate over TNB area exhibits a maximum of $0.70 \mathrm{~km}^{3} /$ day on $30^{\text {th }}$ July that is equivalent to $48.08 \mathrm{~cm} /$ day. These estimates are comparable to those of Petrelli et al. (2008), who simulated the TNB polynya using a coupled atmosphere-sea ice model. She found in her high resolution experiment an ice production maximum daily rate of $26.4 \mathrm{~cm} /$ day during winter. Our results are quite consistent, even if slightly smaller, with ice production estimates obtained by Fusco et al. (2002) by applying a one-dimensional flux model to the TNB polynya. She computed for August 1993 and 1994 a maximum value of ice production of $85 \mathrm{~cm} /$ day and $72 \mathrm{~cm} /$ day respectively. Our daily ice productions result in a cumulative ice production value of 39.29 m over 2005 versus her yearly ice production of $81.7 \mathrm{~m}$ and $68.8 \mathrm{~m}$ for 1993 and 1994 . However, these large values in Fusco et al. (2002) were obtained using AWS forcing, whereas the ice production was found to be significantly underestimated when computed by using the ECMWF data only. The spatially cumulative daily ice production is also showed in Fig. 13. The highest peaks of ice production occur in May, June and July with maxima of $0.61,0.54$ and $0.70 \mathrm{~km}^{3}$ respectively. The 
cumulative ice production, that is the sea ice volume produced in the whole year 2005, is 57.91 $\mathrm{km}^{3}$. This value is consistent with the estimation by Tamura et al. (2008) based on satellite data in combination with ERA-40 reanalysis data, which shows for the TNB polynya a mean annual cumulative sea ice production of $59.2 \pm 10 \mathrm{~km}^{3}$. In particular, the ice volume created in the months of June and July amounts overall to $16.37 \mathrm{~km}^{3}$, which is in good agreement with the value of 16.4 $\mathrm{km}^{3}$ computed by Petrelli et al. (2008) in her winter experiment. The brine rejection, associated with the new ice production, and the HSSW production are also calculated. The brine rejection (kg/day) is parameterized as $P_{S}=\rho_{i} P_{i}\left(S_{1}-S_{i}\right) \times 10^{-3}$ (see Markus et al., 1998; Van Woert, 1999a) where $\mathrm{P}_{\mathrm{i}}$ is the ice production rate. The HSSW production ( $\mathrm{m}^{3} /$ day) is computed following Van Woert (1999a) as $\mathrm{P}_{\mathrm{HSSW}}=\mathrm{P}_{\mathrm{S}} / \rho_{\mathrm{HSSW}}\left(\mathrm{S}_{\mathrm{HSSW}}-\mathrm{S}_{\mathrm{LSSW}}\right) \times 10^{-3}$ where $\rho_{\mathrm{HSSW}}$ is the density of HSSW $\left(1030.45 \mathrm{~kg} / \mathrm{m}^{3}\right), \mathrm{S}_{\mathrm{HSSW}}$ is the salinity of HSSW (34.8) and $\mathrm{S}_{\mathrm{LSSW}}$ is the salinity of Low Salinity Shelf Water or Warm Core Water (34.5) (Jacobs et al., 1985).

The salt and HSSW (Fig. 14) production are larger in wintertime, when the ice production is higher. Their cumulative values in the year 2005 within the TNB polynya are $1.7 \times 10^{12} \mathrm{~kg}$ and $0.5 \times 10^{13} \mathrm{~m}^{3}$ respectively. These values are in good agreement with those of Fusco et al. (2002), Fusco et al. (2009) and Van Woert (1999a). Fusco et al. (2002), for example, estimated a salt production of about $4.6 \times 10^{12} \mathrm{~kg}$ and a HSSW production of $1.5 \times 10^{13} \mathrm{~m}^{3}$ in the years 1993-94. 


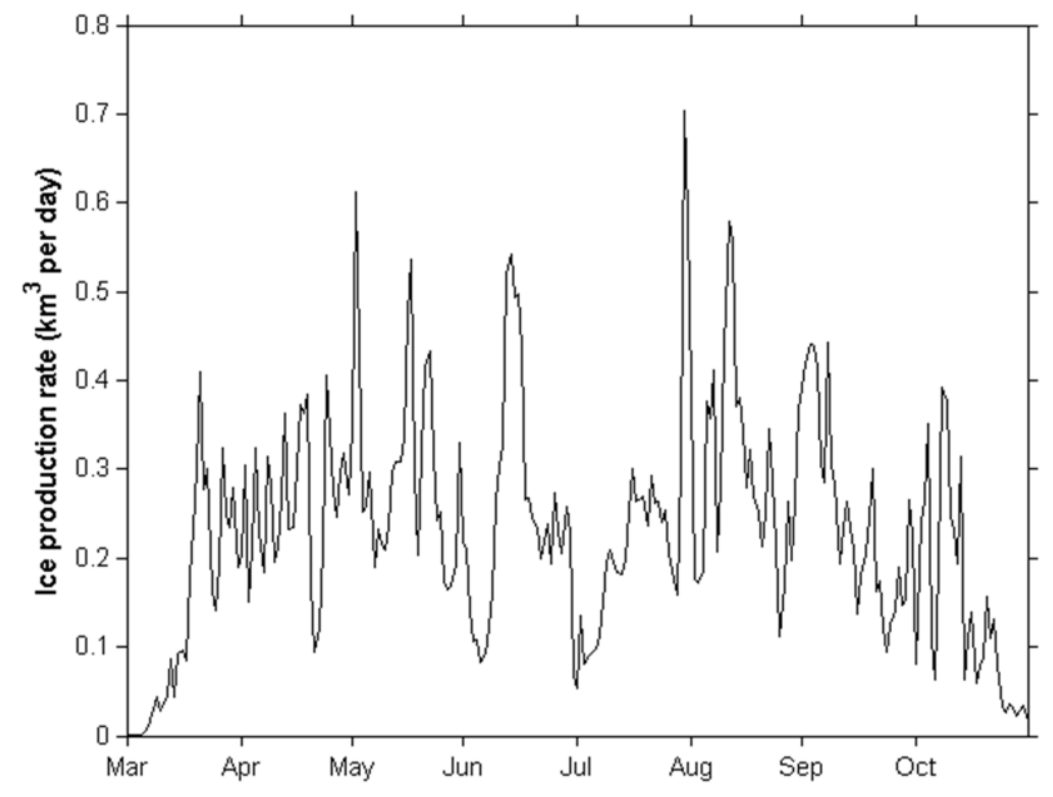

694

Fig. 13: Spatially cumulated daily rate of sea ice production in the TNB region from March to October 2005.

695
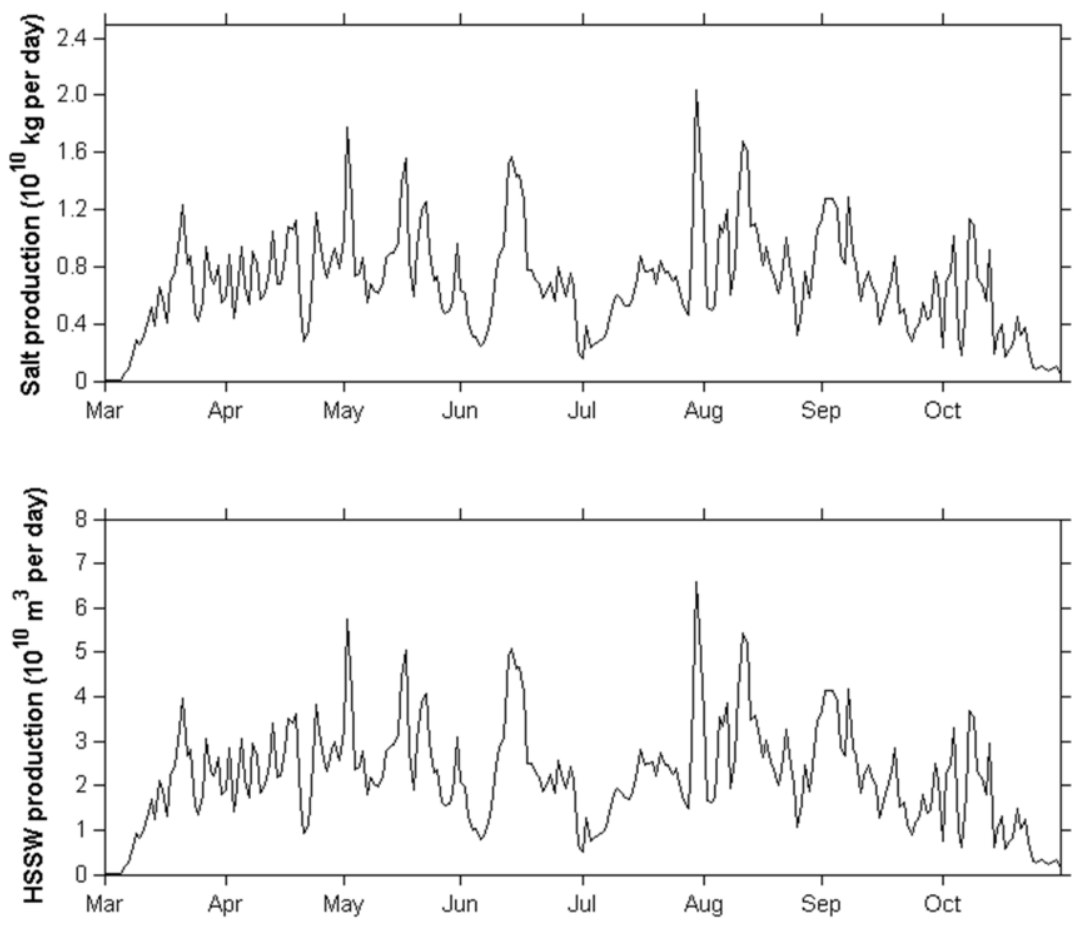

Fig. 14: Daily salt production (top) and HSSW production (bottom) in the TNB region from March to October 2005. 
699 In situ measurements are particularly poor in remote or hardly accessible areas during the Antarctic

700

701 winter, therefore satellite observations represent a useful tool in tuning sea ice-ocean models (Linch et al., 1997). Satellite images in combination with numerical weather prediction model data and in situ data from Automatic Weather Stations provide a good database to study polynya-atmosphere interactions in TNB area (Gallée, 1997; Ciappa et al., 2012).

Measurements of ice thickness and total ice volume in Terra Nova Bay do not exist. However, the model can be ground-truthed, at least in part, by comparing the polynya shape and extent to satellite images, which we do in the following. The NASA's MODIS (Moderate Resolution Imaging Spectroradiometer) sensor provides high temporal and spatial resolution measurements of Earth's land, ocean and atmospheric processes in several spectral bands and swath. The MODIS/Aqua Level 1B $1 \mathrm{~km}$ Calibrated Radiances at $1 \mathrm{~km}$ resolution have been used to retrieve the ice surface temperature (IST) in the TNB region and subsequently to derive the polynya extent. Radiance data from MODIS channels 31 and 32 are converted to brightness temperatures (Kelvins) through the inversion of the Planck's law equation (Key et al., 1994). For ice/snow surface temperature (IST) computation the equation based on the technique of Key et al. (1997), originally developed for the Advanced Very High Resolution Radiometer (AVHRR), is used.

In order to investigate the dependence of the opening/closing cycles of the polynya on the wind forcing, a few significant periods in the wintertime of 2005 characterized by strong katabatic events have been identified. For each period, sea ice concentration charts from ice fields model outputs have been produced. The polynya edge is identified by the first contour line characterized by an ice concentration threshold of 0.7. These maps have been compared with MODIS IST images obtained following the aforementioned procedure for the same period. Figures 15 and 17 show the wind speed from both Rita and Manuela AWSs during two katabatic events observed in May and July 
$722\left(1^{\text {th }}-5^{\text {th }}\right.$ May and $28^{\text {th }}-31^{\text {th }}$ July respectively). The evolution of the polynya extent detected by 723 MODIS can be seen in Figs. 16 and 18 where the modelled sea ice concentration for the same days 724 is also showed. Sea ice concentration maps at the temporal steps closer to those of satellite scenes 725 have been chosen to match at best model and MODIS products.

726 The model reproduces, reasonably well, sea ice concentration, depth and velocity as seen from the 727 comparison with MODIS images. The drift of sea ice responds to wind forcing which shows a 728 predominant West-West North West direction. Stronger winds are responsible for sea ice advection 729 offshore, opening the polynya, and contributing to increasing its extent, while weaker winds just 730 hamper the closure keeping the polynya opened. According to Pease (1987), a seaward wind 731 component exceeding $10 \mathrm{~m} / \mathrm{s}$ is sufficient to maintain a polynya in coastal zones. Our results are in 732 agreement with the suggested threshold.

733

734

735 

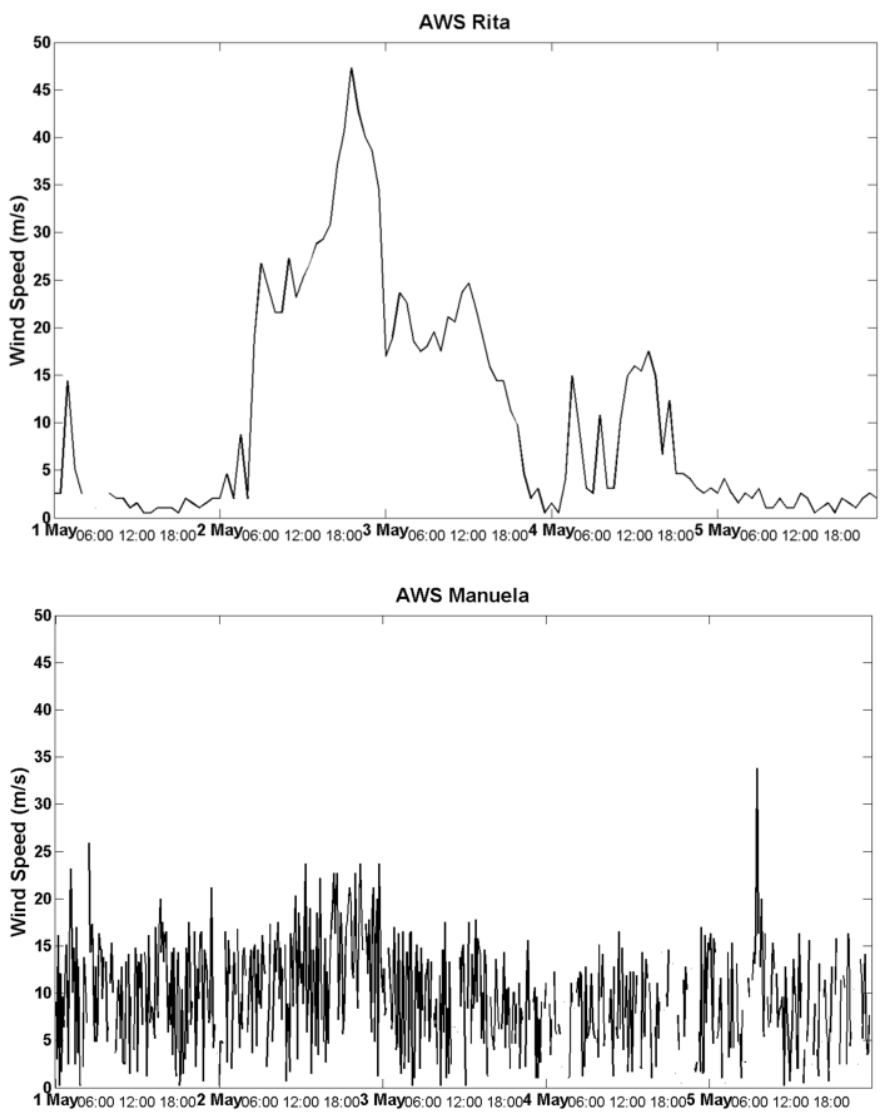

Fig. 15: Wind speed from Rita (top) and Manuela (bottom) AWSs on $1^{\text {th }}-5^{\text {th }}$ May 2005. 

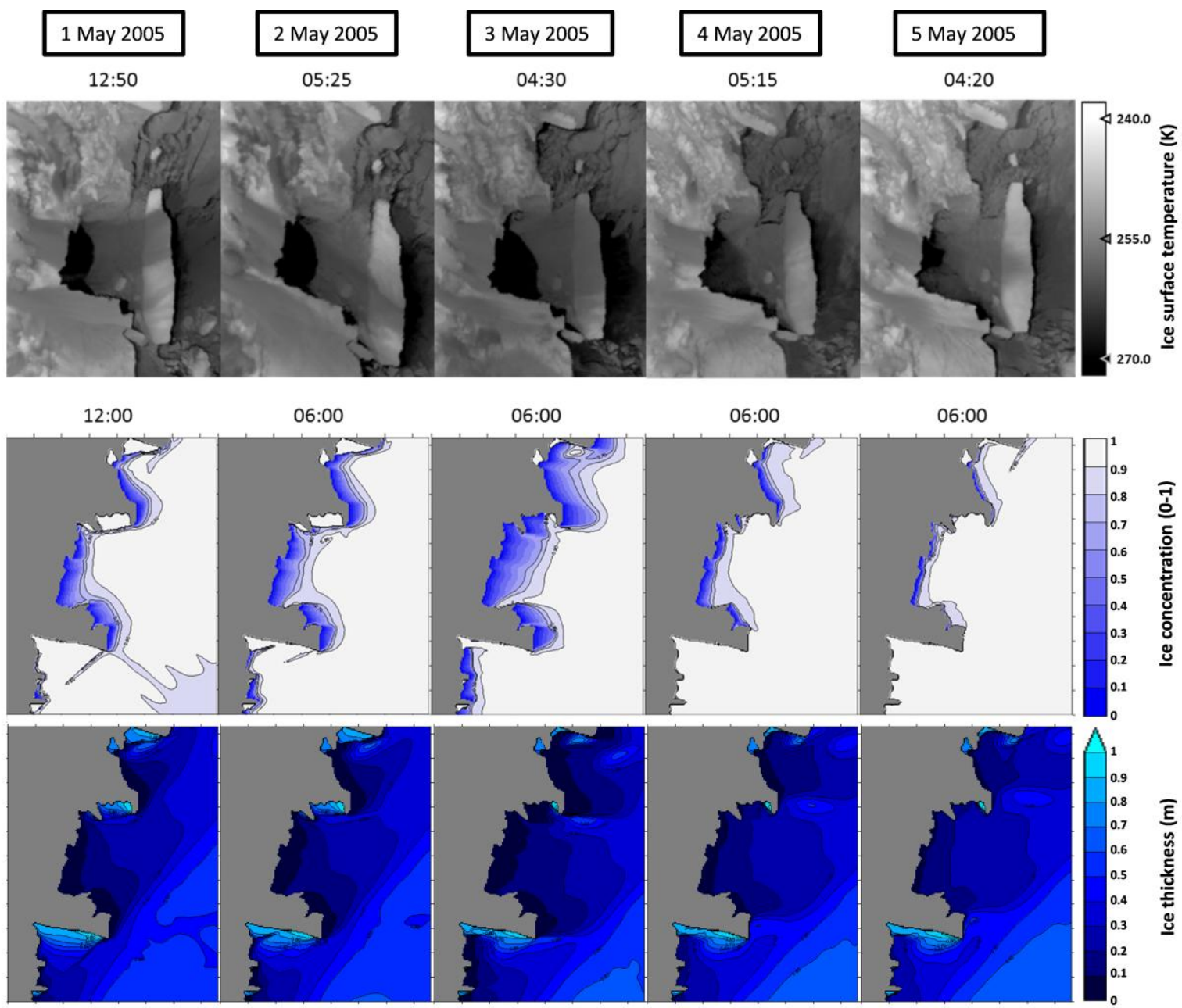

Fig. 16: IST MODIS scenes (top) and the modelled sea ice concentration and thickness maps (bottom) displaying the polynya evolution on $1^{\text {th }}-5^{\text {th }}$ May 2005. 

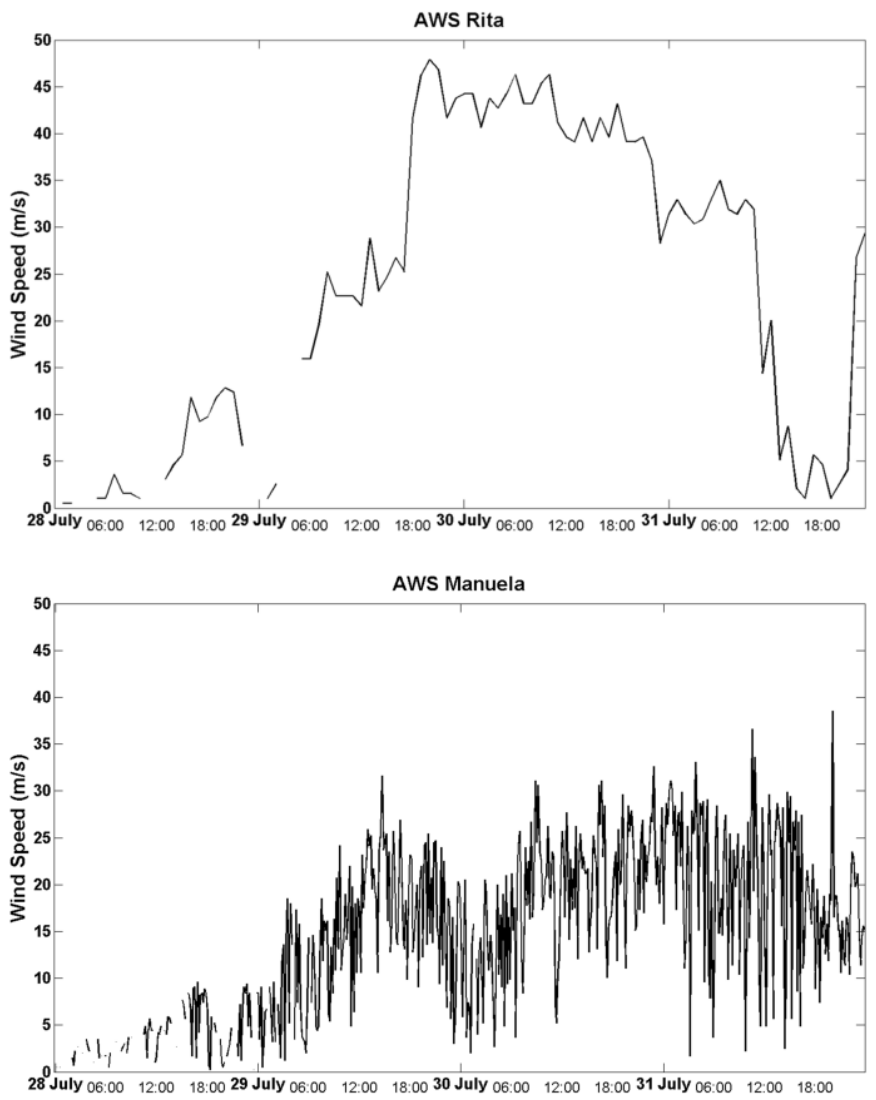

738

Fig. 17: Wind speed from Rita (top) and Manuela (bottom) AWSs on $28^{\text {th }}-31^{\text {th }}$ July 2005 . 

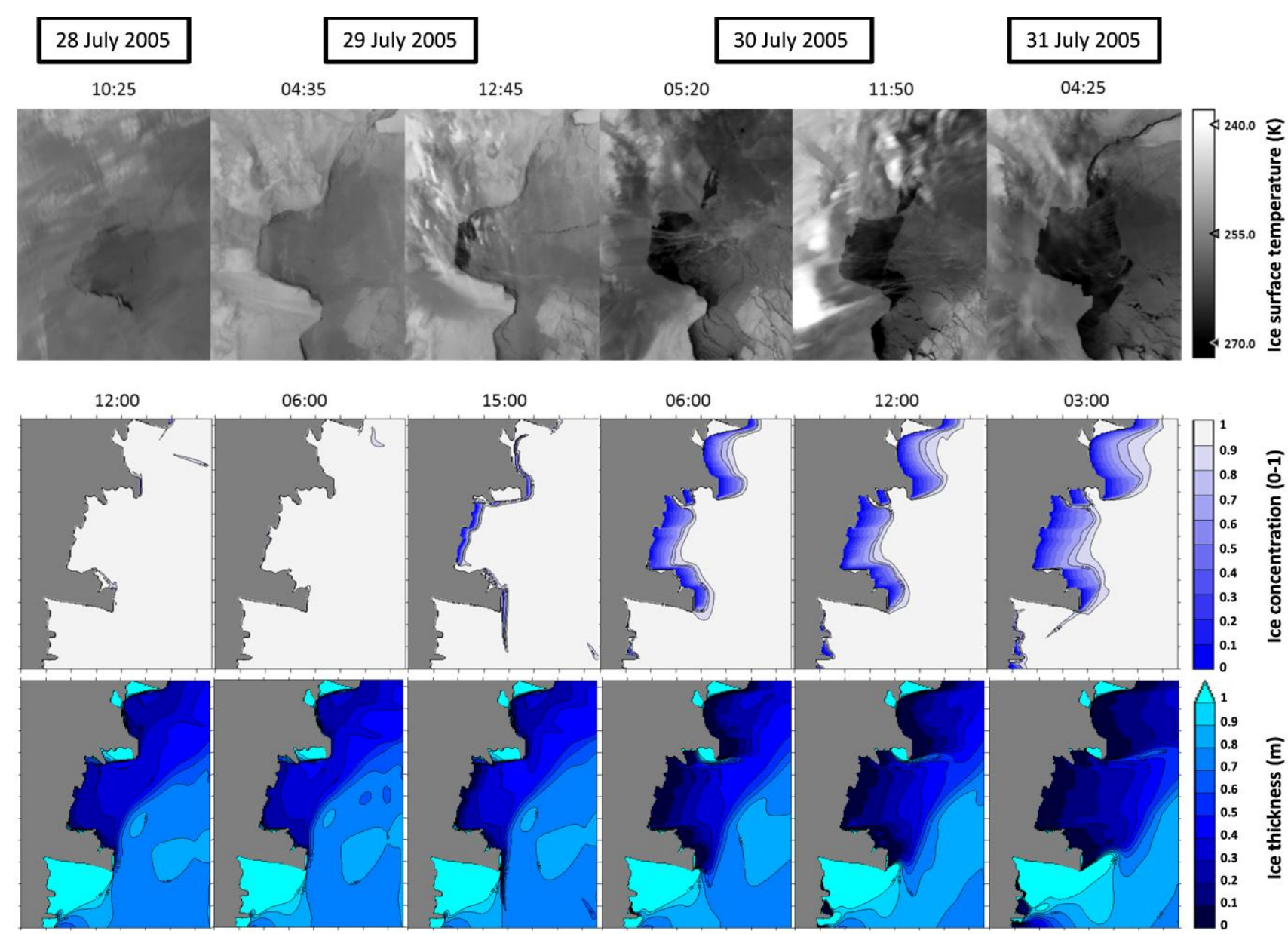

Fig. 18: IST MODIS scenes (top) and the modelled sea ice concentration and thickness maps (bottom) displaying the polynya evolution on $28^{\text {th }}-31^{\text {th }}$ July 2005 .

The small polynya observed at the beginning of the $1^{\text {st }}$ of May (Fig. 16) increases its extent on the $2^{\text {nd }}$ day of the month upon an increase of the wind speed measured by the AWS Rita, exhibiting a

744 value well over $20 \mathrm{~m} / \mathrm{s}$ and reaching a peak of almost $50 \mathrm{~m} / \mathrm{s}$. Wind speed from the AWS Manuela 745 with an average value of $20 \mathrm{~m} / \mathrm{s}$ contributes to enlarge the polynya eastward. The polynya size 746 keeps on increasing at the beginning of $3^{\text {rd }}$ of May until the wind speed drops sharply, below $10 \mathrm{~m} / \mathrm{s}$ 747 for AWS Rita, and the polynya starts closing on $4^{\text {th }}$ and $5^{\text {th }}$ of May. The discrepancies between the 748 spatial distribution of sea ice in model simulations and IST MODIS scenes are thought to be partly 749 due to the iceberg B-15A drifting in front of the TNB approximately in April-May 2005. The 750 presence of this iceberg blocks the drift of sea ice offshore forcing the ice to accumulate in its 751 proximity. In fact, in IST MODIS scenes the edge of the polynya is located more toward the coast 752 and southward reducing thus the northern portion of the whole polynya extent. The simulation of 
sea ice distribution in July 2005 (Fig. 18) shows a higher degree of similarity with that observed in satellite images, probably because the advection of sea ice is less affected by the iceberg moving out of the bay. On $28^{\text {th }}$ July the polynya is almost totally closed because the wind speeds are near to zero. After an enhancement of the wind forcing, the polynya starts opening at the beginning of the $29^{\text {th }}$ of July and expands rapidly seaward. The largest opening of the polynya occurs on $31^{\text {th }}$ July 2005 in response to the stronger wind speeds values recorded previously by AWS stations, near to $50 \mathrm{~m} / \mathrm{s}$ for Rita and $40 \mathrm{~m} / \mathrm{s}$ for Manuela. Some discrepancies between the simulated polynya and that observed in MODIS scenes may probably due to the gaps (missing data) in the AWSs wind datasets.

The TNB polynya extents have been also derived from both MODIS IST scenes and sea ice concentration maps on $28^{\text {th }}-31^{\text {th }}$ July. The aforementioned sea ice concentration threshold of 0.7 has been used for the modelled ice. A varying threshold for IST proposed by Ishikawa et al. (1996) and Zwally et al. (1983) that discriminates open water and thin ice from thick ice or land fast ice has been employed for satellite maps. Setting sea ice concentration to 0.7 , our IST threshold is given by $T_{\text {th }}=0.3 \mathrm{~T}_{\mathrm{f}}+0.7 \mathrm{~T}_{\text {ice }}$ where $\mathrm{T}_{\mathrm{f}}$ is the temperature of the open water at the freezing point and $\mathrm{T}_{\text {ice }}$ is the temperature of sea ice around the polynya. Both temperature values are extracted from the IST scenes after they have been visually inspected one by one. In particular, $\mathrm{T}_{\mathrm{f}}$ is given by the warmest IST found within the polynya and $\mathrm{T}_{\mathrm{ice}}$ is estimated as the average of the IST values found around the open water.

Polynya extents from the $28^{\text {th }}$ July to the $31^{\text {th }}$ July are showed in Table 9 . Polynya extent on the $31^{\text {th }}$ July represents the largest opening of the whole of 2005, as also found in Ciappa et al. (2012). The model-derived polynya extents mostly agree with those computed from MODIS IST images, revealing the same temporal trend in polynya increasing during the observed katabatic event. The polynya extent values are less comparable to the MODIS based extents retrieved by Ciappa et al. (2012) showing a polynya extent of approximately $7615 \mathrm{~km}^{2}$ on 31 July at 04:25 versus the corresponding MODIS-derived and model-derived polynya extents of $3393 \mathrm{~km}^{2}$ and $2831 \mathrm{~km}^{2}$, 
respectively. That is due to the wider domain considered in his estimates, including all the open water fraction occurred north of TNB (Wood Bay) and south of the Drygalski Ice Tongue.

\begin{tabular}{|cc|c|c|}
\hline $\begin{array}{c}\text { TNB polynya event } \\
\text { in July 2005 }\end{array}$ & Model-derived polynya extent $\left.\mathbf{( k m}^{\mathbf{2}}\right)$ & MODIS-derived polynya extent $\left.\mathbf{( k m}^{\mathbf{2}}\right)$ \\
\hline $28^{\text {th }}$ & $12: 00$ & 12 & 40 \\
\hline $29^{\text {th }}$ & $06: 00$ & 0 & 25 \\
\hline $29^{\text {th }}$ & $15: 00$ & 389 & 391 \\
\hline $30^{\text {th }}$ & $06: 00$ & 1858 & 1936 \\
\hline $30^{\text {th }}$ & $12: 00$ & 2148 & 2385 \\
\hline $31^{\text {th }}$ & $03: 00$ & 2831 & 3393 \\
\hline
\end{tabular}

Table 9: TNB polynya extents from model sea ice concentration outputs and from MODIS IST from $28^{\text {th }}$ to $31^{\text {th }}$ July 2005.

\section{Summary and concluding remarks}

This work focuses on the investigation of sea ice formation in the TNB polynya in response to wind forcing. Because of the lack of direct observations related to sea ice fields, models provide valuable insight into the mean state of the ice cover (Flato, 2003) together with satellite observations which indeed fail often in availability and spatial resolution. A coupled sea ice-ocean model that simulates the seasonal cycle of sea ice formation and export within the polynya was presented. The model is applied to the TNB area, including also the nearby regions north and south of the bay in order to characterize at the best seasonal sea ice variability and polynya behaviour. The horizontal resolution is of $1 \mathrm{~km}$, which is sufficient to represent the salient features of the coastline geometry, notably the Drygalski Ice Tongue. The model has been forced by a combination of Era Interim reanalysis by ECMWF and in-situ data from Rita and Manuela AWS, and also by in situ oceanic data.

The modelled sea ice fields have proved to be very sensitive to the atmospheric forcing. The sea ice evolution has been found to be shaped by different parameters involved in the dynamics of sea ice which in turn affects the thermal processes that occur in the ice cover. Several sensitivity experiments have been performed in order to optimize and set up a few main parameterizations and 
coefficients, thus improving the model outputs. The use of a demarcation ice collection thickness $(H)$ varying with the wind speed used by Winsor \& Björk (2000) seems to be the best choice, amongst the ones considered here, for simulating sea ice fields and thermodynamic heat losses through thin ice inside the polynya. In contrast, the rheology parameter $P^{*}$ has not been found to affect significantly the drift of sea ice in this region, resulting in almost unchanged outputs of sea ice concentration and thickness distribution irrespective of the value used for $P^{*}$. The importance of the air drag coefficient, one of the most important factors in modelling ice motion, has been also stressed. First the responses of the model to constant values of the air-ice $\left(C_{d a}\right)$ and ice-ocean $\left(C_{d o}\right)$ drag coefficients and subsequently to the $C_{d a} / C_{d o}$ ratio have been investigated, the latter being the most basic parameter of sea ice dynamics in determining the mean sea ice drift speed (Geiger et al., 1998; Harder and Fisher, 1999). A $C_{d a}$ varying with wind speed has been adopted, while $C_{d o}$ is forced to depend linearly on $C_{d a}$ through a constant factor. Also a wind enhancement function has been developed in order to try to improve the prediction of sea ice fields. However, its application was unsuccessful, causing unrealistically high large values of the wind stress.

A simulation of sea ice formation in TNB has been performed for the entire year 2005 to investigate the response of the polynya dynamics to wind forcing. Unsurprisingly, the largest openings of the polynya match the stronger katabatic winds which have been found in wintertime, mainly from April to October. The largest polynya opening occurs in July, with an extent of $2962 \mathrm{~km}^{2}$, while the polynya extent over the wintertime 2005 ranges between approximately $500 \mathrm{~km}^{2}$ and $900 \mathrm{~km}^{2}$. Sea ice production and the associated brine and HSSW productions have also been computed, exhibiting values cumulated over 2005 of $57.91 \mathrm{~km}^{3}, 1.7 \times 10^{12} \mathrm{~kg}$ and $0.5 \times 10^{13} \mathrm{~m}^{3}$, respectively. These results are in good agreement with those reported by Fusco et al. $(2002,2009)$ who estimated a salt production of about $4.6 \times 10^{12} \mathrm{~kg}$ and a HSSW production of $1.5 \times 10^{13} \mathrm{~m}^{3}$ for the period 1993-1994. In order to support and validate the model outputs, a comparison with sea ice conditions detected by satellite images has been thought essential. Satellite images from the MODIS sensor have been chosen for this purpose since they reach a high spatial resolution of $1 \mathrm{~km}$, the same as that of the 
model. In order to explore the strong relationship between the wind field and the TNB polynya extent, some wintertime periods including significant katabatic events have been selected. For these periods the MODIS IST scenes have been compared with the modelled sea ice concentration maps. The TNB polynya area seems to be reproduced reasonably well by the model in terms of both shape and distribution of sea ice. However, differences in sea ice distribution respect to that observed in the MODIS IST scenes are visually detectable in some regions. These differences are most prominent in the areas located along the coast characterized by the variable shelf-ice borders and the presence of land fast ice. In particular, two areas, namely, the region south of Drygalski Ice Tongue and the region north of the TNB (Wood Bay) appear almost recurrently ice free in the modelled sea ice maps.

The TNB polynya extent has been also derived from MODIS IST scenes and the corresponding model sea ice maps from the $28^{\text {th }}$ to $31^{\text {th }}$ July 2005 . The application of an ice state dependent threshold for IST in MODIS images let us to validate the polynya extent with higher reliability. The model-derived polynya extents are very similar to those computed from MODIS IST images.

Finally, despite the discrepancies in both sea ice distribution in some regions and polynya extents, the model performs well in reproducing sea ice evolution. These discrepancies will be investigated more extensively in the future through either an improvement of the model to capture land-fast ice or, more simply the use of a more accurate land mask including fast ice. The remote sensing detection of the polynya area and its extent is obviously affected by fog, clouds or other atmospheric disturbance that often compromise the quality of the used satellite images. At any rate, modelling the opening and closing polynya events is a difficult task especially if the size of polynya is relatively small, as is the case in Terra Nova Bay (Pease, 1987; Lynch et al., 1997; Petrelli et al., 2008). Our results have further highlighted the sensitivity of sea ice simulations to wind forcing, which is the major aspect stressed in numerous modelling works on Southern Ocean. Accurate sea ice simulations in terms of sea ice distribution and thickness can be achieved, provided that the model is forced with realistic winds and surface boundary conditions, in particular ocean 
temperatures, as found by Stössel et al. (2011). High resolution wind forcing is necessary to capture in more detail coastal sea ice processes, such as coastal polynyas, ice drift and ice compression against coastline features.

\section{Acknowledgments}

The authors are grateful to two reviewers for their constructive comments and suggestions, which have helped to improve the manuscript very significantly. The authors are thankful to the MeteoClimatological Observatory of the Italian National Program for Research in Antarctica (PNRA) and the Antarctic Meteorological Research Center of the University of Wisconsin-Madison for the Automatic Weather Stations data sets. They are also grateful to the European Centre for Mediumrange Weather Forecast for the interim reanalysis and to the MODIS Atmosphere and Archive and Distribution System Nasa Website for free access to MODIS radiance products. This work was performed in the framework of Coastal Ecosystem Functioning in a changing Antarctic ocean project (CEFA) of the PNRA.

\section{References}

Biggs N.R.T. and Willmott A.J., 2001: A steady-state coupled ocean-polynya flux model of the North Water, Baffin Bay, Geophys. Astrophy. Fluid Dyn,. 95, 1-29.

Bromwich D. H. 1989: An extraordinary katabatic wind regime at Terra Nova Bay, Antarctica, Mon Weather Rev., 117 (3), 688-695.

Budillon, G., Fusco, G., \& Spezie, G., 2000: A study of surface heat fluxes in the Ross Sea (Antarctica). Antarctic Science, 12(2), 243-254.

Ciappa A., Pietranera L., and Budillon G., 2012: Observations of the Terra Nova Bay (Antarctica) polynya by MODIS ice surface temperature imagery from 2005 to 2010, Remote Sens. Environ., 119, 158-172.

Connolley W. M., Gregory J. M., Hunke E. C. and McLaren A. J., 2004: On the consistent scaling of terms in the sea ice dynamics equation. J. Phys. Oceanogr., 1776-1780.

Cullather R. I., Bromwich D. H. and Grumbine R.W., 1997: Validation of operational numerical analyses in Antarctic latitudes. J. Geophys. Res., 102, 13761-13784. 
Darby M. S., Willmott A. J. and Mysak L. A., 1994: A nonlinear steady-state model of the North Water Polynya, Baffin Bay. Journal of Physical Oceanography, 24,1011-1020.

Darby M. S., Willmott A. J. and Somerville T. A., 1995: On the influence of coastline orientation on the steady state width of a latent heat polynya. J. Geophys. Res., 100, 13,625-13,633.

Gallée H., 1997: Air-sea interactions over Terra Nova Bay during winter simulation with a coupled atmosphere-polynya model, J. Geophys. Res., 102(D12), 13,835-13,849.

Geiger C. A., Hibler W. D. and Ackley S. F., 1998: Large-scale sea ice drift and deformation: Comparison between models and observations in the western Weddell Sea during 1992, J. Geophys. Res., 103(C10), 21,893-21,913.

Fichefet T. and Morales Maqueda M.A., 1999: Modelling the influence of snow accumulation and snow-ice formation on the seasonal cycle of the Antarctic sea-ice cover. Clim. Dyn., 15, 251-268.

Flato G. M., 2003: Sea Ice Modelling. Chapter 9 in Mass Balance of the Cryosphere: Observations and Modelling of Contemporary and Future Changes, eds. J. Bamber and A. Payne, Cambridge University Press, pg. 367-389.

Frezzotti, M., and M. C. G. Mabin, 1994: Twentieth century behavior of Drygalski Ice Tongue, Ross Sea, Antarctica, Ann. Glaciol., 20, 397-400.

Feltham, D.L. 2008. Sea ice rheology. Annu. Rev. Fluid Mech., 40, 91-112.

Fofonoff, P. and Millard, R.C. Jr, 1983: Algorithms for computation of fundamental properties of seawater, UNESCO Tech. Pap. in Mar. Sci., No. 44, 53 pp

Fusco G., Flocco D., Budillon G., Spezie G., Zambianchi E., 2002: Dynamics and Variability of Terra Nova Bay Polynya, Marine Ecology, 23, 201-209.

Fusco G., Budillon G., Spezie G., 2009: Surface heat fluxes and thermohaline variability in the Ross Sea and in Terra Nova Bay polynya, Cont. Shelf Res. 29, 1887-1895.

Gent P.R., McWilliams J.C., 1990: Isopycnal mixing in ocean circulation models. J. Phys. Oceanogr., 20, pp. 150-155

Harder, M. and Fischer H., 1999: Sea ice dynamics in the Weddell Sea simulated with an optimized model, J. Geophys. Res., 104, 11,151-11,162.

Hibler W. D. III, 1979: A dynamic thermodynamic sea ice model, J. Phys. Oceanog., 9, 815-846.

Hibler, W. D., III and Walsh J. E., 1982: On modeling the seasonal and interannual fluctuations of Arctic sea ice, J. Phys. Oceanogr., 12, $1514-1523$.

Holland Paul R., Kwok R., 2012: Wind-driven trends in Antarctic sea-ice drift, Nature Geoscience 5, 872-875.

Hunke E. C. and J. K. Dukowicz 1997: An elastic-viscous-plastic model for sea ice dynamics, J. Phys. Oceanogr., 27, 1849-1868.

Ishikawa, T., Ukita, J., Ohshima, K. I., Wakatsuchi, M., Yamanouchi, T., \& Ono, N., 1996: Coastal polynyas off East Queen Maud Land observed from NOAA AVHRR data, Journal of Oceanography, 52, 389-398.

Jacobs S. S. and Comiso J. C., 1997: Climate variability in the Amundsen and Bellingshausen Seas. J. Clim. 10, 697709.

Jacobs S.S., Fairbanks R.G. and Horibe Y., 1985: Origin and evolution of water masses near the Antarctic continental margins: evidence from H2 18O/ H2 160 ratios in seawater, Antarct. Res. Ser., 43, 59-85.

Jacobs S. S. and Comiso J. C., 1989: Sea ice and oceanic processes on the Ross Sea continental shelf. J. Geophys. Res., 94, 18195-18211.

Jacobs S. S. and Comiso J. C., 1997: Climate variability in the Amundsen and Bellingshausen Seas. J. Clim. 10, $697-$ 709. 
Jacobs S.S., 2004: Bottom water production and its links with the thermohaline circulation, Antarct. Sci. 16 (4), $427-$ 437.

Key J. R., Maslanik J. A., Papakyriakou T., Serreze M. C. and Schweiger A. J., 1994: On the Validation of SatelliteDerived Sea Ice Surface Temperature, Arctic, 47, 3, 280-287.

Key J. R., Collins J. B., Fowler C. and Stone R. S., 1997: High Latitude Surface Temperature Estimates From Thermal Satellite Data, Remote Sens. Environ., 61, 302-309.

Kern S., Spreen G., Kaleschke L., DE LA Rosa S., and Heygster G., 2007: Polynya Signature Simulation Method polynya area in comparison to AMSR-E $89 \mathrm{GHz}$ sea-ice concentrations in the Ross Sea and off the Adélie Coast, Antarctica, for 2002-05: First results, Ann. Glaciol., 46, 409-418.

Kreysher M., Harder M., Lemke P. and Flato G. M., 2000: Results of the Sea-Ice Model Intercomparison Project: Evaluation of sea ice rheology schemes for use in climate simulations. J. Geophys. Res., 105(C5), 11,299_ 11,320 .

Kurtz D. D. and Bromwich D. H., 1983: Satellite observed behavior of the Terra Nova Bay polynya. J. Geophys. Res., $88,9717-9722$.

Kurtz D. D. and Bromwich D. H., 1985: A recurring, atmospherically forced polynya in Terra Nova Bay. In Oceanology of the Antarctic Continental Shelf, Antarct. Res. Ser., 43, edited by S. S. Jacobs, 177-201, AGU, Washington, D.C.

Kwok R., Comiso J. C., Martin S. and Drucker R., 2007: Ross Sea polynyas: Response of ice concentration retrievals to large areas of thin ice. J. Geophys. Res., 112, C12012.

Large W., and Pond S., 1981: Open ocean momentum flux measurements in moderate to strong winds. J. Phys. Oceanogr., 11, 324-336.

Lefebvre W. and Goosse, H., 2005: Influence of the Southern Annular Mode on the sea ice-ocean system: The role of the thermal and mechanical forcing. Ocean Sci. 1, 145-157.

Lemke P., 1987: A Coupled One-Dimensional Sea Ice-Ocean Model, J. Geophys. Res., 92(C12), 13,164-13,172.

Leppäranta, M., 1981: On the structure and mechanics of pack ice in the Bothnian Bay, Finnish Mar. Res., $248,3-86$.

Liu J. P., Curry J. A. and Martinson D. G., 2004: Interpretation of recent Antarctic sea ice variability, Geophys. Res. Lett. 31, L02205.

Liu J. P. \& Curry J. A., 2010: Accelerated warming of the Southern Ocean and its impacts on the hydrological cycle and sea ice, Proc. Natl Acad. Sci. USA 107, 14987-14992.

Lynch A. H., Glueck M. F., Chapman W. L., Bailey D. A. and J. E. Walsh, 1997: Satellite observation and climate system model simulation of the St. Lawrence Island Polynya, Tellus A, 49, 277-297.

Maksym, T., S.E. Stammerjohn, S. Ackley, and R. Massom. 2012. Antarctic sea ice-A polar opposite? Oceanography 25(3):140-151,

Markus, T., Kottmeier C. and Fahrbach E., 1998: Ice formation in coastal polynyas in the Weddell Sea and their impact on oceanic salinity, in Antarctic Sea Ice: Physical processes, interaction, and variability, Antarct. Res. Ser., vol. 74, edited by M. O. Jeffries, pp. 273 - 292, AGU, Washington, D. C..

Martinsen E. A. and Engedahl H., 1987. Implementation and testing of a lateral boundary scheme as an open-boundary condition in a barotropic ocean model. Coastal Eng. 11, 603-627.

Mathiot, P., Barnier B., Gallée H., Molines J. M., Le Sommer J., Juza M. and Penduff T., (2010): Introducing katabatic winds in global ERA40 fields to simulate their impacts on the Southern Ocean and sea-ice, Ocean Modell., 35 , 146-160. 
Maykut, G.A. 1978. Energy exchange over young sea ice in the central Arctic. J. Geophys. Res., 83(C7), 3646-3658.

McPhee, M. G., 1980: An analysis of pack ice drift in summer, in Sea Ice Processes and Models, edited by R. S. Pritchard, Univ. of Wash. Press, Seattle, 62-75.

Monterey G. and Levitus S., 1997: Seasonal Variability of Mixed Layer Depth for the World Ocean. NOAA Atlas NESDIS 14 U.S. Gov Printing Office, , Wash., D.C., 96 pp.

Mellor G. L. and Kantha L., 1989: An ice-ocean coupled model, J. Geophys. Res., 94, 10,937-10,954.

Morales Maqueda M. Á., Wilmott A. J. and Darby M. S., 1999: A numerical model for intercadal variability of sea ice cover in the Greenland-Iceland-Norwegian Sea, Climate Dynamics, 15(2), 89-113.

Morales Maqueda M. Á., Willmott A. J., Biggs N. R. T., 2004: Polynya Dynamics: A review of observations and modelling, Reviews of Geophysics, 42, RG1004.

Mellor G. L. and Kantha L., 1989: An ice-ocean coupled model, J. Geophys. Res., 94, 10,937-10,954.

Olason E. O., and Harms I., 2010: Polynyas in a dynamic-thermodynamic sea-ice model, The Cryophere, 4, $147-160$.

Orsi A. H., Johnson G. C. and Bullister J. L., 1999: Circulation, mixing and production of Antarctic bottom water, Progress in Oceanography, 43, Pergamon, 55-109.

Ou H. W., 1988: A time-dependent model of a coastal polynya, J. Phys. Oceanogr., 18, 584-590.

Overland J. E., 1985: Atmospheric boundary layer structure and drag coefficients over sea ice, J. Geophys. Res., 90, 9029-9049.

Owens W. B., Lemke P., 1990: Sensitivity studies with a sea ice-mixed layer-pycnocline model in the Weddell Sea. J. Geophys. Res., 95, C6, 9527-9538.

Pacanowski R. and Philander S.G.H., 1981: Parameterization of vertical mixing in numerical models of tropical oceans, J. Geophys. Res. 11, 1443-1451.

Parkinson C. L. and Cavalieri D. J., 2012: Antarctic sea ice variability and trends, 1979-2010, The Cryosphere, 6, 871880.

Parmiggiani, F. 2006: Fluctuations of Terra Nova Bay polynya as observed by active (ASAR) and passive (AMSR-E) microwave radiometers, Int. J. Remote Sensing, 27(12), 2459-2467.

Pease C. H., 1987: The size of wind-driven coastal polynyas, J. Geophys. Res., 92, 7049-7059.

Petrelli P., Bindoff N. L. and Bergamasco A., 2008: The sea ice dynamics of Terra Nova Bay and Ross Ice Shelf Polynyas during a spring and winter simulation, J. Geophys. Res., 113.

Rothrock D. A., 1979: Modeling sea-ice features and processes, Journal of Glaciology, 24, 90.

Rusciano E., Budillon G., Fusco G., and Spezie G., 2013: Evidence of atmosphere-sea ice-ocean coupling in the Terra Nova Bay polynya (Ross Sea-Antarctica), Continental Shelf Research 61-62, 112-124.

Russell J.L., Stouffer R.J., and Dixon K.W., 2006: Intercomparison of the Southern Ocean circulations in IPCC coupled model control simulations, J. Clim. 19:4,560-4,575.

Semtner A. J., 1976: A model for the thermodynamic growth of sea ice in numerical investigations of climate, J. Phys. Oceanogr., 6, 27-37.

Steele, M., J. Zhang, D. Rothrock and H. Stern. 1997. The force balance of sea ice in a numerical model of the Arctic Ocean. J. Geophys. Res., 102(C9), 21,061-21,079.

Stössel A., Lemke P. and Owens W.B., 1990: Coupled sea ice-mixed layer simulations for the Southern Ocean, J. Geophys. Res., 95, 9539-9555.

Stössel A., 1992: Sensitivity of the Southern Ocean sea-ice simulations to different atmospheric forcing algorithms, Tellus A, 395-413. 
Stössel A., Zhang Z., and Vihma T., 2011: The effect of alternative real-time wind forcing on Southern Ocean sea-ice simulations, J. Geophys. Res., 116, C11021.

Tamura T., Ohshima Kay I. and Nihashi S., 2008: Mapping of sea ice production for Antarctic coastal polynyas, J. Geophys. Lett., 35.

Tear S., Willmott A.J., Biggs N.R.T., Morales Maqueda M.A., 2003: One-dimensional models for the closure of a coastal latent heat polynya, J. Phys. Oceanogr. 33, 329-342.

Trumbore S.E., Jacobs S. S. and Smethie JR W. M., 1991: Chlorofuorocarbon evidence for rapid ventilation of the Ross Sea. Deep-Sea Research, 38, 845-870.

Turner J., Comiso J. C., Marshall G. J., Lachlan-Cope T. A., Bracegirdle T., Maksym T., Meredith M. P., Wang Z., and Orr A., 2009: Non-annular atmospheric circulation change induced by stratospheric ozone depletion and its role in the recent increase of Antarctic sea ice extent, Geophys. Res. Lett., 36, L08502.

Van Woert M. L., 1999a: The wintertime expansion and contraction of the Terra Nova Bay polynya. In Oceanography of the Ross Sea: Antarctica, edited by G. Spezie and G. M. R. Manzella, pp. 145-164, Springer-Verlag, New York.

Van Woert M. L., 1999b: Wintertime dynamics of the Terra Nova Bay polynya. J. Geophys. Res., 104, 7753-7769.

Willmott A. J., Holland D. M. and Morales Maqueda, M. A., 2007: Polynya modelling. In: Smith, Walker, O.; Barber, David, G., (eds.) Polynyas: windows to the world. Amsterdam, Elsevier, 87-125. (Elsevier Oceanography Series, 74).

Winsor P. and Björk G., 2000: Polynya activity in the Arctic Ocean from 1958 to 1997, J. Geophys. Res., Oceans 105 , 8789-8803.

Zhang J, 2007: Increasing Antarctic Sea Ice under Warming Atmospheric and Oceanic Conditions, J. Climate, 20, $2515-2529$.

Zwally H. J., Comiso J. C., Parkinson C. L., Campbell W. J., Carsey F. D., and Gloersen P., 1983: Antarctic Sea Ice, 1973-1976: Satellite Passive-Microwave Observations,Washington, DC, National Aeronautics and Space Administration, $206 \mathrm{pp}$. 


\section{Figure and table captions}

1033 Fig. 1: Overview map of TNB (Western Ross Sea) showing the major geographical features of this region and its surroundings (Kurtz and Bromwich, 1983).

Fig. 2: Schematic view of the main variables of the coupled sea ice - ocean model. The radiative and turbulent heat fluxes are separately calculated over the ice free (leads) and ice covered areas.

Fig. 3: The model domain showing the Drygalski Ice Tongue (DIT) and the two preferential paths of the katabatic flows, the Priestley and the Reeves Glaciers. The italian base, Mario Zucchelli Station (MZS), and the location of the automatic weather stations, Rita (AWS-R: $74.72^{\circ} \mathrm{S}$, $164.03^{\circ} \mathrm{E}$ ) and Manuela (AWS-M: $74.95^{\circ} \mathrm{S}, 163.69^{\circ} \mathrm{E}$ ) are also indicated.

Fig. 4: Diagram flow of the coupled sea ice - ocean model.

Fig. 5: Maps of wind speed (a), modelled ice drift velocity (b) and modelled ocean current (c) overlaid by the corresponding wind speed vectors, ice drift velocity vectors and ocean current vectors on $8^{\text {th }}$ July 2000 for CASE 1 to CASE 3.

Fig. 6: Modelled ice drift velocity (left) and modelled ocean current (right) overlaid by the corresponding ice drift velocity vectors and ocean current vectors on $8^{\text {th }}$ July 2000 for CASE 4.

Fig. 7: Modelled sea ice concentration (a) and thickness (b) on 8th July 2000 for CASE 5 to CASE

9. The color version of this figure is available online.

Fig. 8: Daily ice production (left) on July 2000 for CASE 5 to CASE 9 within a smaller area of the 1050 domain, defined as TNB region (right), extending approximately from $310 \mathrm{~km}$ to $425 \mathrm{~km}$ in $\mathrm{Y}$ and bordered by $\mathrm{X}=120 \mathrm{~km}$.

Fig. 9: Wind speeds (a), sea ice drift velocities (b) and ocean currents (c) with the superimposed and $\mathrm{E}_{34}$. 
1055 Fig. 10: Modelled sea ice concentration (a) and thickness (b) on $30^{\text {th }}$ July 2005 for $E_{15}, E_{35}, E_{11}, E_{31}$ 1056 and $\mathrm{E}_{34}$. The color version of this figure is available online.

1057 Fig. 11: Wind speeds and modelled sea ice drift velocities with the superimposed wind and ice drift 1058 vectors field (top) and sea ice concentration and thickness distribution (bottom) on $30^{\text {th }}$ July 2005 1059 for $\mathrm{E}_{\mathrm{r}}$.

1060 Fig. 12: Model-derived polynya extent in the TNB region from March to October 2005.

1061 Fig. 13: Spatially cumulated daily rate of sea ice production in the TNB region from March to 1062 October 2005.

1063 Fig. 14: Daily salt production (top) and HSSW production (bottom) in the TNB region from March 1064 to October 2005.

1065 Fig. 15: Wind speed from Rita (top) and Manuela (bottom) AWSs on $1^{\text {th }}-5^{\text {th }}$ May 2005.

1066 Fig. 16: IST MODIS scenes (top) and the modelled sea ice concentration and thickness maps 1067 (bottom) displaying the polynya evolution on $1^{\text {th }}-5^{\text {th }}$ May 2005. The color version of this figure is 1068 available online.

1069 Fig. 17: Wind speed from Rita (top) and Manuela (bottom) AWSs on $28^{\text {th }}-31^{\text {th }}$ July 2005.

Fig. 18: IST MODIS scenes (top) and the modelled sea ice concentration and thickness maps 1071 (bottom) displaying the polynya evolution on $28^{\text {th }}-31^{\text {th }}$ July 2005 . The color version of this figure 1072 is available online.

1073 Table 1: Input parameters of the model. The " $x$ " stands for a varying value assigned to that 1074 parameter in the sensitivity experiments.

1075 Table 2: Physical parameters of atmosphere, sea ice and ocean.

1076 Table3: Case studies on the influence of the parameter $R$ on wind fields. 
1077 Table 4: Sensitivity tests of sea ice evolution with respect to $H$.

1078 Table 5: Sea ice production in July 2000 for the experiments CASE 5 to CASE 9.

1079 Table 6: Sensitivity tests with respect to the air-ice and ice-ocean drag coefficients. The double 1080 sub-index identifies the wind and ocean drag coefficients used in each experiment.

1081 Table 7: Monthly maximum and mean polynya extent of the TNB polynya from March to October 10822005.

1083 Table 8: Daily sea ice production rates from spatially cumulated ice production in TNB polynya 1084 region from March to October 2005.

1085 Table 9: TNB polynya extents from model sea ice concentration outputs and from MODIS IST 1086 from $28^{\text {th }}$ to $31^{\text {th }}$ July 2005. 


\section{Figure(s)}

Click here to download high resolution image

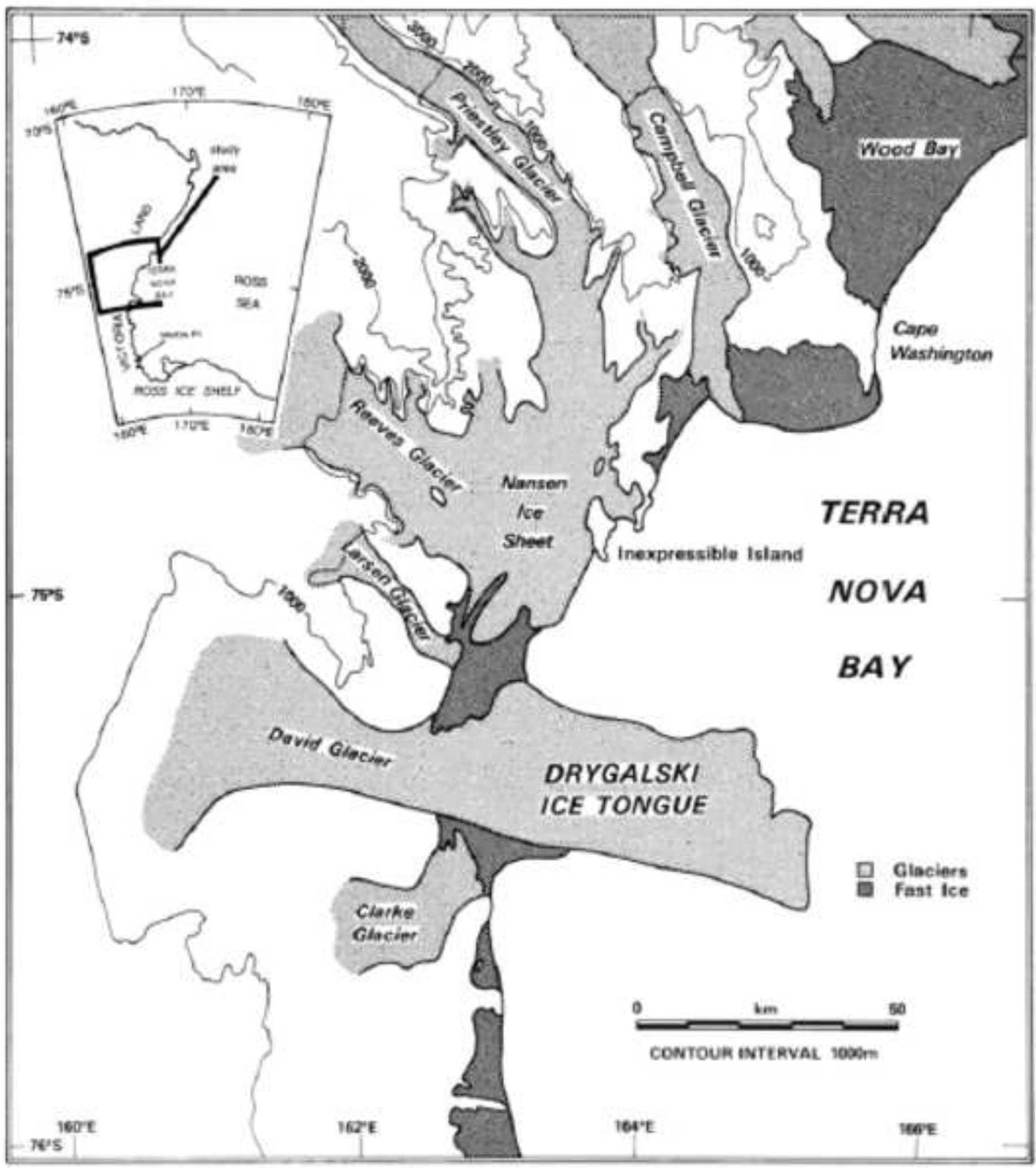


Click here to download high resolution image

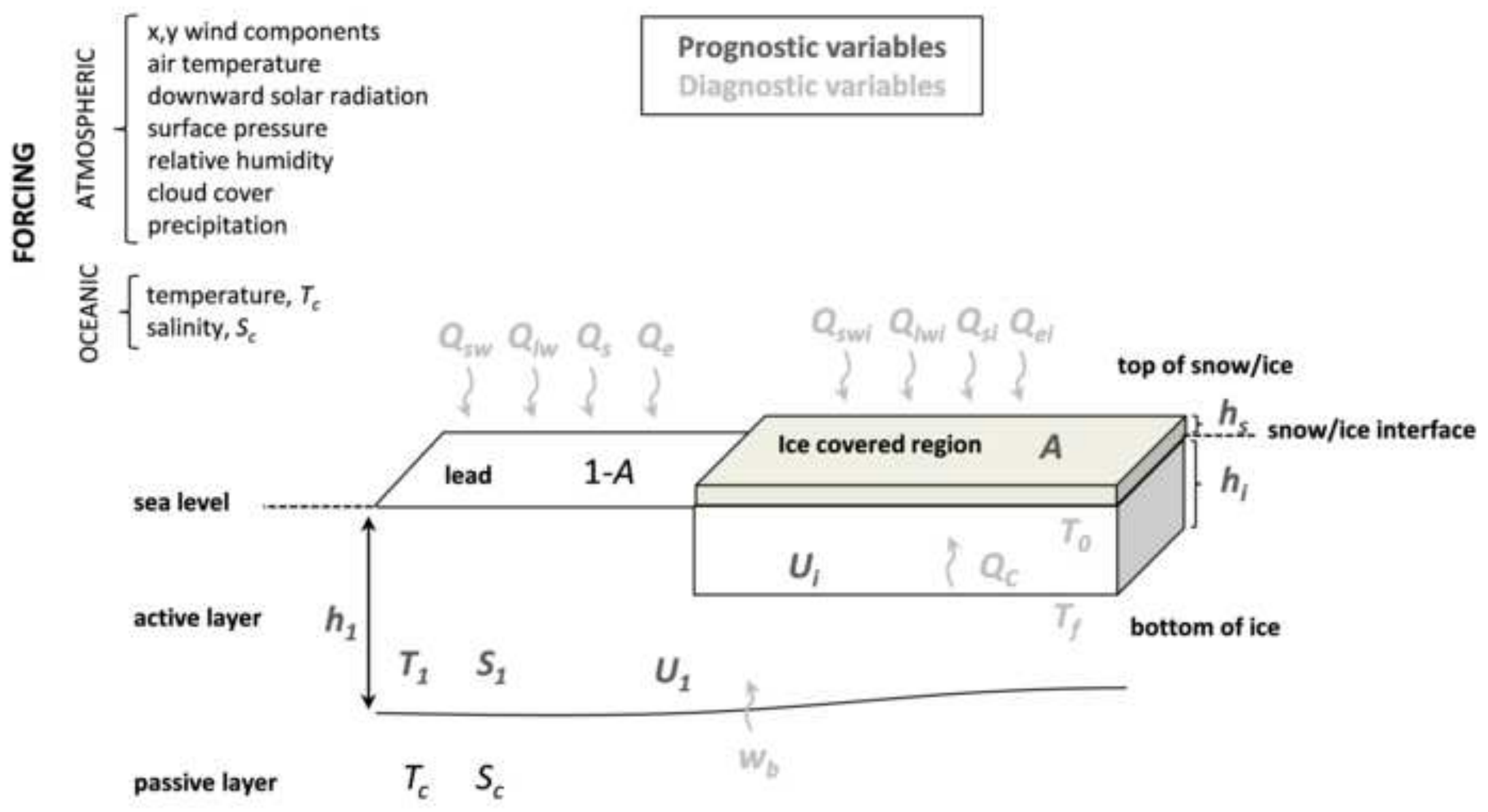

$\sum_{\varangle}$ - temperature, $T_{c}$ salinity, $S_{c}$

passive layer

$T_{c} \quad S_{c}$ 
Click here to download high resolution image

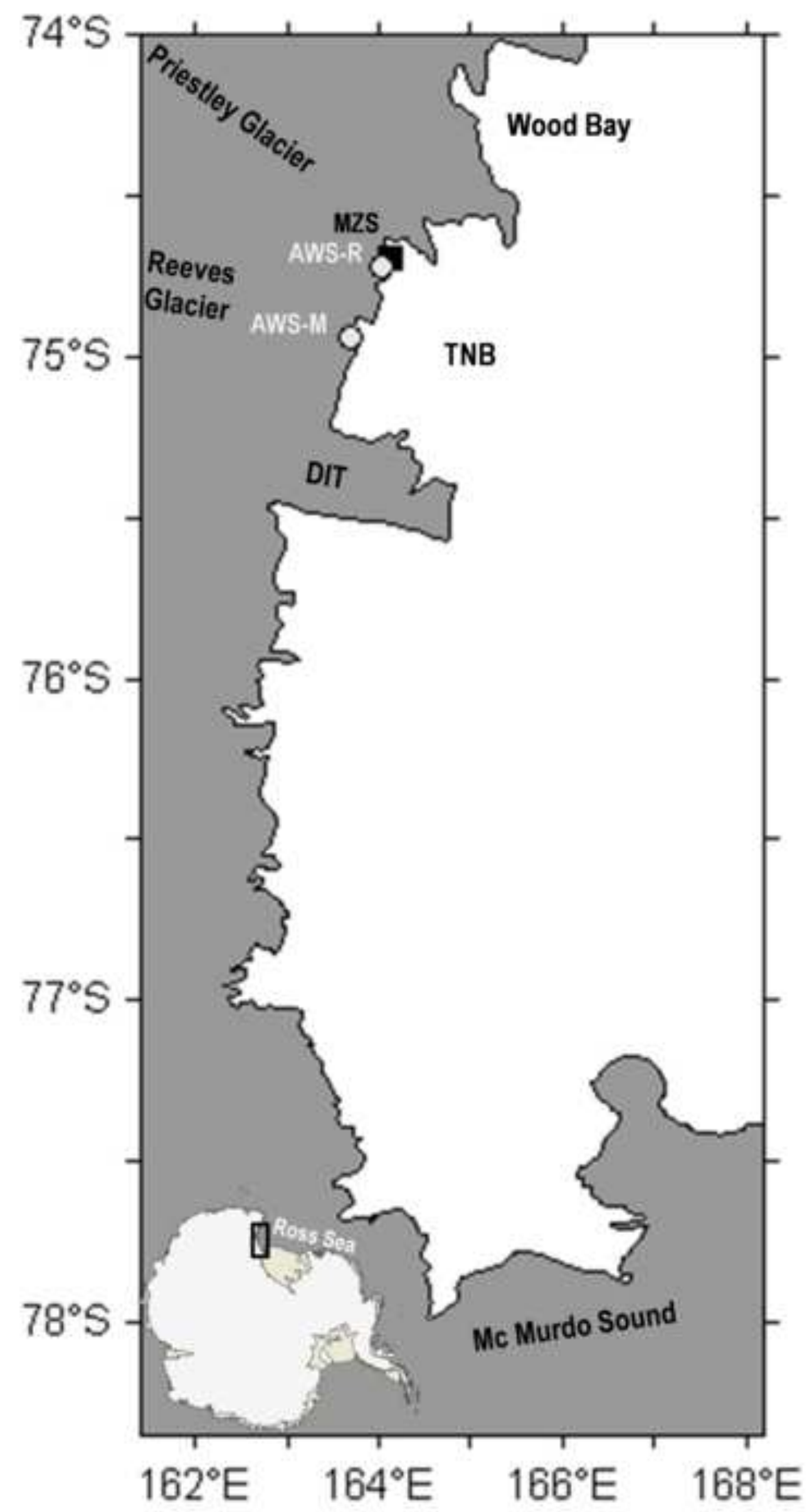


Click here to download high resolution image

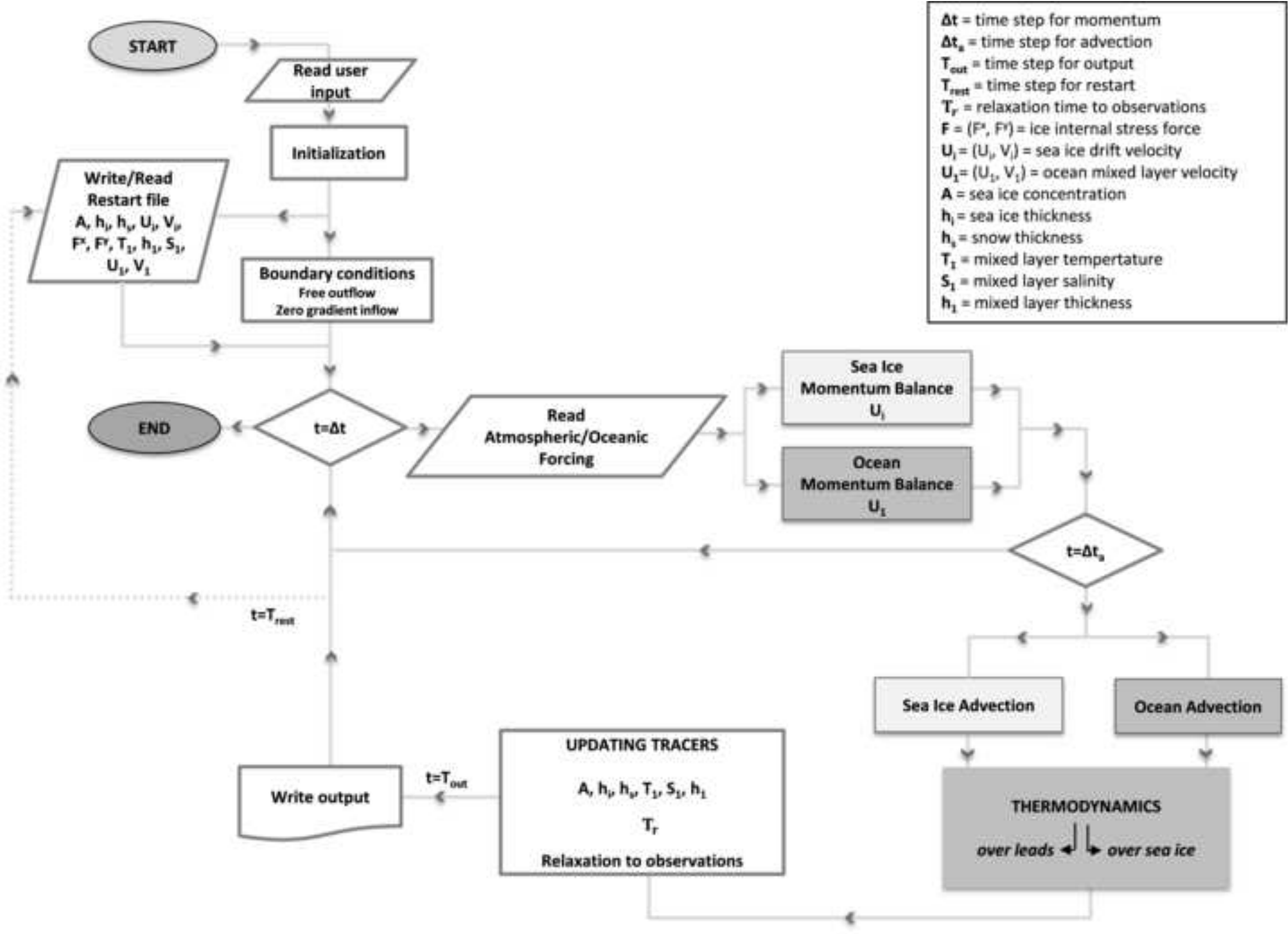

$\Delta t=$ time step for momentum

time step for advection

$T_{r}=$ relaxation time to observations

$\mathrm{A}=$ sea ice concentration

= mixed layer salinity

$h_{1}=$ mixed layer thickness 
Figure(s)

Click here to download high resolution image

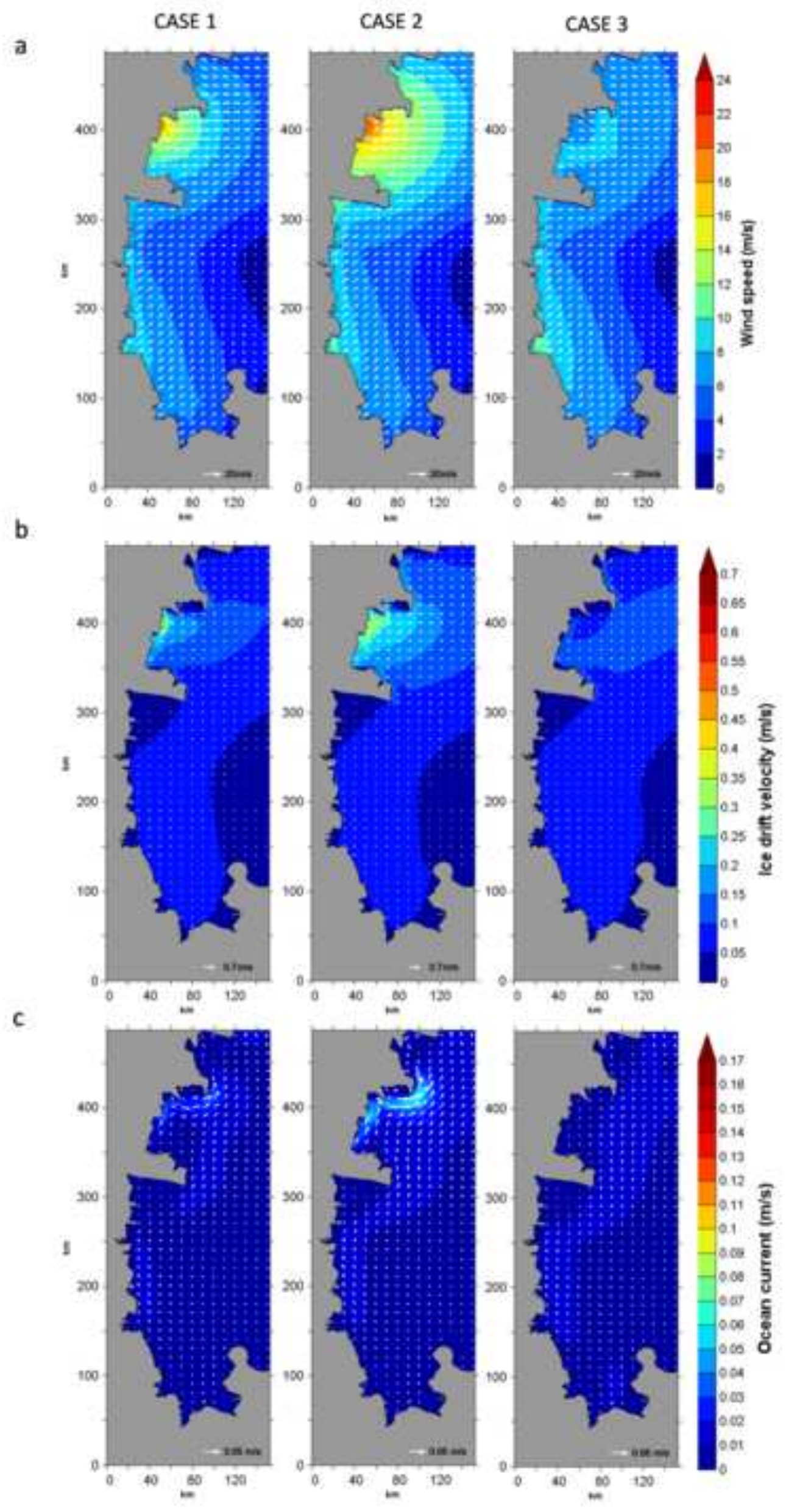




\section{CASE 4}
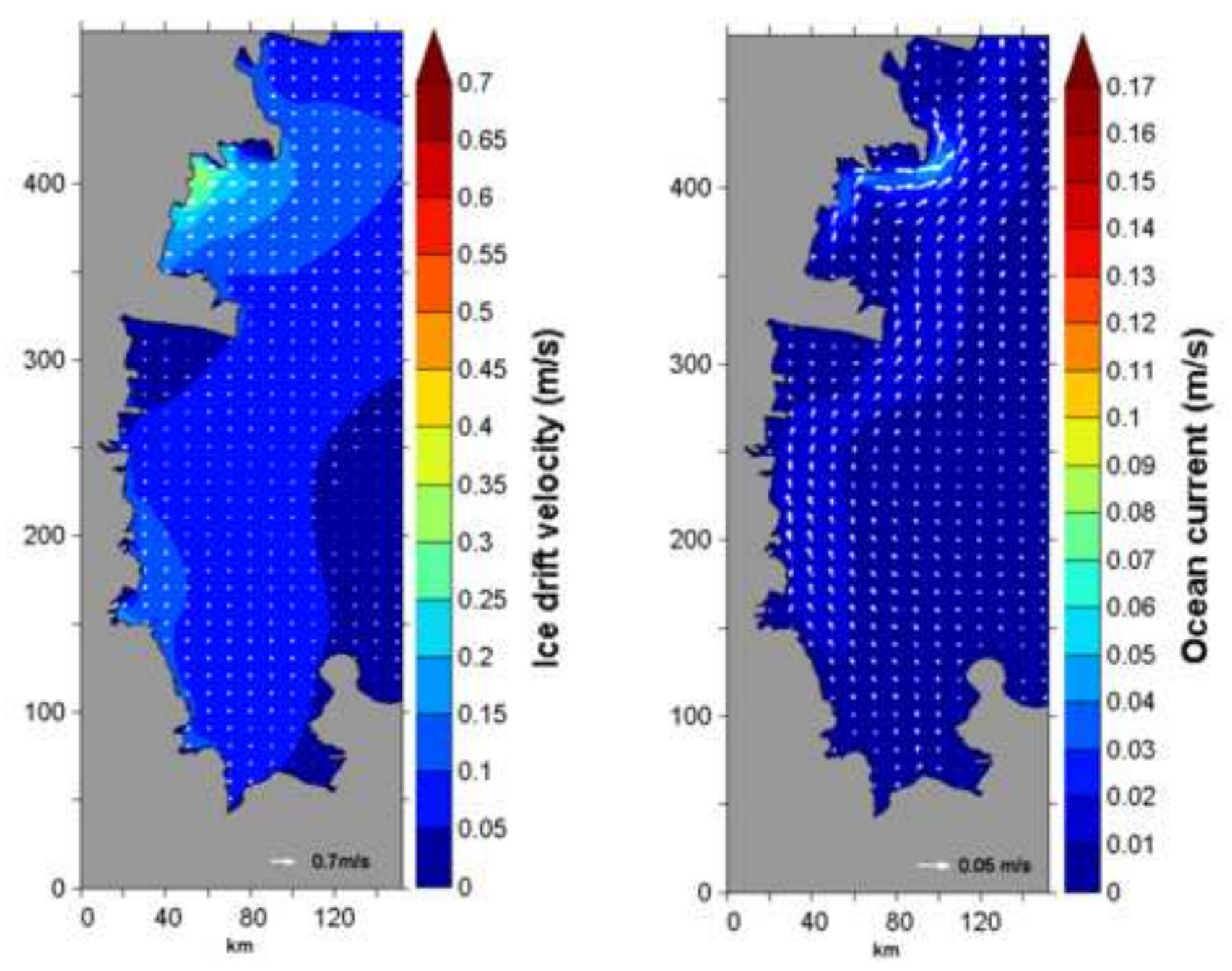
a
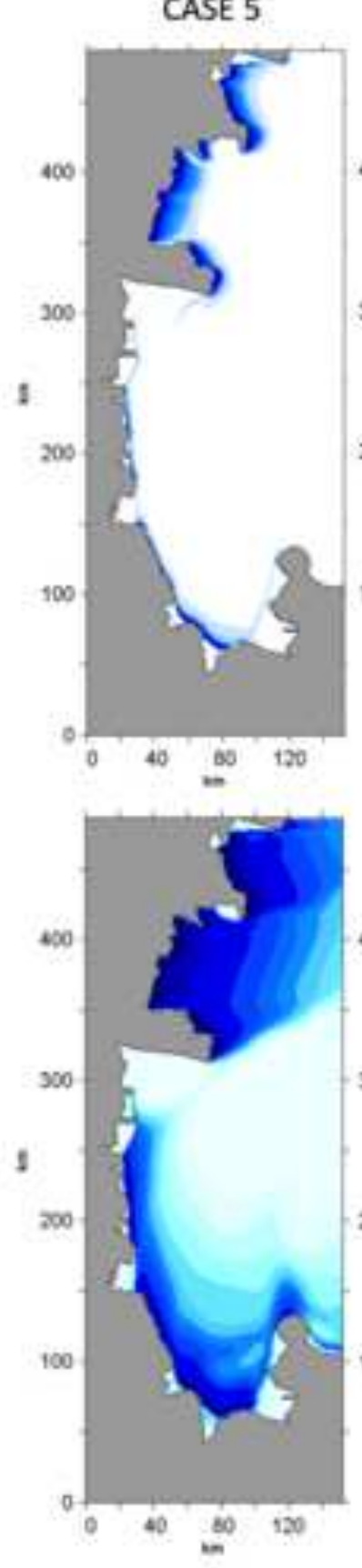

CASE 6
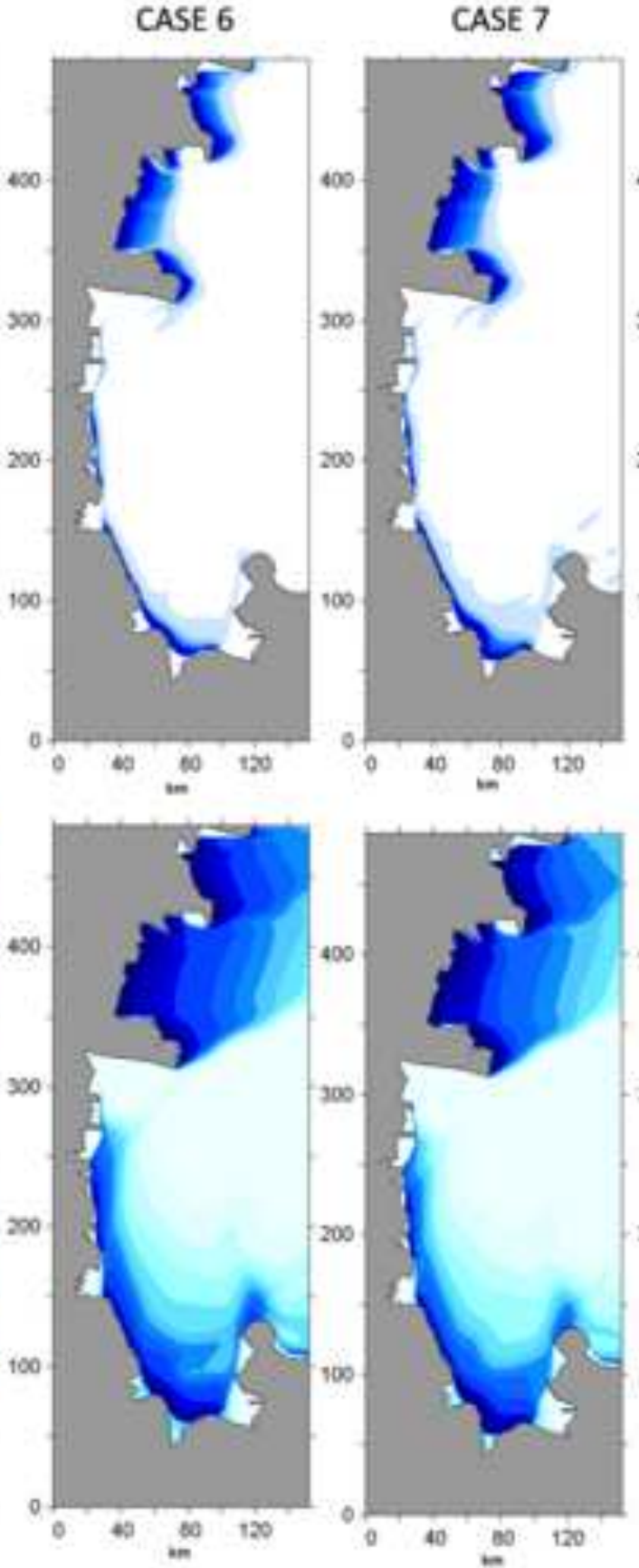

CASE 8
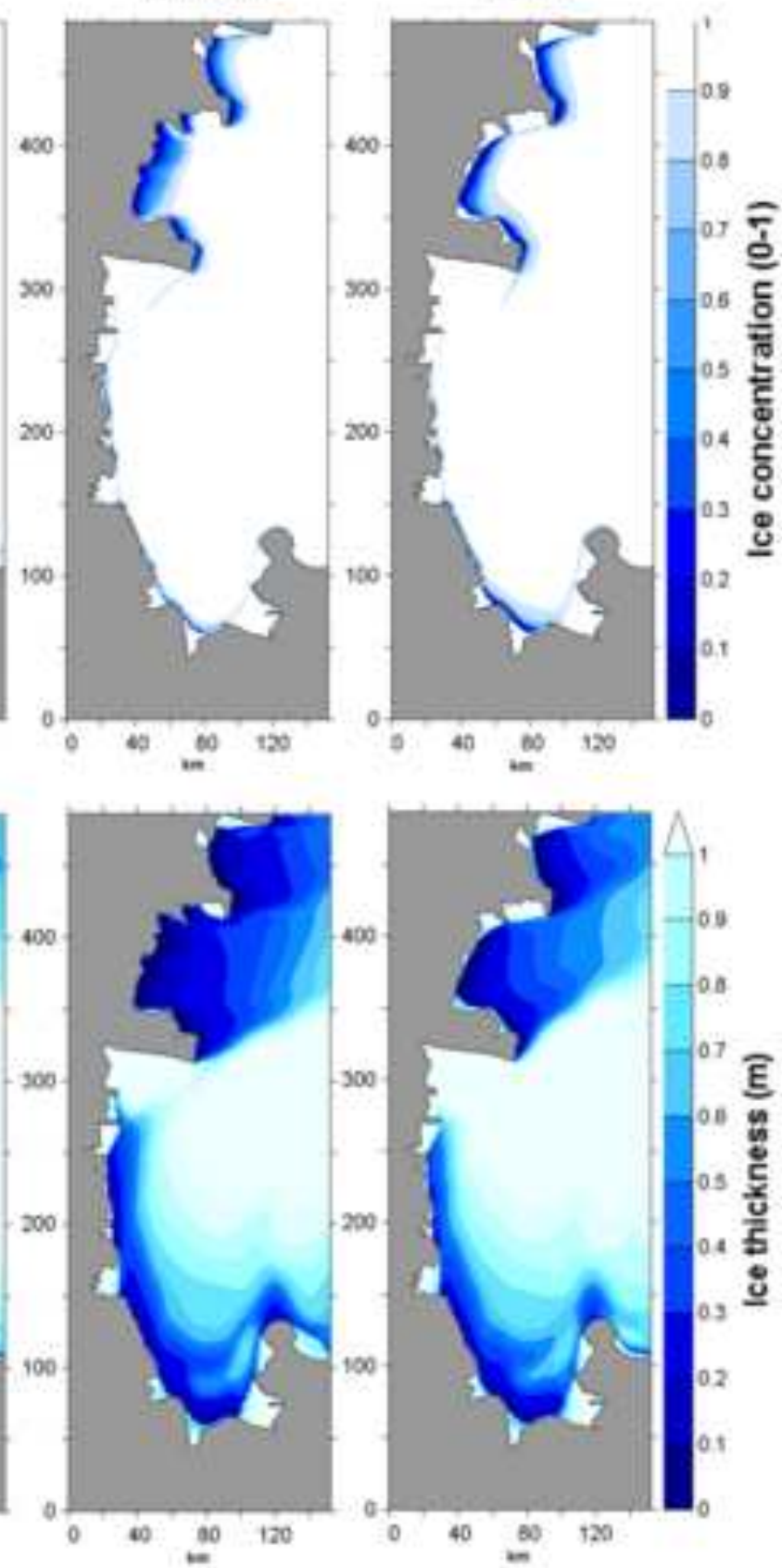

CASE 9

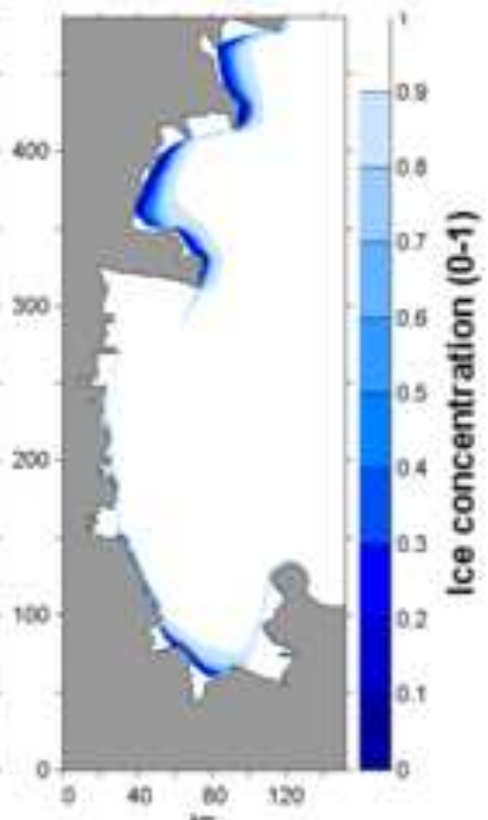




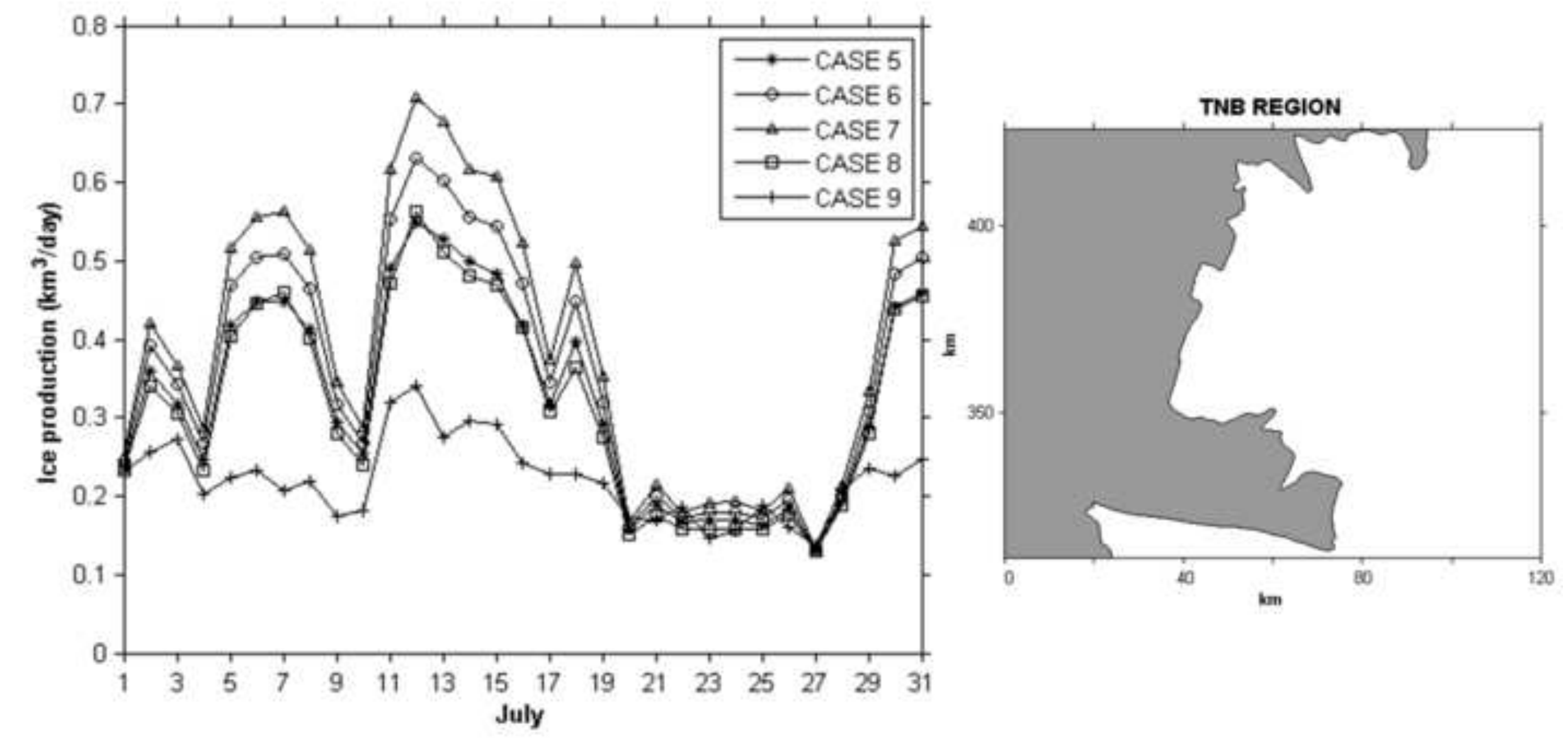


Figure(s)

Click here to download high resolution image

a
$E_{15}$
$E_{35}$
$E_{11}$
$E_{31}$
$E_{34}$
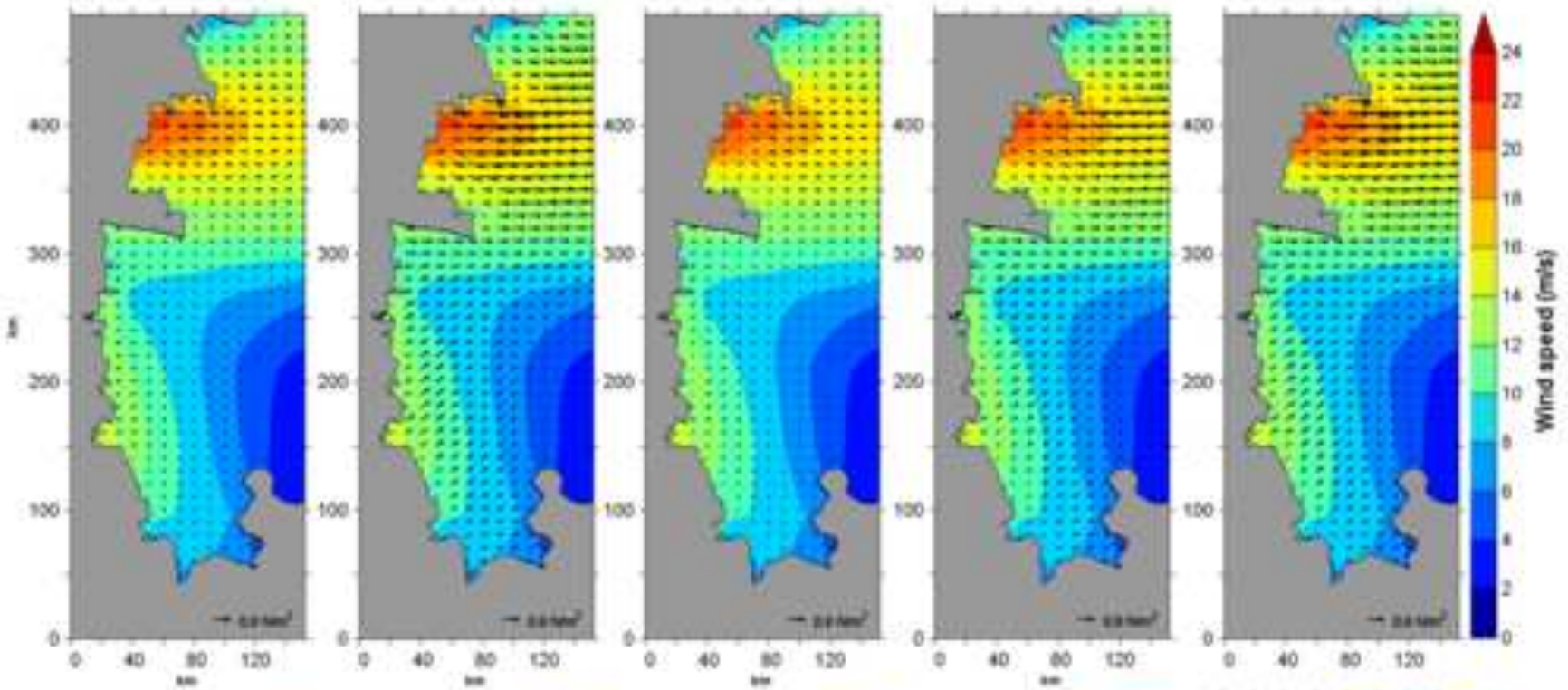

b

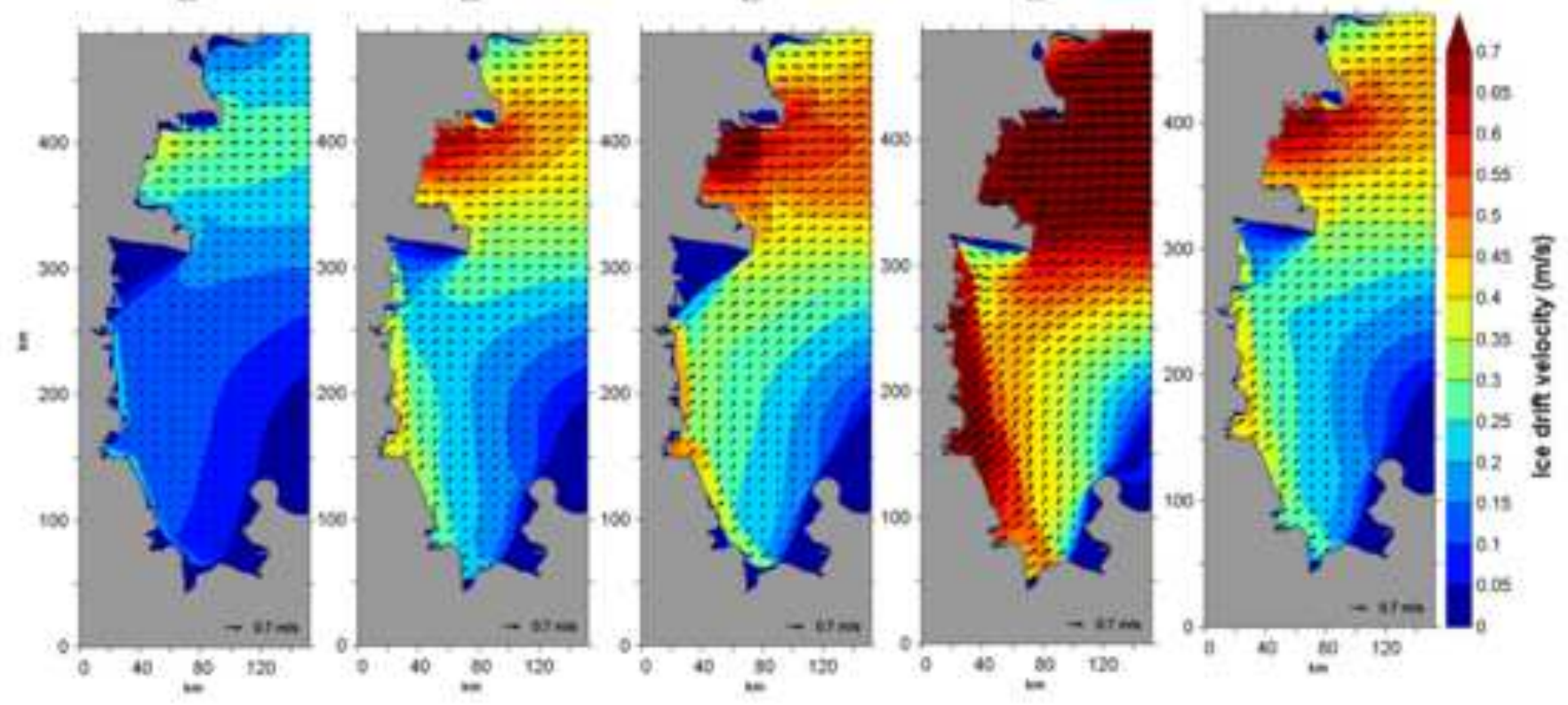

c
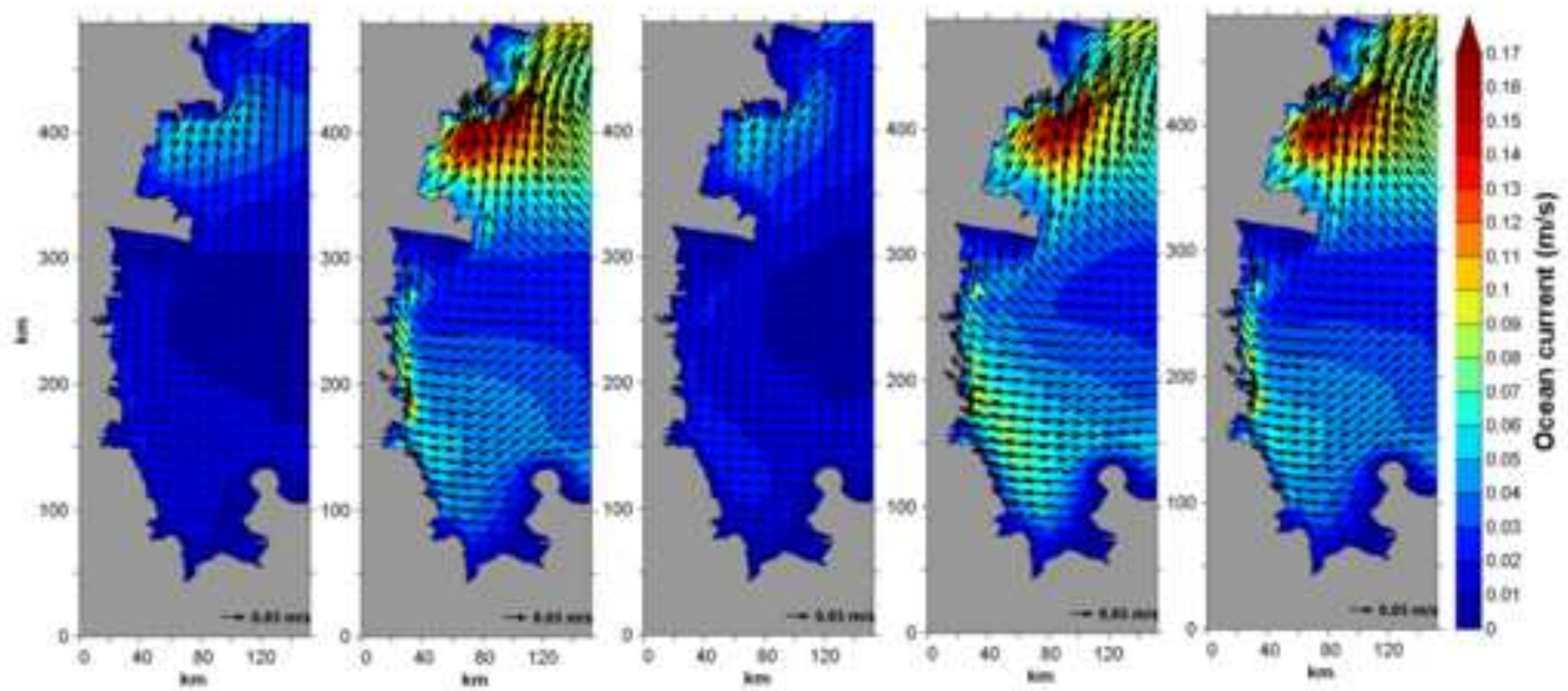
Click here to download high resolution image

a

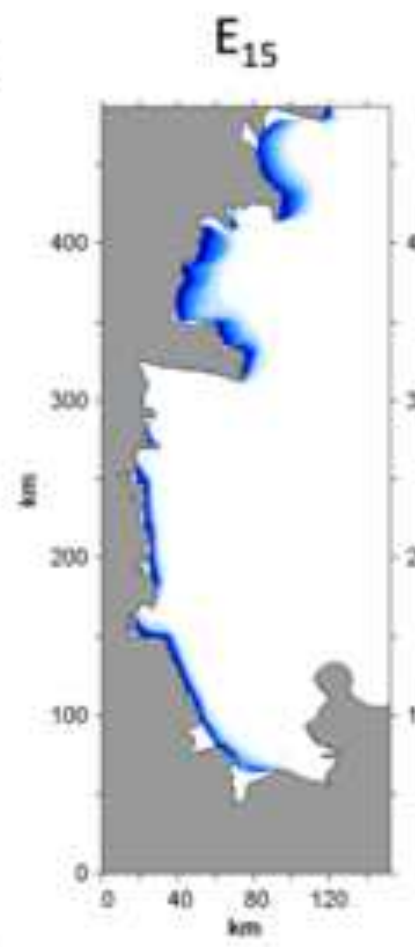

b

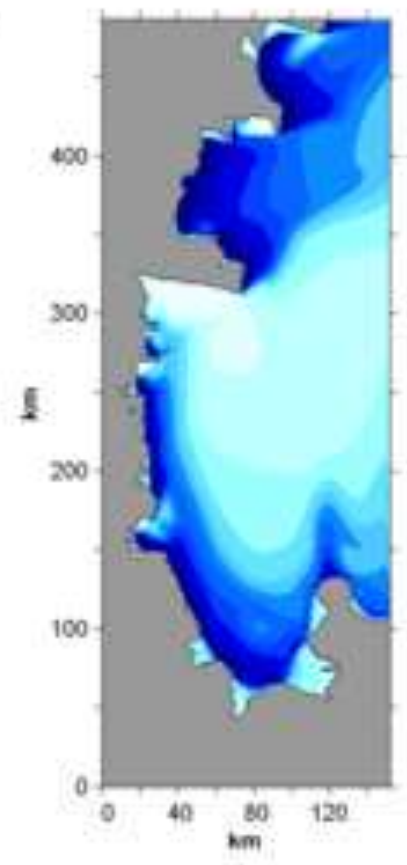

$E_{35}$

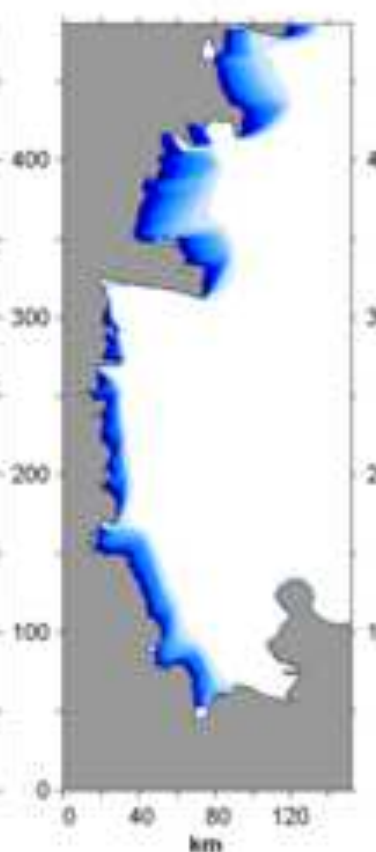

$E_{11}$

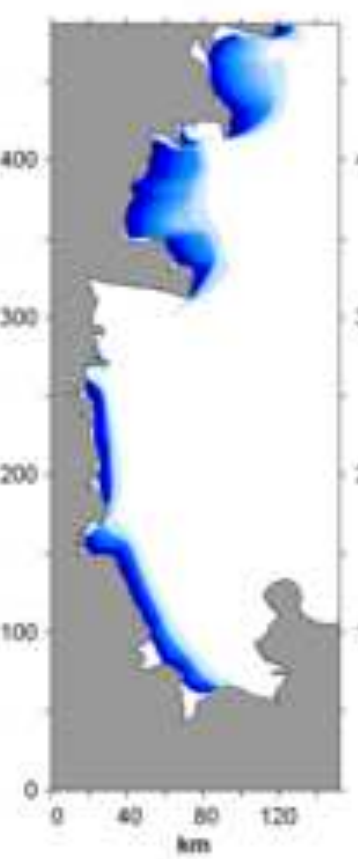

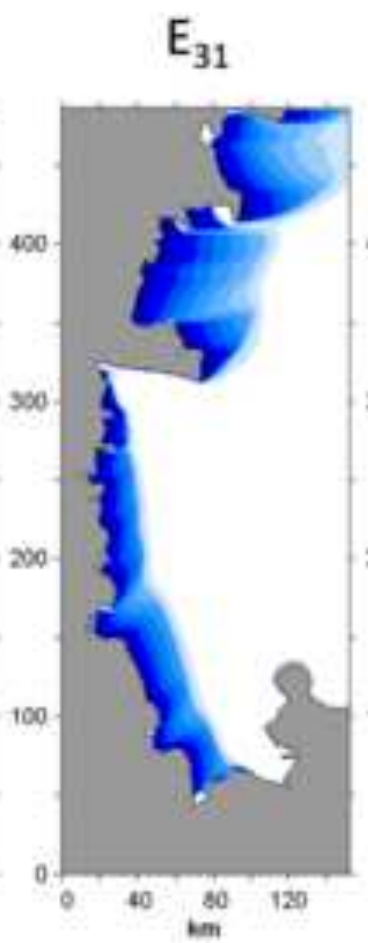
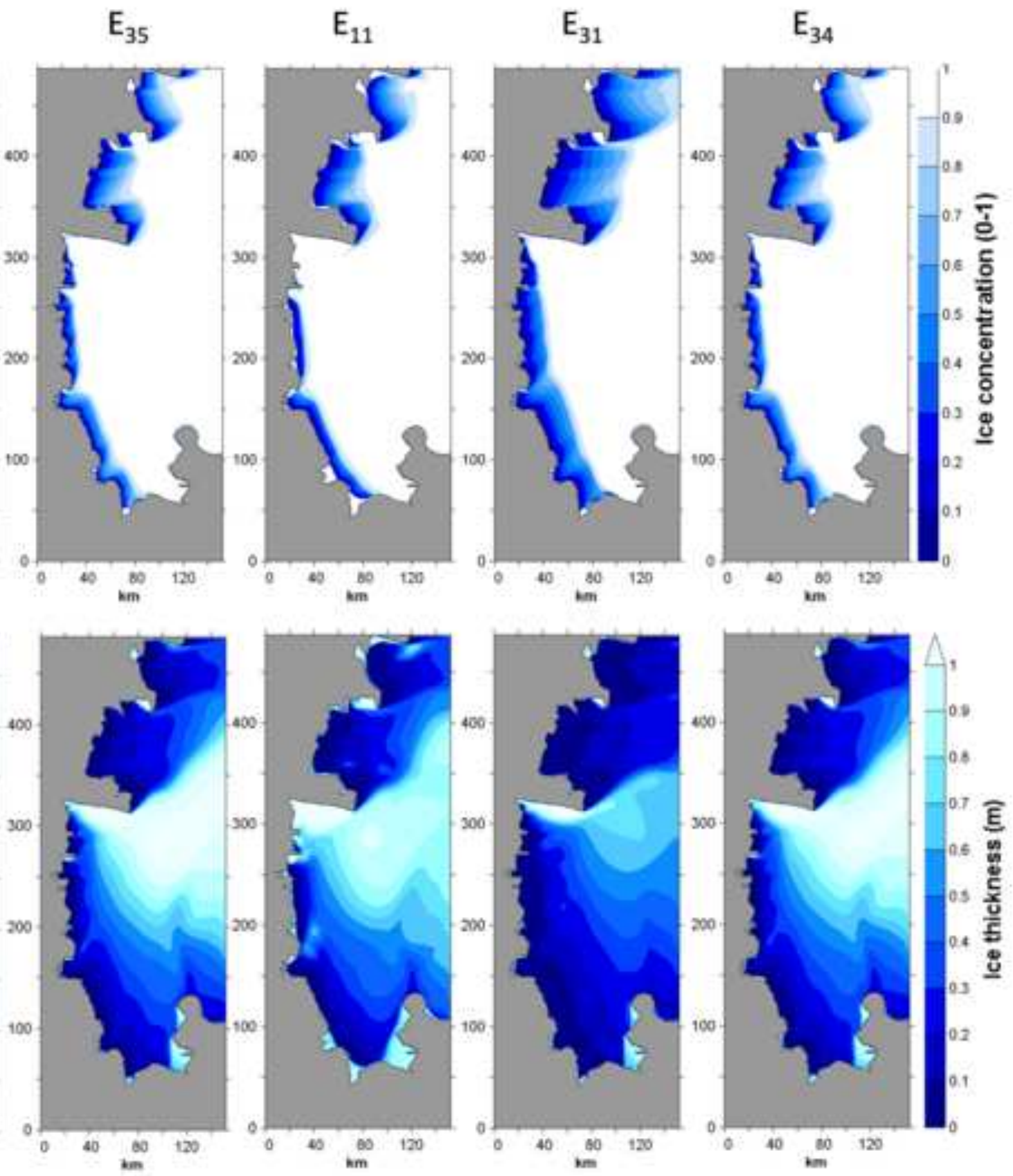
Figure(s)

Click here to download high resolution image

$E_{r}$
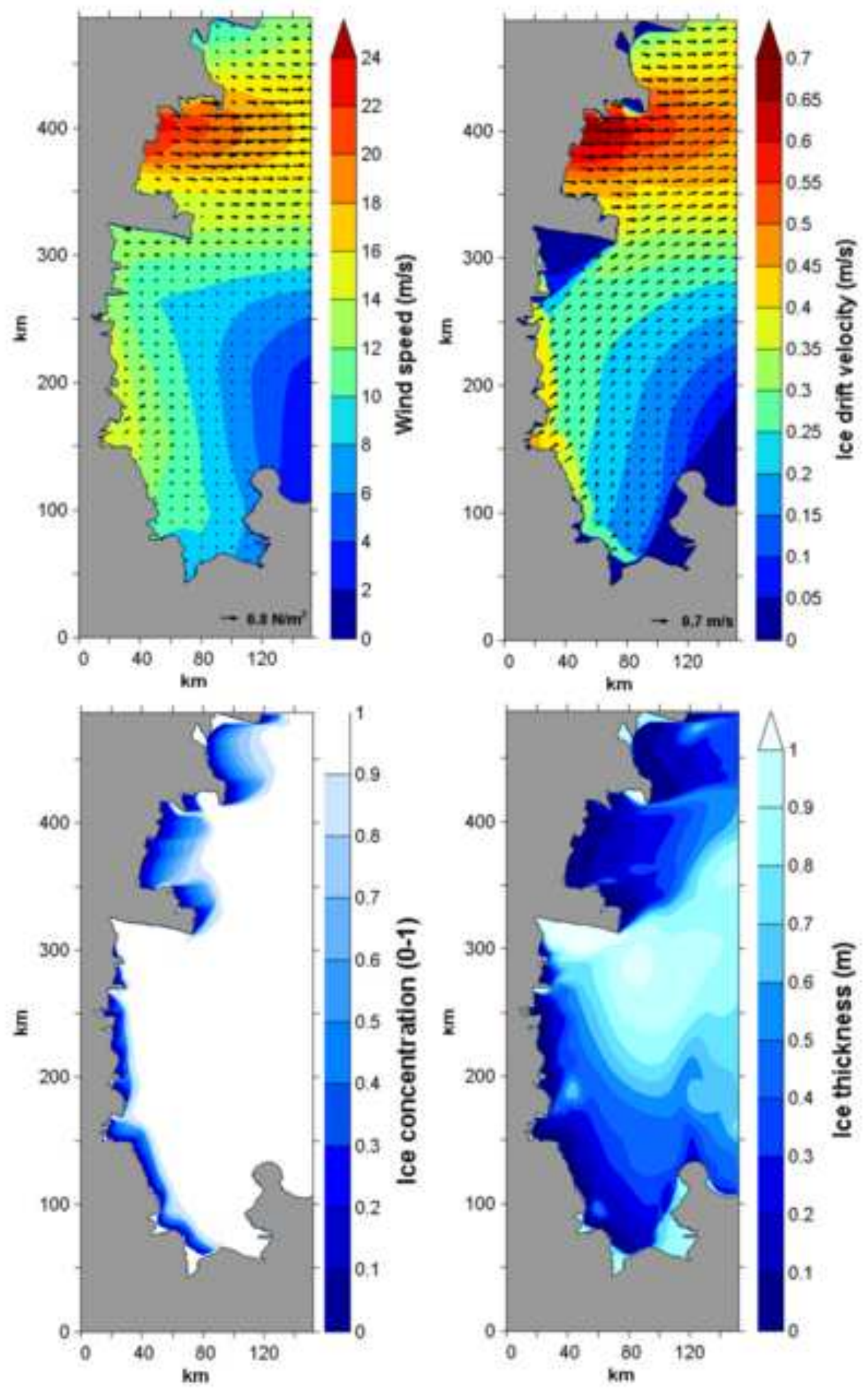


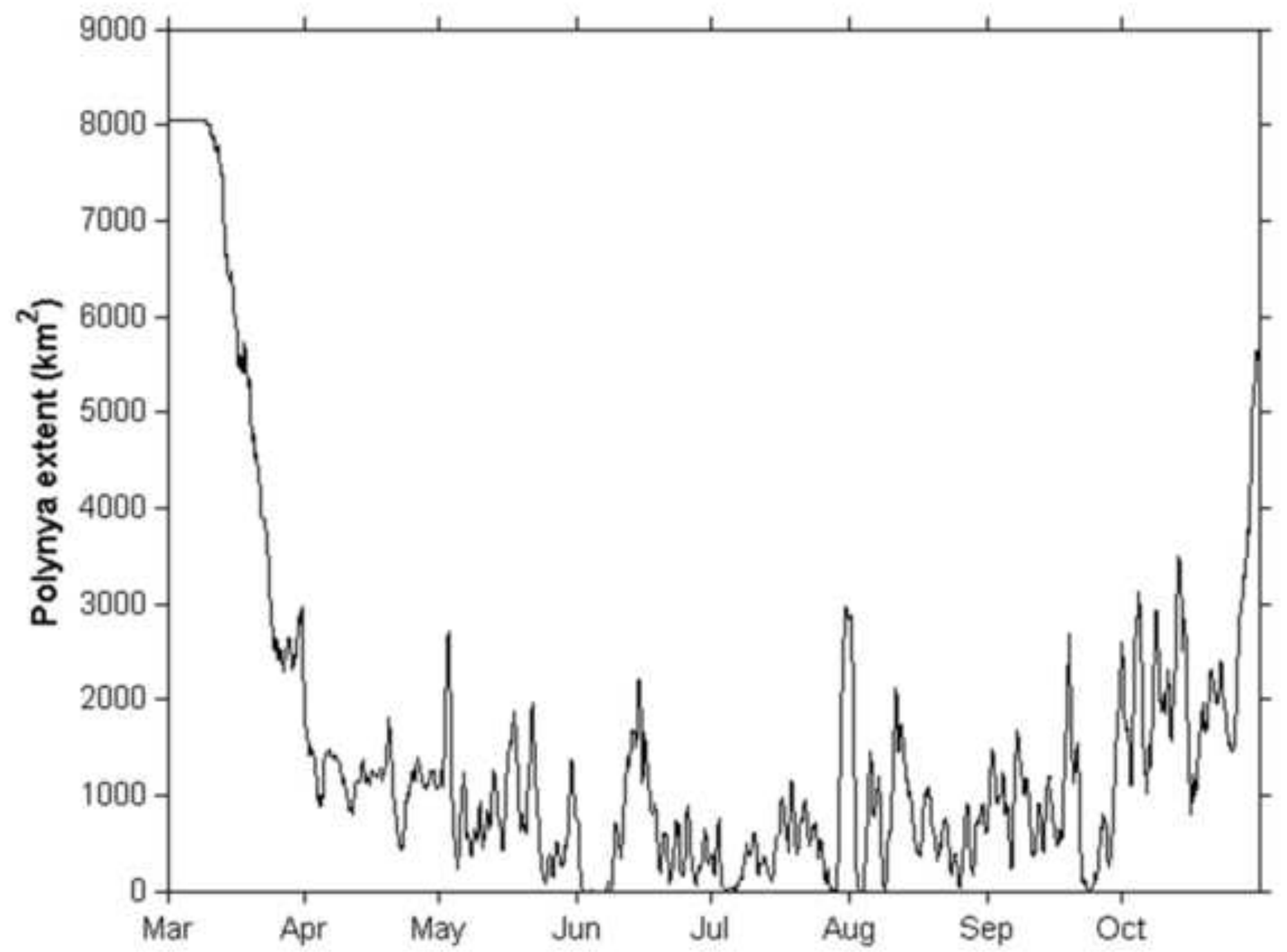




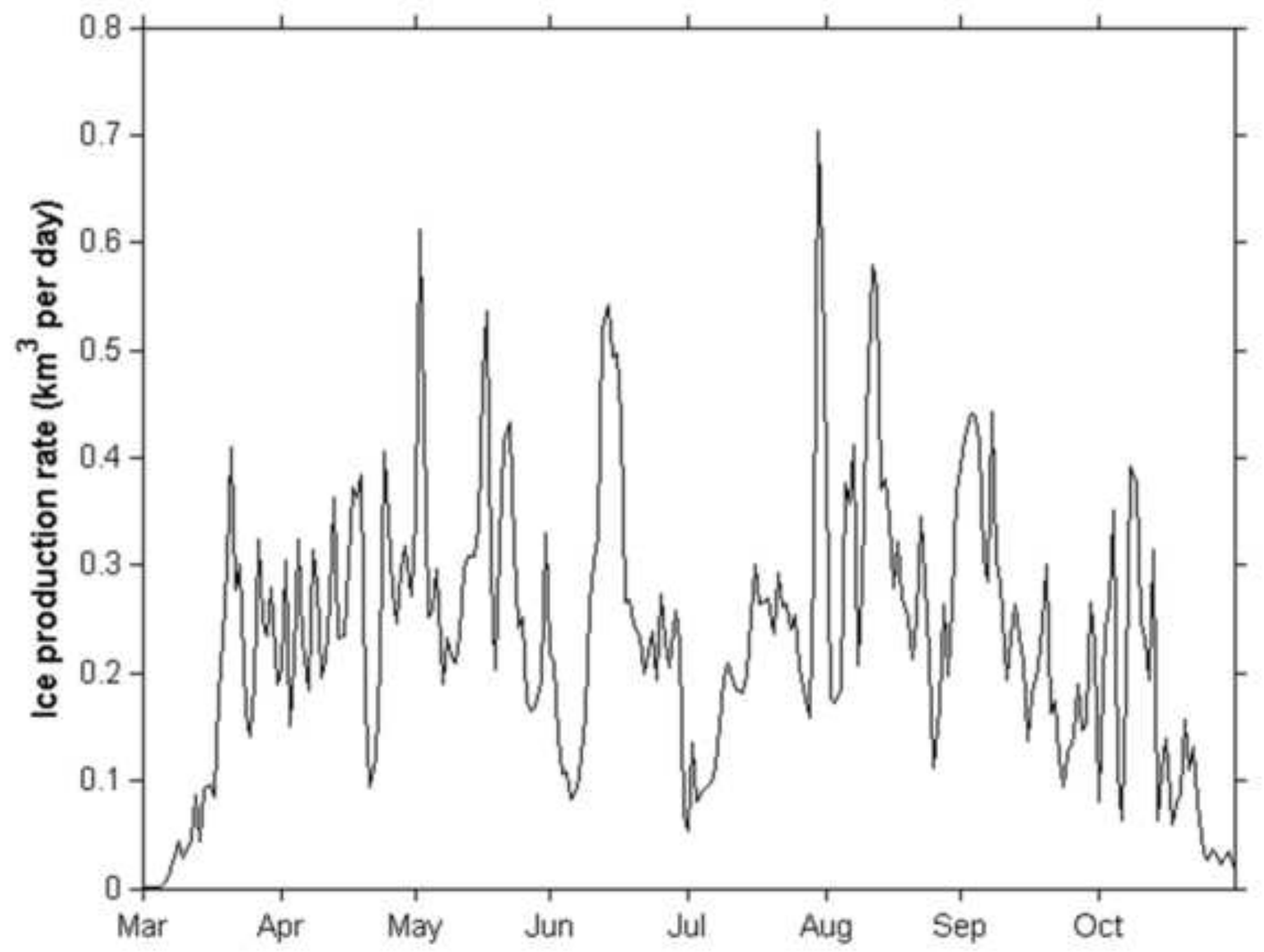



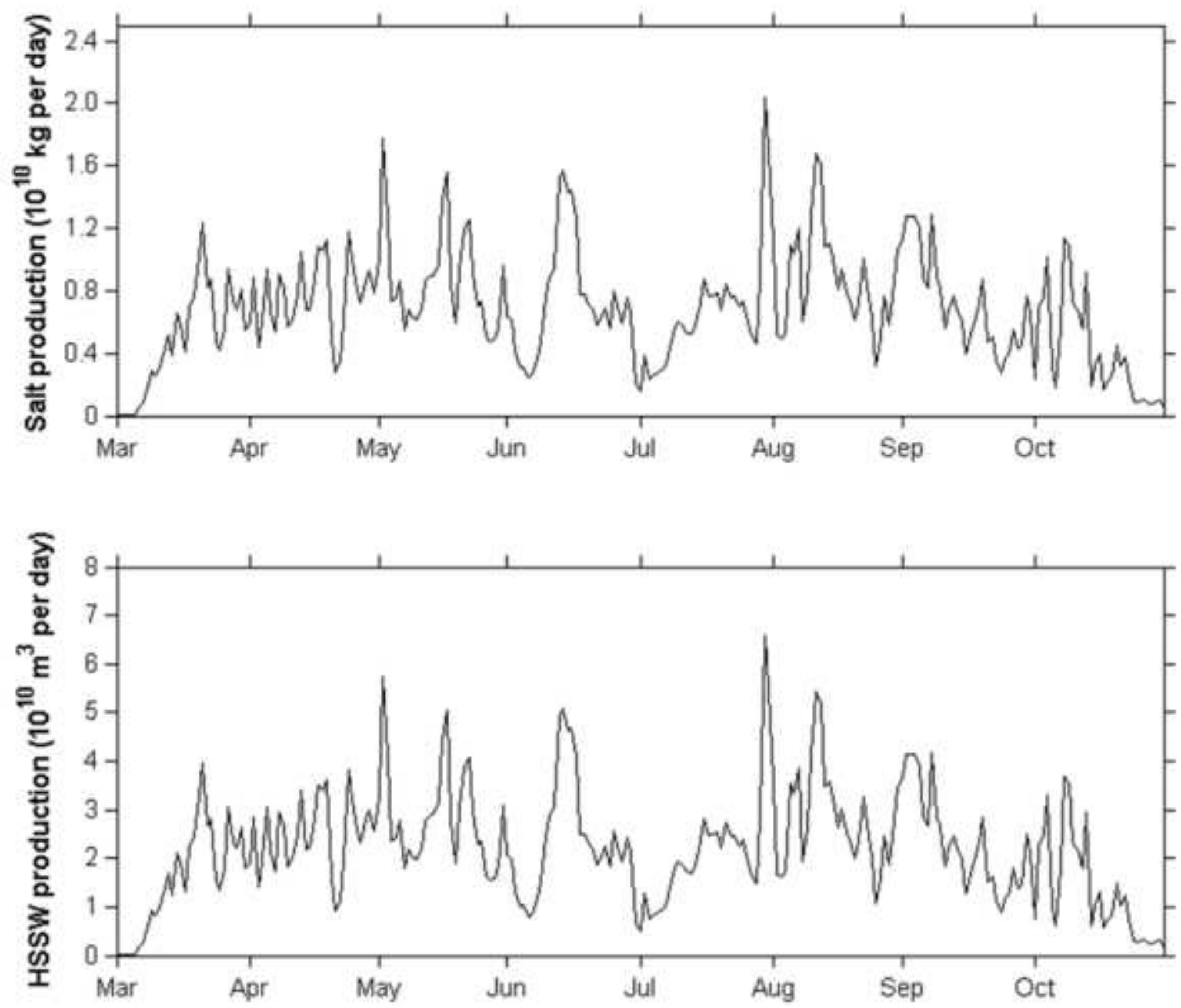
Click here to download high resolution image

AWS Rita

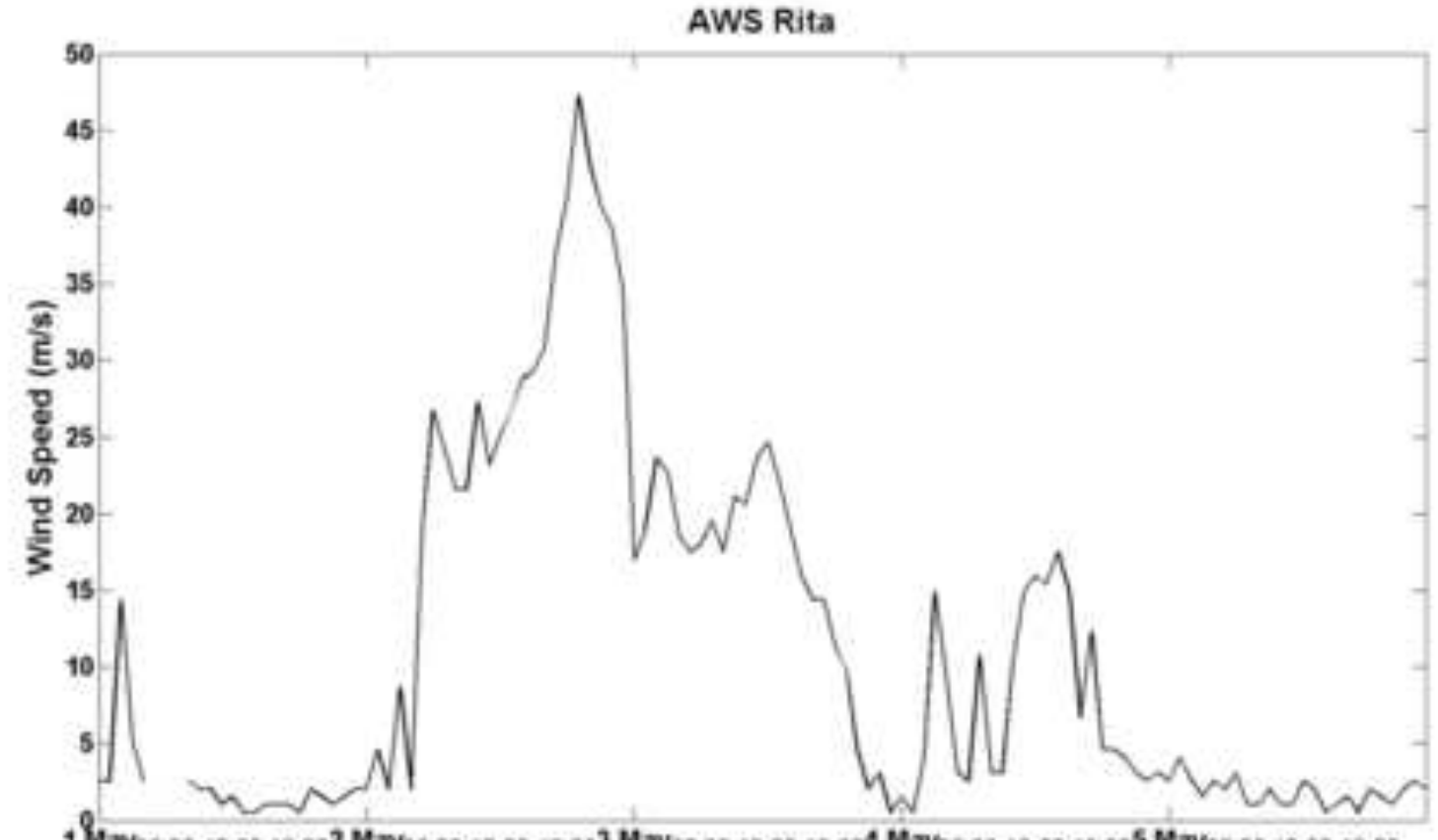

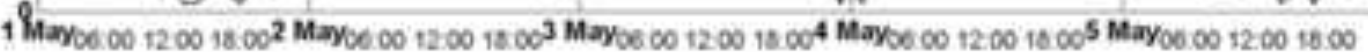

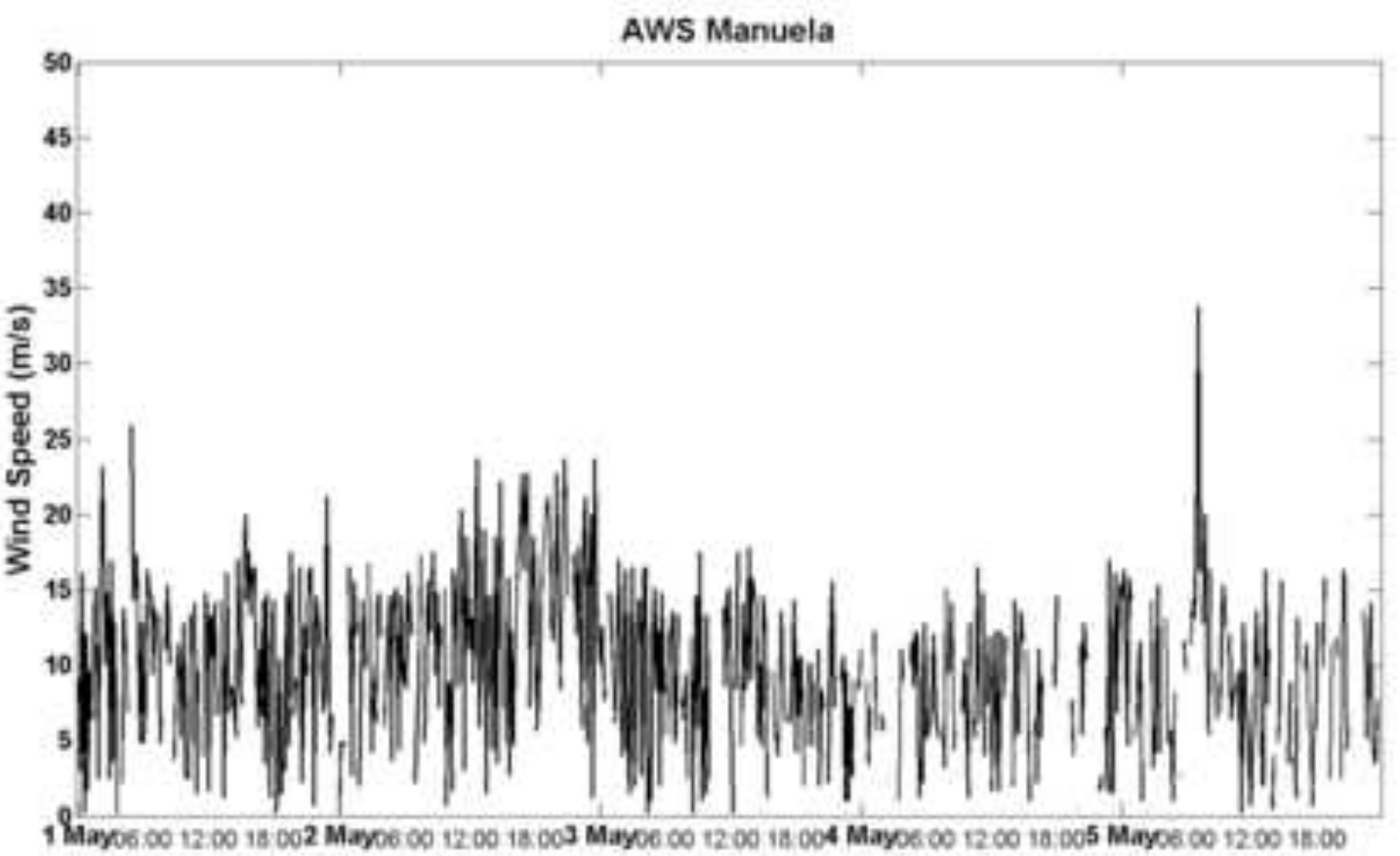


Click here to download high resolution image
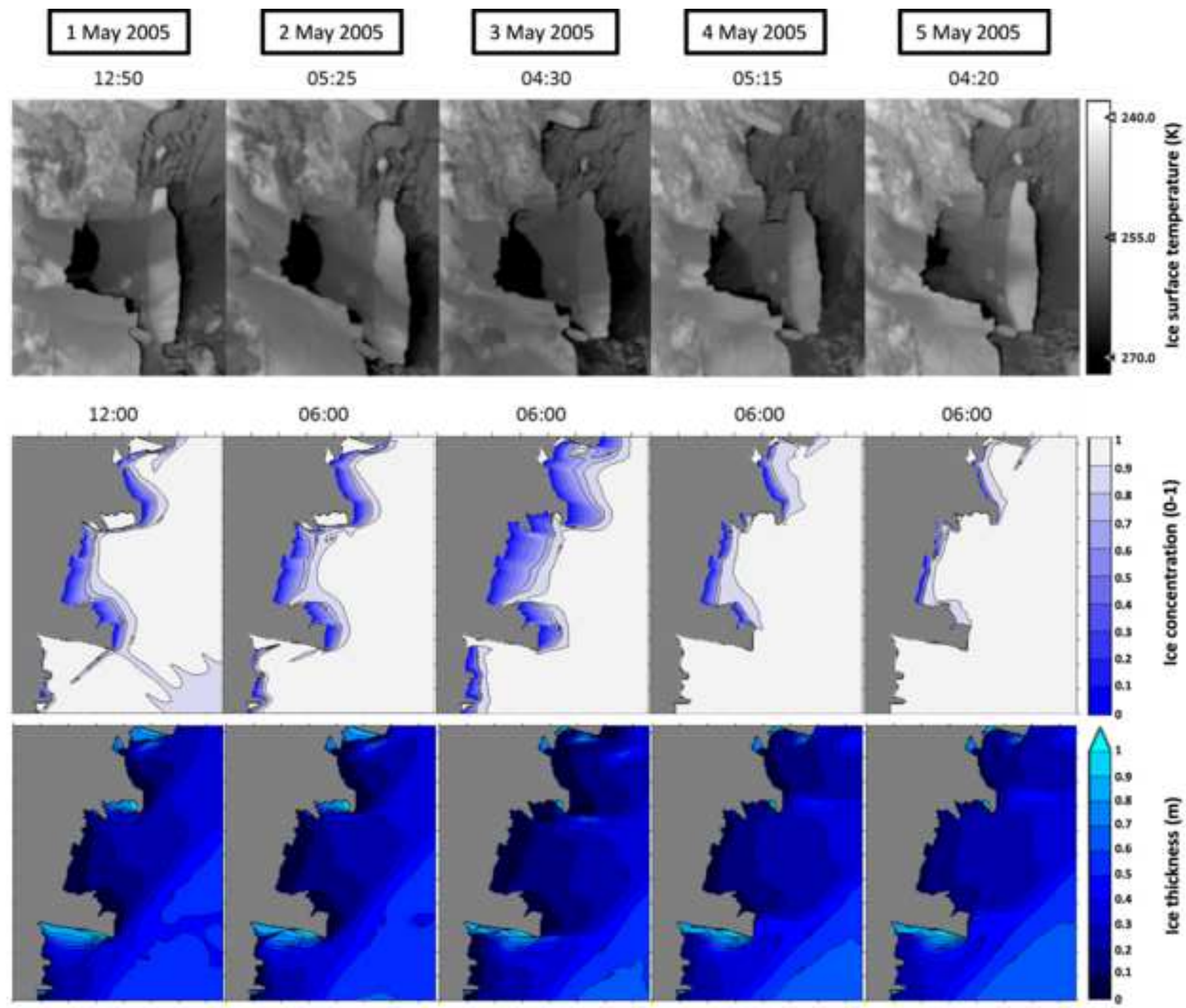
Click here to download high resolution image
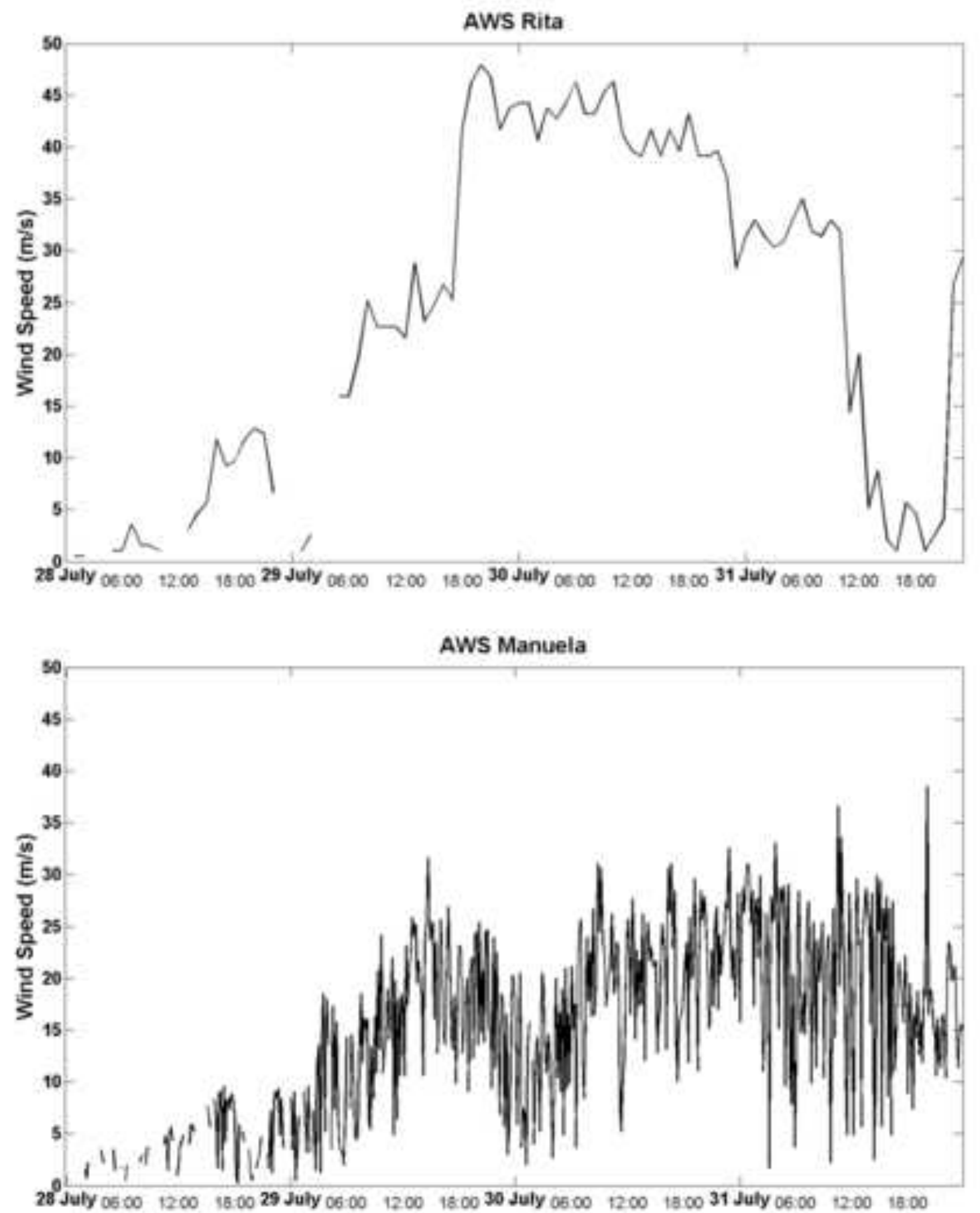
Click here to download high resolution image
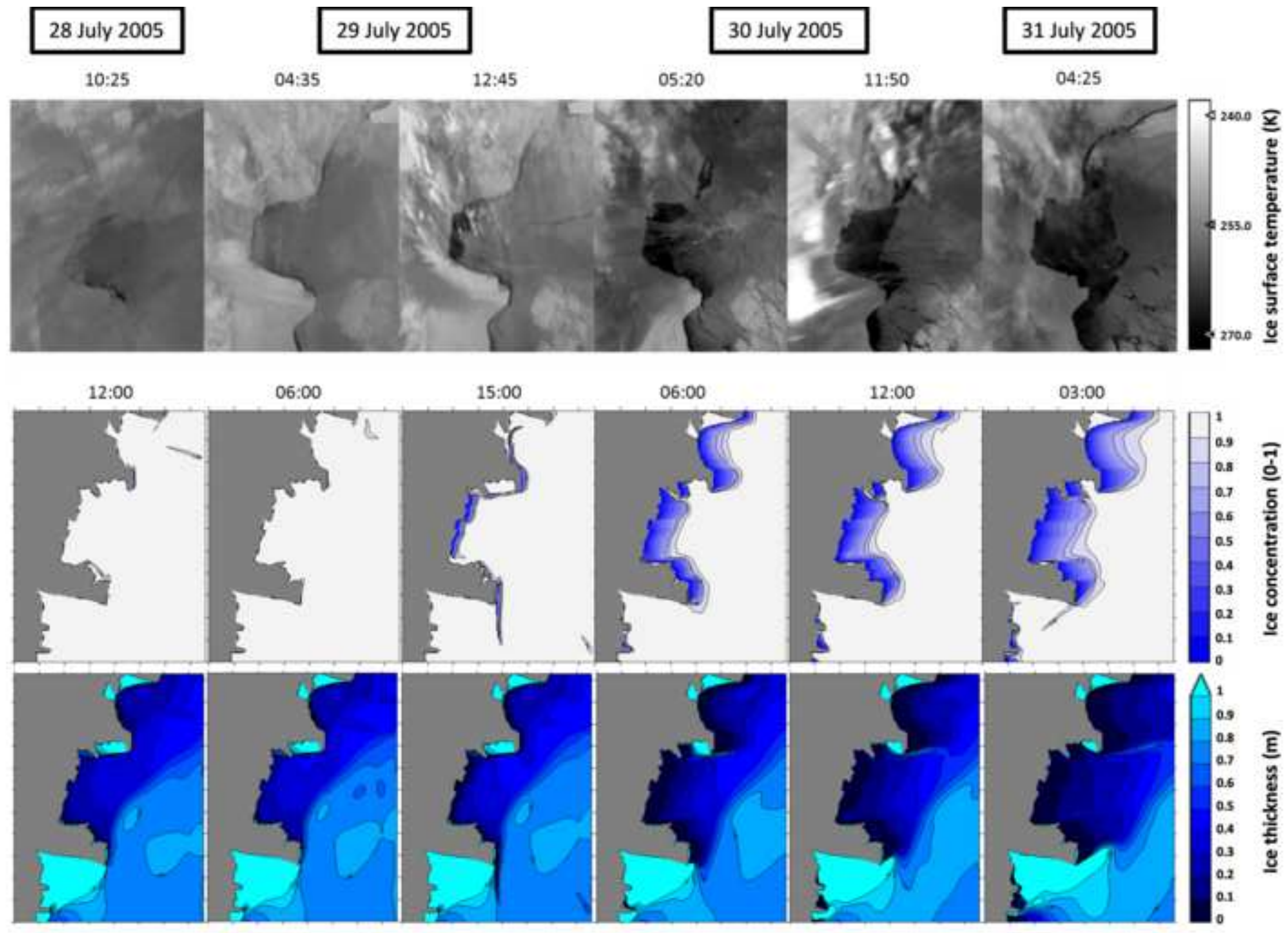


\section{Click here to download Table(s): Table 1.docx}

\begin{tabular}{lcc}
\hline Parameter & Symbol & Value \\
\hline X domain & $X$ & $154000 \mathrm{~m}$ \\
Y domain & $Y$ & $488000 \mathrm{~m}$ \\
T domain & $T$ & x days \\
Time step for momentum & $\Delta t$ & $1.2 \mathrm{~s}$ \\
Time step for advection & $\Delta t_{a}$ & $600 \mathrm{~s}$ \\
Elastic timescale (EVP ice rheology) & $\Delta t e$ & $180 \mathrm{~s}$ \\
Air drag coefficient & $C_{d a}$ & $\mathrm{X}$ \\
Ocean drag coefficient & $C_{d o}$ & $\mathrm{x}$ \\
Ice strength parameter & $P^{*}$ & $\mathrm{~N} / \mathrm{m}^{2}$ \\
Ice concentration parameter & $C$ & 20 \\
Creep limit & $c$ & $5 \times 10^{-11} 1 / \mathrm{s}$ \\
Eccentricity of the elliptical yield curve & $e$ & 2 \\
Demarcation ice collection thickness in leads & $H$ & $\mathrm{x} \mathrm{m}$ \\
\hline
\end{tabular}




\section{Click here to download Table(s): Table 2.docx}

\begin{tabular}{lcc}
\hline Parameter & Symbol & Value \\
\hline Ocean horizontal viscosity & $A_{H}$ & $2 \times 10^{2} \mathrm{~m}^{2} \mathrm{~s}^{-1}$ \\
Ocean eddy thickness diffusivity & $\kappa_{e}$ & $2 \times 10^{2} \mathrm{~m}^{2} \mathrm{~s}^{-1}$ \\
Thermal conductivity of sea ice & $\kappa_{i}$ & $2.2 \mathrm{~W} / \mathrm{m} / \mathrm{K}$ \\
Thermal conductivity of snow & $\kappa_{s}$ & $0.3 \mathrm{~W} / \mathrm{m} / \mathrm{K}$ \\
Emissivity of atmosphere & $\varepsilon_{a}$ & 0.95 \\
Emissivity of ocean & $\varepsilon_{o}$ & 0.985 \\
Albedo of ocean & $\alpha_{o}$ & 0.07 \\
Albedo of ice & $\alpha_{i}$ & $0.07-0.7$ \\
Albedo of snow & $\alpha_{s n}$ & 0.85 \\
Latent heat of fusion of ice & $L_{f i}$ & $3.34 \times 10^{5} \mathrm{~J} / \mathrm{kg}$ \\
Latent heat of vaporization of water & $L_{e}$ & $2.5 \times 10^{6} \mathrm{~J} / \mathrm{kg}$ \\
Latent heat of fusion of snow & $L_{f s n}$ & $3.34 \times 10^{5} \mathrm{~J} / \mathrm{kg}$ \\
Latent heat of sublimation of snow & $L_{s s n}$ & $2.834 \times 10^{6} \mathrm{~J} / \mathrm{kg}$ \\
Specific heat capacity of ocean & $c_{p a}$ & $3985 \mathrm{~J} / \mathrm{kg} / \mathrm{K}$ \\
Specific heat capacity of air & $c_{p a}$ & $1004 \mathrm{~J} / \mathrm{kg} / \mathrm{K}$ \\
Density of air & $\rho_{a}$ & $1.3 \mathrm{Kg} / \mathrm{m}^{3}$ \\
Density of ice & $\rho_{i}$ & $900 \mathrm{Kg} / \mathrm{m}^{3}$ \\
Density of snow & $\rho_{s}$ & $330 \mathrm{Kg} / \mathrm{m}^{3}$ \\
Density of ocean & $\rho_{o}$ & $1024 \mathrm{Kg} / \mathrm{m}^{3}$ \\
Melting point of freshwater ice & $t_{f u s}$ & $0 \mathrm{C}^{\circ} \mathrm{C}$ \\
Salinity of sea ice & $s_{i}$ & 4 \\
Exchange coeff. for sensible heat (leads/ice) & $c_{H}$ & $1.75 \times 10^{-3}$ \\
Exchange coeff. for latent heat over leads & $c_{E}$ & $1.75 \times 10^{-3}$ \\
Exchange coeff. for latent heat over ice & $c_{E}$ & $1 \times 10^{-3}$ \\
Stefan-Boltzmann constant & $K$ & $1 \times 10^{-3} \mathrm{~W} \mathrm{~m} \mathrm{~s}^{-1}$ \\
Minimum vertical viscosity & $7 \mathrm{~K}^{-4}$ \\
Scale depth of mechanical dissipation & $v_{m i n}$ & $50 \mathrm{~m}$ \\
Scale depth of convective dissipation & $h_{w}$ & \\
\hline & $h_{c}$ & $5.67 \times 10^{-8} \mathrm{~W}$ \\
\hline
\end{tabular}




\section{Table(s)}

Click here to download Table(s): Table 3.docx

\begin{tabular}{cc}
\hline Experiment & $\boldsymbol{R}(\mathbf{k m})$ \\
\hline CASE 1 & 25 \\
CASE 2 & 50 \\
CASE 3 & no merging \\
\hline
\end{tabular}




\section{Table(s)}

Click here to download Table(s): Table 4.docx

\begin{tabular}{cc}
\hline Experiment & $\boldsymbol{H}(\mathbf{m})$ \\
\hline CASE 5 & 0.2 \\
CASE 6 & 0.3 \\
CASE 7 & 0.4 \\
CASE 8 & $\mathrm{f}(\mathrm{V})$ \\
CASE 9 & 0.2 no merging \\
\hline
\end{tabular}

CASE 9

0.2 no merging 
Click here to download Table(s): Table 5.docx

Experiment

Sea ice production $\left(\mathrm{km}^{3}\right)$ in July 2000

10.08

CASE 6

CASE 7

CASE 8

11.09

CASE 9

9.79

6.83 


\section{Table(s)}

Click here to download Table(s): Table 6.docx

\begin{tabular}{|ll|ll|l|}
\hline \multicolumn{2}{|c|}{ Experiment } & \multicolumn{1}{c|}{$C_{d a}$} & \multicolumn{1}{c|}{$C_{d o}$} \\
\hline $\mathrm{E}_{15}$ & $\underline{\mathrm{CTRL}}$ & $1 \times 10^{-3}$ & & $5 \times 10^{-3}$ \\
$\mathrm{E}_{35}$ & & $3 \times 10^{-3}$ & & $5 \times 10^{-3}$ \\
$\mathrm{E}_{11}$ & $1 \times 10^{-3}$ & & $1 \times 10^{-3}$ \\
$\mathrm{E}_{31}$ & & $3 \times 10^{-3}$ & & $1 \times 10^{-3}$ \\
$\mathrm{E}_{34}$ & $3 \times 10^{-3}$ & & $4 \times 10^{-3}$ \\
$\mathrm{E}_{\mathrm{r}}$ & & $1 \times 10^{-3}$ & $\mathrm{~V} \leq 10 \mathrm{~m} / \mathrm{s}$ & $1.3 \times C_{\mathrm{da}}$ \\
\hline
\end{tabular}




\section{Table(s)}

Click here to download Table(s): Table 7.docx

\begin{tabular}{c|cc}
\hline Winter months & Maximum Polynya extent $\left(\mathbf{k m}^{2}\right)$ & Mean Polynya extent $\left.\mathbf{( k m}^{2}\right)$ \\
\hline March & 7946 & 5574 \\
April & 1806 & 1174 \\
May & 2688 & 871.2 \\
June & 2205 & 557.2 \\
July & 2962 & 532.5 \\
August & 2868 & 766.9 \\
September & 2674 & 875.6 \\
October & 5637 & 2304 \\
\hline
\end{tabular}


Click here to download Table(s): Table 8.docx

\begin{tabular}{cccc}
\hline Winter months & $\begin{array}{c}\text { Maximum daily rates } \\
\text { of sea ice production } \\
\left(\mathbf{k m}^{\mathbf{3}} / \mathbf{d a y}\right)\end{array}$ & $\begin{array}{c}\text { Mean daily rates } \\
\text { of sea ice production } \\
\left(\mathbf{k m}^{\mathbf{3}} / \mathbf{d a y}\right)\end{array}$ & $\begin{array}{c}\text { Monthly cumulative sea ice } \\
\left(\mathbf{k m}^{\mathbf{3}}\right)\end{array}$ \\
\hline March & 0.42 & 0.16 & 4.99 \\
April & 0.40 & 0.26 & 7.86 \\
May & 0.61 & 0.30 & 9.25 \\
June & 0.54 & 0.25 & 7.52 \\
July & 0.70 & 0.22 & 6.98 \\
August & 0.58 & 0.30 & 9.39 \\
September & 0.44 & 0.24 & 7.34 \\
October & 0.39 & 0.14 & 4.29 \\
\hline
\end{tabular}


Click here to download Table(s): Table 9.docx

\begin{tabular}{|cc|c|c|}
\hline $\begin{array}{c}\text { TNB polynya event } \\
\text { in July 2005 }\end{array}$ & Model-derived polynya extent $\left.\mathbf{( k m}^{\mathbf{2}}\right)$ & MODIS-derived polynya extent $\left.\mathbf{( k m}^{\mathbf{2}}\right)$ \\
\hline $28^{\text {th }}$ & $12: 00$ & 12 & 40 \\
\hline $29^{\text {th }}$ & $06: 00$ & 0 & 25 \\
\hline $29^{\text {th }}$ & $15: 00$ & 389 & 391 \\
\hline $30^{\text {th }}$ & $06: 00$ & 1858 & 1936 \\
\hline $30^{\text {th }}$ & $12: 00$ & 2148 & 2385 \\
\hline $31^{\text {th }}$ & $03: 00$ & 2831 & 3393 \\
\hline
\end{tabular}

